JORGE LUIZ DIAZ PINAYA

PROCESSO DE PRÉ-ANÁLISE PARA A MODELAGEM DE DISTRIBUIÇÂO DE ESPÉCIES 
JORGE LUIZ DIAZ PINAYA

\section{PROCESSO DE PRÉ-ANÁLISE PARA A MODELAGEM DE} DISTRIBUIÇÃO DE ESPÉCIES

Dissertação apresentada à Escola Politécnica da Universidade de São Paulo para obtenção do título de Mestre em Ciências

São Paulo

2013 
JORGE LUIZ DIAZ PINAYA

\section{PROCESSO DE PRÉ-ANÁLISE PARA A MODELAGEM DE DISTRIBUIÇÃO DE ESPÉCIES}

Dissertação apresentada à Escola Politécnica da Universidade de São Paulo para obtenção do título de Mestre em Ciências

Àrea de Concentração: Sistemas Digitais

Orientador: Prof. Dr. Pedro Luiz Pizzigatti Corrêa 


\section{DEDICATÓRIA}

Dedico este trabalho a minha esposa Maria del Carmen e filhos Ana Carolina, Walter Hugo e Ana Claudia 


\section{AGRADECIMENTOS}

Ao Prof. Dr. Pedro Luiz Pizzigatti Corrêa do Laboratório de Tecnologia da Informação no agronegócio e Ambiente - Laboratório de Automação Agrícola, Escola Politécnica da Universidade de São Paulo, pela orientação e constante estímulo transmitido durante todo este trabalho.

Ao Prof. Dr. Antonio Mauro Saraiva, Prof. Dr. Carlos Eduardo Cugnasca e Prof. Dr. André Riyuiti Hirakawa, Laboratório de Tecnologia da Informação no agronegócio e Ambiente - Laboratório de Automação Agrícola, Escola Politécnica da Universidade de São Paulo, pelo apoio e incentivo ao longo deste trabalho.

A Profa. Dra. Selma Shin Shimizu Melnikoffe, Prof. Dr. Jorge Luis Risco Becerra, Prof. Dr. Kechi Hirama, Profa Dra. Lúcia Vilela Leite Filgueiras, Prof. Dr. Paulo Sérgio Muniz Silva e Prof Dr. Jorge Rady de Almeida Júnior, Laboratório de Tecnologia de Software, Escola Politécnica da Universidade de São Paulo, pelo apoio e incentivo ao longo deste trabalho.

Ao Prof. Dr. Townsend Peterson, University of Kansas, EUA, pelas discussões sobre conceitos de Modelagem de Distribuição de Espécies e os desáfios cientificos a serem atendidos por uma nova geração da ferramentas de Modelagem de Distribuição de Espécie.

Ao Prof. Dr. Enrique Martínez-Meyer, Instituto de Biología, Universidad Nacional Autónoma de México, pelas discussões sobre conceitos de Modelagem de Distribuição de Espécies e aplicação de Modelagem de Distribuição de Espécie para projeção de distribuição geográfica em cenários definidos no Special Report on Emissions Scenarios (SRES) pelo Intergovernamental Panel on Climate Change (IPCC).

Ao Prof. Dr. Friedrich Recknagel da Environmental Biology, School of Earth and Environmental Sciences, University of Adelaide, Austrália, pela discussão sobre conceitos de Modelagem Ecológica e Hybrid Evolutionary Algorithms (HEA).

Ao Prof. Dr. Dr. Jean P Boubli, Reader in Animal Ecology, School of Environment \& Life Sciences, University of Salford, UK, pela discussão sobre conceitos de Modelagem de Distribuição de Espécies e Distribuição Geográfica de Primatas e Mamíferos de Médio e Grande porte do Brasil.

Ao Doutorando Rafael Fonseca, Universidade de Brasília e Assistente Técnico da Deutsche Gesellschaft für Internationale Zusammenarbeit (GIZ) $\mathrm{GmbH}$, Instituto Chico Mendes de Biodiversidade - ICMBIO, pela discussão sobre Modelagem de Distribuição de Espécies da Fauna Brasileira e Padrões de Metadados em Projetos de parceira Poli-USP/ GIZ/ Ministério do Meio Ambiente e Instituto Chico Mendes de Biodiversidade - ICMBIO. 
A Dra. Keila Elizabeth Macfadem Juarez, Departamento de Conservação da Biodiversidade, Secretaria de Biodiversidade e Florestas do Ministério do Meio Ambiente, pela discussão sobre Interoperabilidade de Dados de Biodiversidade, Padrões de Metadados, Diretrizes e Política para Dados de Biodiversidade, Processo de Modelagem de Distribuição de Espécies e ferramentas para Modelagem de Distribuição de Espécies.

Ao Dr. Rodrigo Silva Pinto Jorge, Coordenador de Autorização e Informação Científica em Biodiversidade - COINF, Coordenação Geral de Pesquisa e Monitoramento - CGPEQ, Diretoria de Pesquisa, Avaliação e Monitoramento da Biodiversidade - DIBIO, Instituto Chico Mendes de Conservação da Biodiversidade ICMBio/MMA, pela discussão sobre Interoperabilidade de Dados de Biodiversidade, Padrões de Metadados, Unidades de Conservação Federais e Modelagem de Distribuição de Espécies .

Ao Dr. Eduardo Dalcin, Instituto de Pesquisas Jardim Botânico do Rio de Janeiro, Diretoria de Pesquisas, Núcleo de Computação Científica e Geoprocessamento, pela discussão sobre Qualidade de dados de Biodiversidade, Interoperabilidade de Dados de Biodiversidade, Padrões de Metadados e Modelagem de Distribuição de Espécies

Ao Prof. Dr. Laurindo Campos, Coordenação de Tecnologia da Informação, Núcleo de BioGeo Informática, Laboratório de Interoperabilidade Semântica, Instituto Nacional de Pesquisas da Amazônia, Ministério da Ciência, Tecnologia e Inovação, pela discussão sobre conceitos e aspectos específicos da Distribuição Geográfica de Espécies de Mosquitos que são vetores do Plasmodium que causa a Malária em humanos na Amazônia Brasileira.

Ao Prof. Dr. Wesley A. C. Godoy, Lab. Ecologia de Insetos e Entomologia Florestal, Depto. Entomologia e Acarologia - ESALQ - USP, pela oportunidade de participar da pesquisa e publicação de artigos sobre análise do impacto das mudanças climáticas na Distribuição Geográfica da Melipona mandacaia e Melipona Quadrifasciata em cenários definidos no Special Report on Emissions Scenarios (SRES) pelo Intergovernamental Panel on Climate Change (IPCC).

A Dra. Lorena Andrade Nunes, pesquisadora no Laboratório de Entomologia do Centro de Ciências Agrárias Ambientais e Biológicas da Universidade Federal do Recôncavo da Bahia, pela oportunidade de participar da pesquisa e publicação de artigos sobre análise do impacto das mudanças climáticas na Distribuição Geográfica da Melipona mandacaia e Melipona Quadrifasciata em cenários definidos no Special Report on Emissions Scenarios (SRES) pelo Intergovernamental Panel on Climate Change (IPCC).

Ao Prof. Dr. Alfredo Carvalho, Laboratório de Entomologia do Centro de Ciências Agrárias Ambientais e Biológicas da Universidade Federal do Recôncavo da Bahia, pela oportunidade de participar da pesquisa e publicação de artigos sobre análise do impacto das mudanças climáticas na Distribuição Geográfica da Melipona mandacaia e Melipona Quadrifasciata em cenários definidos no Special Report on Emissions Scenarios (SRES) pelo Intergovernamental Panel on Climate Change (IPCC). 
Ao Prof. Dr. Paulo Inácio de Knegt López de Prado e Prof. Dr. Alexandre Adalardo de Oliveira, do Departamento de Ecologia do Instituto de Biociências da Universidade de São Paulo, pela oportunidade de participar das discussões sobre o uso da Linguagem R para análise de Dados Ecológicos.

Ao Prof Dr. Sergio Rosso, Prof Dr. Roberto Munehisa Shimizu, do Departamento de Ecologia do Instituto de Biociências da Universidade de São Paulo, pela oportunidade de participar das discussões sobre Planejamento e Análise de Pesquisas Ecológicas.

A Profa. Dra. Fabiana Soares Santana, Coordenadora do curso de Bacharelado em Ciência da Computação, Universidade Federal do ABC, pela discussão de conceitos de Modelagem Nicho Ecológico e a oportunidade de participar na pesquisa sobre arquitetura de ferramentas Modelagem de Distribuição de Espécies, bem como na elaboração de diversos artigos sobre a arquitetura e o processo de Modelagem de Distribuição de Espécies com a ferramenta openModeller.

A Profa. Dra. Tereza Cristina Giannini, Universidade de Santo Amaro e PósDoutoranda no Laboratório de Tecnologia da Informação no agronegócio e Ambiente - Laboratório de Automação Agrícola da Escola Politécnica da Universidade de São Paulo, pesquisadora no BeeLab do Instituto de Biociências da Universidade de São Paulo, pelas discussões sobre conceitos de Modelagem de Distribuição de Espécies e a oportunidade de participar da pesquisa e publicação de artigos sobre Modelagem de Distribuição de Espécies.

Ao MSc. e Doutorando André Luis Acosta do Laboratório de Tecnologia da Informação no agronegócio e Ambiente - Laboratório de Automação Agrícola da Escola Politécnica da Universidade de São Paulo, biólogo pela UNESP e Mestre em Ecologia pelo Centro de Investigações em Biodiversidade e Recursos Genéticos da Universidade do Porto, pesquisador no BeeLab do Instituto de Biociências da Universidade de São Paulo, pelas discussões sobre conceitos de Modelagem de Distribuição de Espécies e a oportunidade de participar da pesquisa e publicação de artigos sobre Modelagem de Distribuição de Espécies.

Ao Dr. Fabrício Augusto Rodrigues, do Laboratório de Tecnologia da Informação no agronegócio e Ambiente - Laboratório de Automação Agrícola da Escola Politécnica da Universidade de São Paulo, pelas discussões sobre conceitos de Modelagem de Distribuição de Espécies e sobre a Arquitetura e Algoritmos da Ferramenta openModeller.

Ao Dr. Sidney Tadeu Rodrigues, Coordenador do Laboratório de Ecologia da Paisagem do WWF-Brasil, pelas discussões sobre Modelagem de distribuição de Espécies e Unidades de Conservação.

Ao MSc. e Doutorando Silvio Stanzani do Laboratório de Arquitetura e Computação de Alto Desempenho, Escola Politécnica da Universidade de São Paulo, pelas discussões sobre ferramentas de Modelagem de Distribuição de Espécies em ambiente de arquitetura de alto desempenho. 
Ao MSc. e Doutorando Daniel Lins da Silva, Tecnologia da Informação no agronegócio e Ambiente - Laboratório de Automação Agrícola, Escola Politécnica da Universidade de São Paulo, pelas discussões sobre padrões de Metadados e ferramentas para Interoperabilidade de Dados de Biodiversidade.

Ao MSc. e Doutorando Cleverton Borba, Tecnologia da Informação no agronegócio e Ambiente - Laboratório de Automação Agrícola, Escola Politécnica da Universidade de São Paulo, pelas discussões sobre Modelagem de Distribuição de Espéceis.

Ao MSc. e Doutorando Allan Koch Veiga, Tecnologia da Informação no agronegócio e Ambiente - Laboratório de Automação Agrícola, Escola Politécnica da Universidade de São Paulo, pelas discussões sobre conceitos de Qualidade de Dados em Biodiversidade.

Ao MSc. e Doutorando Willian Ferreira Costa, Tecnologia da Informação no agronegócio e Ambiente - Laboratório de Automação Agrícola, Escola Politécnica da Universidade de São Paulo, pelas discussões sobre conceitos de georreferenciamento, mapas e ferramenta GIS.

Ao MSc e Doutorando Pablo de Morais Andrade, do Instituto de Matemática e Estatística da Universidade de São Paulo, pelas discussões sobre conceitos de estatística, processos estocásticos, distribuições e modelagem.

Ao MSc. e Doutorando Walter Hugo Lopez Pinaya, Universidade Federal do ABC, pela parceria no desenvolvimento de ferramentas para Coleta de Dados de Biodiversidade.

Ao Prof. Dr. Marco Tulio Carvalho de Andrade, Prof. Dr. Edson Satoshi Gomi e Profa. Dra. Cíntia Borges Margi, Prof. Dr. Pedro Luiz Pizzigatti Corrêa e Prof Dr. Antonio Mauro Saraiva pela oportunidade em participar da monitoria de disciplinas de graduação no Departamento de Engenharia de Computação e Sistemas Digitais (PCS) da Universidade de São Paulo.

À Deutsche Gesellschaft für Internationale Zusammenarbeit (GIZ) $G m b H$, pela oportunidade de participação no projeto de Modelagem de Distribuição de Espécies da Fauna Brasileira e Padrões de Metadados, em parceira Poli-USP/ GIZ/ Ministério do Meio Ambiente (MMA) e Instituto Chico Mendes de Biodiversidade (ICMBIO).

Agradecer aos colegas e professores do Departamento de Engenharia de Computação e Sistemas Digitais (PCS), e especialmente aos colegas do Laboratório de Tecnologia da Informação no agronegócio e Ambiente - Laboratório de Automação Agrícola da Escola Politécnica da Universidade de São Paulo e do Laboratório de Abelhas do Instituto de Biociências da Universidade de São Paulo, que colaboraram direta ou indiretamente com a elaboração deste trabalho. 


\section{RESUMO}

A área de pesquisa científica, denominada computação e biodiversidade, tem por desafio suprir a demanda por tecnologias de apoio à conservação da biodiversidade, fornecendo ferramentas computacionais aplicadas ao estudo da biodiversidade. Os modelos de distribuição geográfica de espécies têm uma importante contribuição para 0 entendimento da biodiversidade e no apoio para a tomada de decisão em conservação dos recursos de biodiversidade. Os resultados da modelagem de distribuição de espécies, não apresentam com clareza os tratamentos aplicados aos dados na etapa de pré-analise e os critérios de seleção das variáveis preditoras, o que agrava a incerteza quanto aos resultados obtidos e prejudica a reprodutibilidade do experimento. Assim, o objetivo desta pesquisa é apresentar o processo de modelagem de distribuição de espécie com destaque para as atividades de préanálise e atividades de seleção das variáveis preditoras. O processo de modelagem de distribuição de espécies proposto é avaliado por meio de estudo de caso de Modelagem de Distribuição de Espécies do polinizador Centris hyptidis e das plantas oleaginosas Angelonia campestris e Angelonia cornigera, que considera como fator biótico a especialização da interações entre essas plantas e o polinizador. Neste estudo de caso pode-se verificar que a aplicação de técnicas estatísticas exploratórias de dados na etapa de pré-análise do processo de modelagem distribuição de espécies permite a avaliação da qualidade dos pontos de ocorrência, essenciais para o desempenho preditivo do modelo final.

Palavras-chave: Computação e Biodiversidade, Sistema de Informação Geográfica, Geoestatística, Biodiversidade, Biogeografia, Modelagem de distribuição de espécies. 


\section{ABSTRACT}

The area of research called biodiversity informatics, or bioinformatics, has to face the challenge of meeting the demand for technologies to support the conservation of biodiversity, providing computational tools applied to the study of biodiversity. The models of geographic distribution of species have a fundamental implication for understanding the biodiversity and conservation decision making. Researches on modeling species distributions generally do not present clearly the treatments applied to the data in the pre-analysis and criteria for selection of predictor variables, which increases the uncertainty regarding the results and affect the reproducibility of experiment. The objective of this research is to present the process of species distribution modeling with emphasis on the activities of preanalysis and activities selection of the predictor variables, such as to favor its repeatability and reproducibility by other researchers. The process of modeling species distribution proposed is validated on a case study of modeling distribution of pollinator species Centris hyptidis and oilseed Angelonia campestris and Angelonia cornigera, a biotic factor that considers the specialization of these interactions between plants and pollinators. In this case study we can observe one of the main contributions of this work: the application of statistical techniques for data exploration in the pre-analysis of species distribution modeling process, with improved capacity for evaluation and selection of points of occurrence essential to the performance of the predictive model.

Keywords: Geographic information system, Distribuition Spatial, Geostatistic, Geoprocessing, Biodiversity, Biogeography, Algorithms, Data Modelling. 


\section{LISTA DE ILUSTRAÇÔES}

Figura 1: O Diagrama de BAM apresenta região equivalente à distribuição geográfica da espécie, que tem a combinação adequada dos fatores bióticos, abióticos e ainda é acessível pela espécie.

Figura 2: Framework teórico para Modelagem de Distribuição de Espécies............................. 49

Figura 3: Apresentação das Fases relacionadas ao Processo de Modelagem de Distribuição de Espécies

Figura 4: Mapa da Distribuição Potencial da Espécie Centris Hyptidis e os pontos de ocorrências gerado com o openModeller.

Figura 5: Diagrama de atividades UML com o detalhe dos relacionamentos entre as atividades do Processo de Modelagem de Distribuição de Espécies proposto. 66

Figura 6: Apresentação da hipótese inicial simplificada para o exemplo de modelagem de distribuição de espécies.

Figura 7: Apresentação dos pontos de ocorrência para o exemplo de modelagem de distribuição de espécies.

Figura 8: Gráfico Box-plot da espécie Centris hyptidis em relação à Temperatura Média Anual (Bio1)

Figura 9: Gráfico Box-plot das espécies: 1- Angelonia campestris, 2- Angelonia cornigera e 3- Centris hyptidis em relação à Precipitação Média Anual (Bio12).

Figura 10: Diagrama de gradiente latitudinal espécie Centris hyptidis em relação à Temperatura Média Anual (Bio1)

Figura 11: Gráfico da espécie Centris hyptidis de impacto da Precipitação Anual (Bio12) em relação à Temperatura Média Anual (Bio1).

Figura 12: Gráfico de Gradiente Latitudinal da espécie Centris hyptidis relativo à Variação Diurna Média de Temperatura (Bio2)

Figura 13: Gráfico de Gradiente Latitudinal da espécie Angelonia campestris relativo à Precipitação do mês mais seco (Bio14).

Figura 14: Gráfico de Histograma da espécie Angelonia campestris relativo à Precipitação do mês mais seco (Bio14).

Figura 15: Categorização dos pontos de ocorrência de Centris hyptidis pelo Bioma.

Figura 16: Gráfico com o resultado do teste AUC da Modelagem de Distribuição Potencial da espécie Centris hyptidis com o algoritmo de Entropia Máxima.

Figura 17: Gráfico com o resultado do teste de Erro de Comissão e Omissão da Modelagem de Distribuição Potencial da espécie Centris hyptidis com o algoritmo de Entropia Máxima. 85 Figura 18: Gráfico com os resultados do teste de Jackknife da Modelagem de Distribuição Potencial da espécie Centris hyptidis com o algoritmo de Entropia Máxima.

Figura 19: Mapa da Modelagem de Distribuição Potencial da espécie Centris hyptidis com o algoritmo de Entropia Máxima.

Figura 20: Mapa com o resultado da Modelagem de Distribuição Potencial da espécie Angelonia campestris utilizando o algoritmo de Entropia Máxima 
Figura 21: Mapa com o resultado da Modelagem de Distribuição Potencial da espécie Angelonia cornigera utilizando o algoritmo de Entropia Máxima

Figura 22: Mapa com o resultado da Modelagem de Distribuição Potencial da espécie Centris hyptidis utilizando o algoritmo de Entropia Máxima 90

Figura 23: Curva de resposta da espécie Angelonia campestris em relação a variável preditora Precipitação do mês mais seco (Bio14) com o outlier 96

Figura 24: Curva de resposta da espécie Angelonia campestris em relação a variável preditora Precipitação do mês mais seco (Bio14) com a aplicação do filtro para a remoção do outlier 


\section{LISTA DE TABELAS}

Tabela 1: Atividades do Processo de Distribuição de Espécies .................................................. 51

Tabela 2: Relatório de modelagem do openModeller Desktop.................................................. 63

Tabela 3: Lista das 19 variáveis bioclimáticas utilizadas como variáveis preditoras

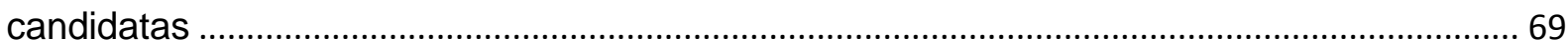

Tabela 4: Medidas para a variável preditora temperatura média anual (Bio1)........................ 71 Tabela 5: Comparação do impacto na contribuição das variáveis preditoras ao Modelo com a aplicação do filtro para remoção de outliers ........................................................................ 98 


\section{LISTA DE ABREVIATURAS E SIGLAS}

BIOCOMP Núcleo de Apoio à Pesquisa em Biodiversidade e Computação

CGPEQ Coordenação Geral de Pesquisa e Monitoramento

DIBIO Diretoria de Pesquisa, Avaliação e Monitoramento da Biodiversidade

ENFA Ecological Niche Factor Analysis

ENM Environmental (or ecological) Niche Models

GAM Generalized Additive Models

GARP Genetic Algorithm for Rule-set Production

GBIF Global Biodiversity Information Facility

GeoTIFF Geographic Tagged Image File Format

GIS Geographic Information System

GIZ Deutsche Gesellschaft für Internationale Zusammenarbeit (GIZ) GmbH

GLM General Linear Models

HEA Hybrid Evolutionary Algorithms

HSM Habitat Suitability Models

IABIN Inter-American Biodiversity Information Network

ICMBIO Instituto Chico Mendes de Biodiversidade

INPE Instituto Nacional de Pesquisas Espaciais 
IPCC Intergovernmental Panel on Climate Change

IUCN International Union for Conservation of Nature

LAA Laboratório de Tecnologia da Informação no agronegócio e Ambiente Laboratório de Automação Agrícola

MDE Modelos de Distribuição de Espécies

MMA Ministério do Meio Ambiente

PCA Principal Component Analysis

PNG Portable Network Graphics

RSF Resource Selection Functions

SDM Species Distribution Models

SRES Special Report on Emissions Scenarios

TAPIR TDWG Acess Protocol for Information Retrieval

TDWG Taxonomic Database Working Group

UML Unified Modeling Language

USP Universidade de São Paulo

XML eXtensible Markup Language 


\section{SUMÁRIO}

1 INTRODUÇÃO

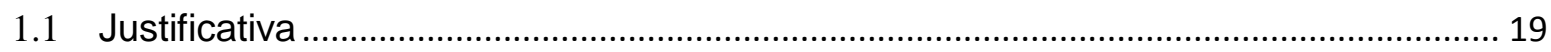

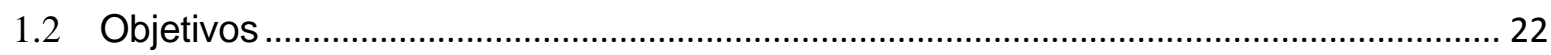

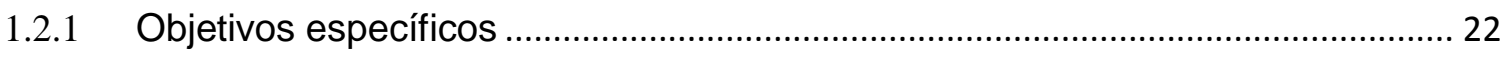

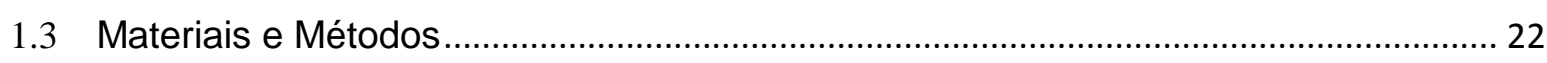

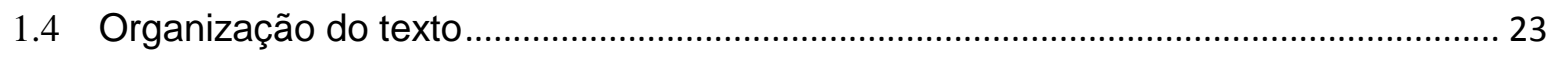

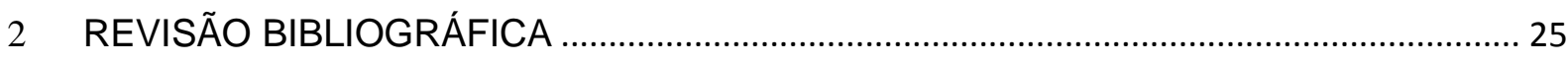

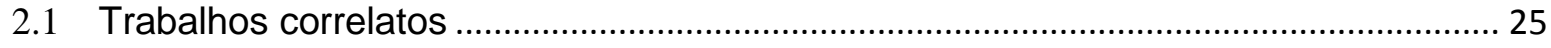

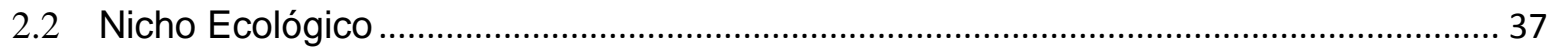

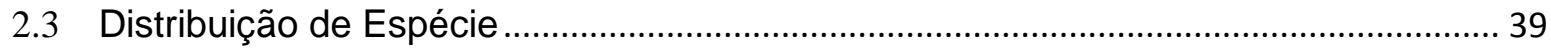

2.4 Dados de presença-ausência de espécie ........................................................................ 43

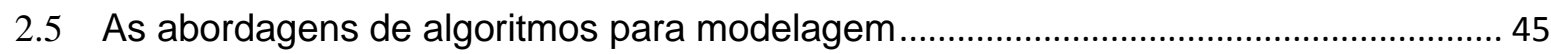

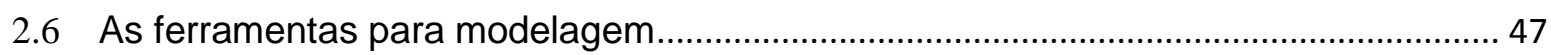

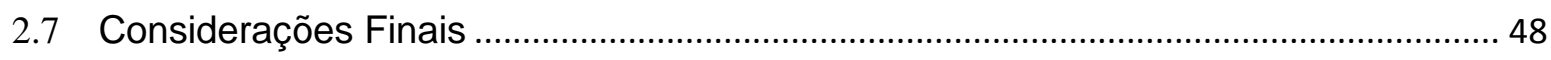

3 PROCESSO DE MODELAGEM DE DISTRIBUIÇÃO DE ESPÉCIES ............................... 49

3.1 Processo de modelagem de distribuição de espécies proposto .................................... 49

3.2 Fases do Processo de Modelagem de Distribuição de Espécies .................................. 52

3.2.1 Fase de construção da hipótese científica ............................................................... 53

3.2.2 Fase de Pré-Análise dos Dados ............................................................................. 54

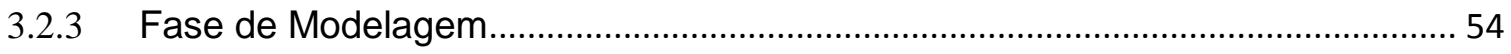

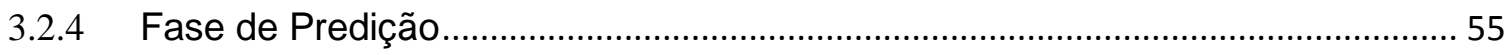

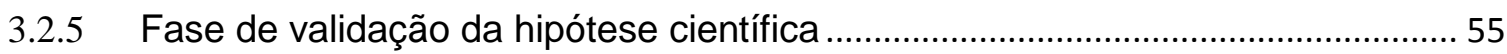

3.3 Etapas do Processo de Modelagem de Distribuição de Espécies ............................... 56

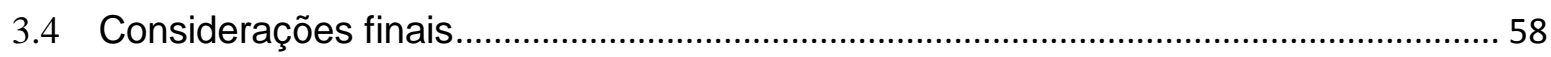

4 Estudo de Caso do Processo de Modelagem de Distribuição de Espécies ..................... 59

4.1 Modelagem de Distribuição da Espécie Centris hyptidis com openModeller Desktop59

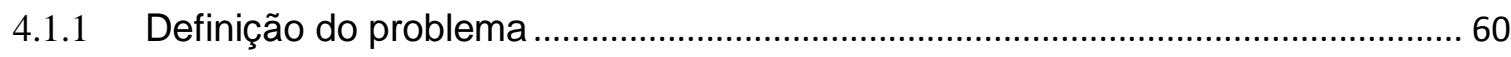

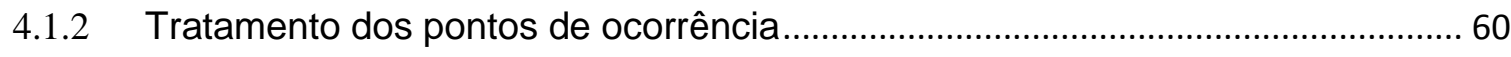

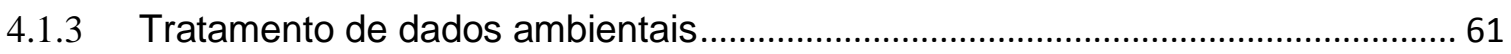




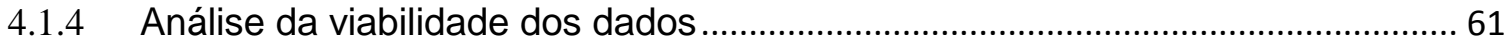

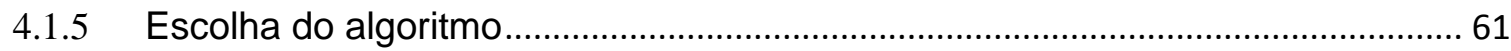

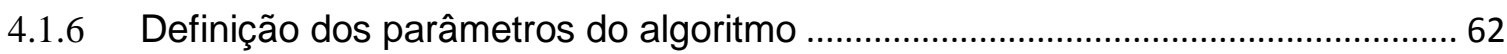

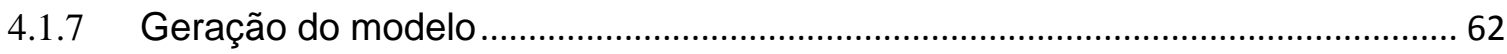

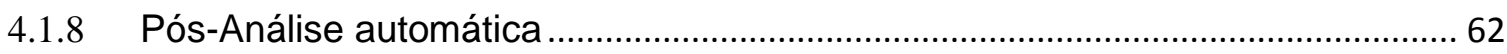

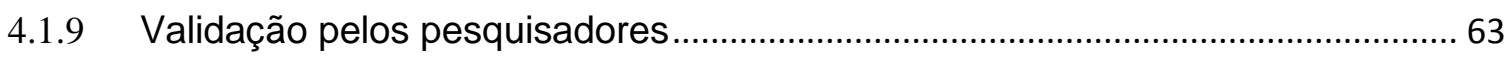

4.2 Modelagem de Distribuição da Espécie Centris hyptidis considerando a interação

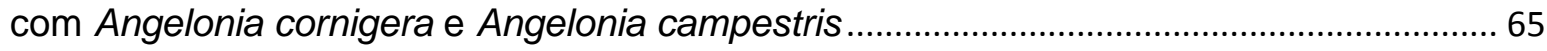

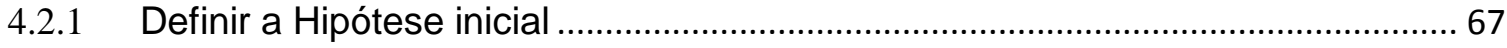

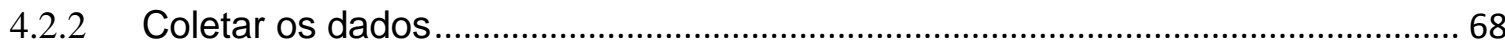

4.2.3 Análise dos dados em relação às variáveis preditoras candidatas e a posição

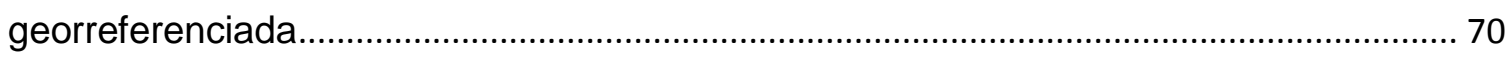

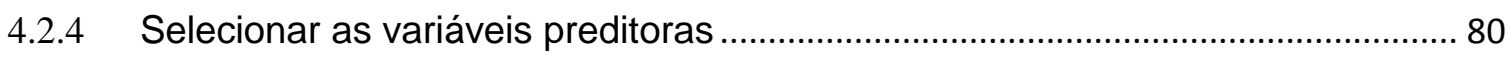

4.2.5 Selecionar e executar o algoritmo de modelagem de distribuição de espécie ... 83

4.2.6 Predição da distribuição de espécie na área de interesse...................................... 86

4.2.7 Validar a hipótese científica com a análise de um conjunto de predições de

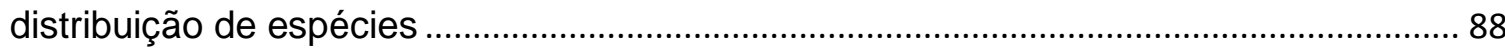

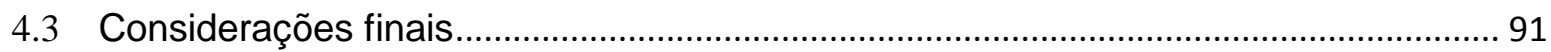

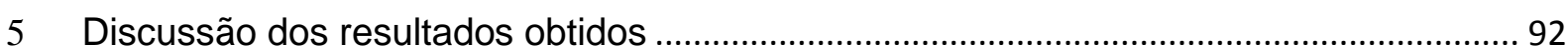

5.1 Estrutura e organização do Processo de Modelagem de Distribuição de Espécies .. 93

5.2 Técnica de filtragem para remoção de outliers................................................................. 94

5.3 Resultados da aplicação do filtro outliers nas curvas de resposta das variáveis

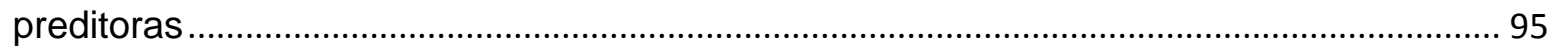

5.4 Resultados da aplicação do filtro outliers no peso das contribuições das variáveis

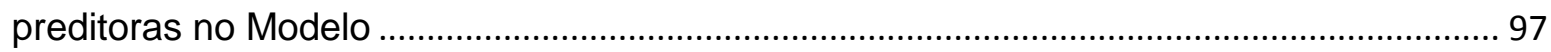

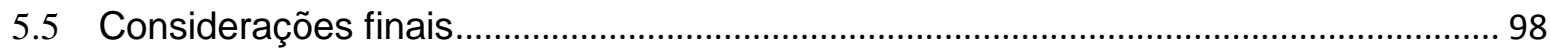

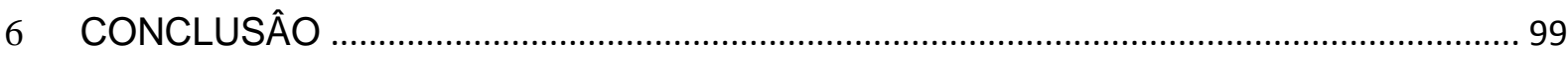

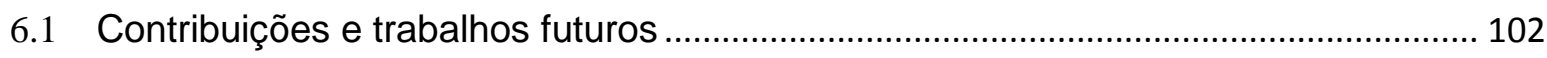

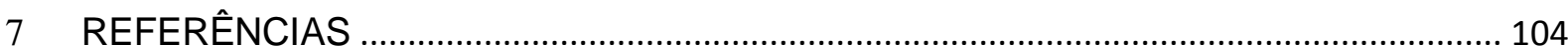




\section{INTRODUÇÃO}

O processo para gerar um modelo para descrever a distribuição probabilística de espécies é complexo, pois requer manipular uma grande quantidade de dados, a utilização de diferentes pacotes de software para a conversão de dados, para a geração do modelo e para diferentes tipos de processamento e análises, entre outras atividades (SANTANA et al., 2008).

As técnicas de modelagem computacional para distribuição de espécies são críticas para a tarefa de identificar áreas com alto risco de perda de biodivesidade. Estas ferramentas podem auxiliar na conservação da biodiversidade, no planejamento do uso de regiões não habitadas, nas estimativas de risco de invasão de espécies, na proposta de reintrodução de espécies e mesmo no planejamento de proteção de espécies ameaçadas (CORRÊA et al., 2011).

Os Modelos de Distribuição de Espécies (MDE) são ferramentas numéricas que combinam observações de ocorrência de espécies ou abundância com estimadores ambientais. $\mathrm{O}$ termo de MDS foi anteriormente referenciado como variam amplamente, como modelos bioclimáticos, envelopes climáticos, Environmental (or ecological) Niche Models (ENMs), modelos de habitat, Resource Selection Functions (RSF), mapas e, mais fracamente, modelos correlativos ou modelos espaciais, conforme Elith e Leathwick (2009).

Segundo Soberón e Peterson (2005), os fatores que são mais importantes para determinar a área de distribuição da espécie na modelagem de distribuição de espécie são os limites de tolerância e as necessidade da espécie à condições abióticas, a existência de outras espécies com as quais interage, e o seu potencial de dispersão e de colonização dentro de um determinado período de tempo.

A Modelagem de Distribuição de Espécie pode usar exclusivamente dados abióticos que definem as características do habitat, tais como as condições climáticas, tipo de solo e a altitude. Por exemplo, a aplicação do nicho ecológico, relacionando as variáveis ambientais com a probabilidade de ocorrência de 
espécies, para predizer a presença, ausência ou abundância da espécie através da área de estudo (RUSHTON; ORMEROD; KERBY, 2004; HIRZEL; LAY, 2008).

Porém, com o desenvolvimento de novas técnicas de modelagem de distribuição de espécies, tornou-se possível a inclusão de outros conjuntos de dados, como os aspectos bióticos, que correspondem às interações entre espécie e seus parceiros mutualistas, seus predadores, competidores, entre outros, que ocupam o mesmo ambiente, e os movimentos espaciais dos indivíduos e populações, que determinam sua dinâmica de ocupação e dispersão (SOBERÓN; NAKAMURA, 2009; THUILLER, 2003).

Pode-se ainda destacar as inciativas dedicadas a disponibilização de dados de interações entre organismos, especialmente polinizadores e plantas, como o Inter-American Biodiversity Information Network (IABIN) (www.iabin.net) .

Ainda segundo Peterson (2006) e Elith et al. (2006), na modelagem de distribuição de espécies, além dos algoritmos de modelagem e as variáveis preditoras, também estão envolvidos neste processo diversos tipos de dados e formatos de dados, e técnicas de análise de dados, como por exemplo, o formato Darwin Core do Taxonomic Database Working Group (TDWG) (www.tdwg.org), e o protocolo TDWG Acess Protocol for Information Retrieval (TAPIR) (www.tdwg.org/activities/tapir/).

Dessa forma, considera-se que o Processo de Modelagem de Distribuição de Espécie utilizado para a criação de um Modelo é complexo. O Processo de Modelagem de Distribuição de Espécie é composto de várias etapas, como préanálise, análise e pós-análise, e as atividades específicas de cada etapa, como data clearing e o teste do desempenho preditivo do modelo (CORRÊA et al., 2011; ELITH, LEATHWICK, 2009).

\subsection{Justificativa}

A gestão de recursos naturais está relacionada com o entendimento e o estabelecimento de estratégias para a conservação da biodiversidade, e é um dos 
principais desafios que a humanidade enfrenta e enfrentará nas próximas décadas (CORRÊA et al., 2011).

Assim, esta área de pesquisa científica, denominada Computação e Biodiversidade, em Inglês Biodiversity Informatics, tem que enfrentar o desafio de suprir a demanda por tecnologia de apoio à conservação da biodiversidade (CORRÊA et al., 2011; PETERSON et al., 2010).

Segundo Peterson (2010), as atividades atuais da Biodiversity Informatics estão focalizadas na extração de dados, que incluem a digitalização e a classificação de registros de espécimes; na compilação de dados, que incluem tarefas como curadoria de dados, organizando suas informações, e publicá-los em redes de informação; e na exibição e visualização desses dados, que incluem a visualização em termos geográficos da distribuição conhecida da espécie.

Uma das principais desvantagens dos dados de registros de espécimes é a sua falta de integralidade e integridade, e o uso de Modelos permite preencher falhas no conhecimento da distribuição de espécies (CHAPMAN, 2005a,b e c).

Além disso, a integração dessas fontes de dados em estimativas de distribuições de espécies fornecem informações essenciais sobre a disposição da biodiversidade em todo o planeta (PETERSON, 2010).

A Modelagem de Distribuição de Espécies (MDE) fornece um novo meio para examinar as alterações na distribuição das espécies, alterações nas populações e na sua diversidade ao longo do tempo. Como por exemplo, na avaliação se a distribuição potencial de uma espécie pode aumentar ou diminuir com as alterações climáticas (BROENNIMANN et al., 2012; RODDER et al., 2011)

Segundo Peterson (2011), os modelos de nicho oferecem o potencial para prever áreas potenciais de distribuição de espécies em cenários específicos de mudanças climáticas. Desta forma, as possíveis alterações na distribuição de uma única espécie são avaliadas para detectar a capacidade de populações permanecerem estáveis nas próximas décadas. 
Segundo Warren e Sefert (2011), os modelos de distribuição de espécies são utilizados em um de quatro modos:

a) Estimar a aptidão relativa de um habitat conhecido a ser ocupado pela espécie;

b) Estimar a aptidão relativa de um habitat em áreas geográficas que não são conhecidas como sendo ocupados pela espécie;

c) Estimar alterações na adequação do habitat ao longo do tempo, dado um cenário específico de mudança climática; e

d) Estimativa do nicho de espécies.

A capacidade de transferência do modelo de distribuição de espécie para outra região, ou escala, pode apresentar problemas conceituais e práticos relativos à amostragem da região, conforme Menke et al. (2009) e Barve (2011).

A capacidade de transferência do modelo de distribuição de espécie pode ser afetada pelas variáveis preditoras utilizadas, pois estas variáveis são afetadas de diferentes formas pela escala da área de interesse, conforme Soberón e Peterson (2005).

Além disso, é importante destacar que os modelos de distribuição de espécies inapropriadamente complexos, ou muito simples, também apresentam uma reduzida capacidade de inferir a importância relativa das variáveis preditoras na restrição de distribuição geográfica da espécie. Neste caso, o termo "complexidade" é relativa a quantidade de variáveis preditoras utilizadas na modelagem.

A complexidade do modelo de distribuição de espécie também reduz a capacidade de transferência para cenários específicos de mudanças climáticas, conforme Warren e Seifert (2011).

Segundo Hampe (2004) e Sánchez-Cordero (2008), quando é feita a transferência para outro cenário ambiental podem aparecer problemas como as interações bióticas, a adaptação genética e problemas relativos à capacidade de dispersão da espécie. 
Além disso, a capacidade de avaliar o desenpenho do modelo de distribuição de espécie é afetada pela autocorrelação espacial dos pontos de ocorrência, que impede a separação dos pontos utilizados para teste e treinamento em grupos independentes, conforme Veloz (2009).

\subsection{Objetivos}

O objetivo desta pesquisa é definir a Seleção das Variáveis Preditoras na Etapa de Pré-Análise dos Dados no Processo de Modelagem de Distribuição de Espécies.

\subsubsection{Objetivos específicos}

- Destacar na Etapa de Pré-Análise do Processo de Modelagem de Distribuição de Espécies a identificação dos outliers, ou valores discrepantes, associados aos Dados de Pontos de Ocorrências da Espécie e Variáveis Preditoras.

- Especificar as atividades de Seleção de Variáveis Preditoras na Etapa de PréAnálise do Processo de Modelagem de Distribuição de Espécies.

\subsection{Materiais e Métodos}

A fase inicial da pesquisa envolveu o estudo teórico e prático sobre as atividades envolvidas no Processo de Modelagem de Distribuição de Espécies baseado no conceito de nicho ecológico, conforme Soberon e Peterson (2005).

O Algoritmo de Entropia Máxima (PHILLIPS et al., 2006) foi escolhido para avaliação do processo, por ter uma boa aceitação na comunidade de Computação e Biodiversidade (ELITH et al., 2011), e um desempenho melhor em estudos comparativos entre os métodos utilizados para Modelagem de Distribuição de Espécies, como em Elith et al. (2006). 
Foi realizado um levantamento bibliográfico sobre Processos de Modelagem de Distribuição de Espécie propostos na literatura. Com destaque para a pesquisa de Santana et al. (2008), Elith e Leathwick (2009b), Rodrigues (2012) e Giannini et al. (2012a), que descrevem o Processo de Modelagem de Distribuição de Espécies baseados no conceito de Nicho Ecológico.

No entanto, foi adotado como base o Processo de Modelagem de Distribuição de Espécies definido por (SANTANA et al., 2008), em razão de ter sido desenvolvido para uma ferramenta que integra múltiplos algoritmos de modelagem de distribuição de espécies, como a ferramenta openModeller (MUÑOZ et al., 2009).

As novas Etapas do Processo de Modelagem de Distribuição de Espécies propostas nesta pesquisa ainda não são cobertas pela versão atual da ferramenta openModeller, dessa maneira optou-se por desenvolver utilizando scripts na Linguagem de Programação R (R Development Core Team, 2009).

A Seleção das Variáveis Preditoras na Etapa de Pré-análise do Processo de Modelagem de Distribuição de Espécies proposto foi validada pela aplicação do Processo em um estudo de caso de Modelagem de Distribuição de Espécie envolvendo a interação da espécie de abelha Centris hyptidis e plantas oleaginosas da espécie Angelonia campestris e Angelonia cornigera, na região nordeste do Brasil (GIANNINI et al., 2012; GIANNINI; SARAIVA; ALVES-DOS-SANTOS, 2010).

Neste trabalho foi utilizado algoritmo de Entropia Máxima disponível no pacote "Dismo" (HIJMANS, 2011) da linguagem R. Desta forma, foi facilitada a integração dos dados utilizados pelas diferentes etapas e atividades do Processo de Modelagem de Distribuição de Espécies proposto e análise dos resultados obtidos.

\subsection{Organização do texto}

- O Capítulo 1 apresenta a motivação e justificativa, seus objetivos e a metodologia da pesquisa. 
- O Capítulo 2 apresenta uma revisão bibliográfica sobre o tema proposto, abrangendo as técnicas computacionais envolvidas neste trabalho e os conceitos relacionados à modelagem de distribuição de espécies.

- O Capítulo 3 apresenta materiais e métodos com as técnicas propostas para melhoria do Processo de Modelagem de Distribuição de Espécies.

- O Capítulo 4 apresenta o estudo de caso de Modelagem de Distribuição de Espécies, com a aplicação do Processo de Distribuição de Espécies proposto neste trabalho e discussão dos resultados obtidos.

- O Capítulo 5 apresenta a discussão e as conclusões deste trabalho e as recomendações para trabalhos futuros.

- O Capítulo 6 apresenta as Referências Bibliográficas.

Cada Capítulo é iniciado com uma breve descrição de cada Seção. O Capítulo é encerrado por uma Seção com um breve resumo e as considerações finais, com exceção do Capitulo 6 das Referências Bibliográficas. 


\section{REVISÃO BIBLIOGRÁFICA}

Neste Capítulo é apresentada uma revisão da literatura sobre os conceitos e as técnicas utilizadas no Processo de criação de um Modelo de Distribuição de Espécies. Na Seção 2.1, são apresentados os Trabalhos Correlatos. Na Seção 2.2, é apresentada a evolução do conceito de Nicho Ecológico. Na Seção 2.3, são apresentados os principais aspectos do Processo de Modelagem de distribuição de espécies. Na Seção 2.4, são apresentados os conceitos relativos aos Dados de Presença e Ausência da Espécie. Na Seção 2.5 são apresentados diferentes abordagens de Algoritmos para Modelagem de Distribuição de Espécies. Na Seção 2.6, são apresentadas as considerações finais sobre este Capítulo.

\subsection{Trabalhos correlatos}

Segundo Santana et al. (2008), o Processo de Modelagem de Distribuição de Espécies pode ser subdividido nos seguintes passos:

- Passo 1: Definição do problema.

Neste passo o experimento de modelagem de distribuição de espécie é definido; o conjunto de questões ecológicas a serem respondidas pelo modelo é especificado considerando as espécies selecionadas, a área geográfica de interesse, as camadas ambientais e a resolução geográfica a ser adotada para o modelo.

- Passo 2: Tratamento dos pontos de ocorrência.

Neste passo os pontos de ocorrência e ausência de espécies são preparados para o processo de modelagem, o que inclui a resolução de problemas como erros de digitalização, pontos fora dos limites da região e pontos com valores absurdos, isto é Data Clearing (CHAPMAN, 2005a e 2005b). 
- Passo 3: Tratamento de dados ambientais.

Neste passo é realizada a Identificação, a aquisição e a conversão dos dados ambientais necessários para a geração de um modelo de nicho ecológico. O uso de dados ambientais requer um trabalho adicional para torna-los compatíveis, pois usualmente os dados ambientais estão disponíveis em diferentes formatos de dados, sistemas de coordenadas de georeferenciamento, projeções e resoluções.

- Passo 4: Análise da viabilidade dos dados

Neste passo são analisados os dados obtidos nas três etapas anteriores, e decidido se estes dados permitem prosseguir com o processo de modelagem e se são suficientes para responder às questões científicas. Por exemplo, se a resolução dos dados disponíveis é compatível com a questão a ser respondidas pelo processo de modelagem.

- Passo 5: Escolha do algoritmo.

Neste passo é escolhido o algoritmo que será aplicado para geração dos modelos de nicho ecológico. Os dados disponíveis, bióticos ou abióticos, podem ser adequados à geração de um modelo usando um algoritmo e não o outro, pois todos os algoritmos de modelagem basicamente representam a implantação de um método matemático específico para analisar os dados e obter um modelo de nicho ecológico. Por exemplo, na abordagem correlativa de modelagem de nicho ecológico os algoritmos podem extrapolar a partir das associações entre os pontos de ocorrências e um conjunto de dados ambientais para identificar as áreas previstas de presença em um mapa.

- Passo 6: Definição dos parâmetros.

Neste passo são definidos os valores numéricos para os parâmetros de configuração do algoritmo, para controlar alguns aspectos de seu 
comportamento; sendo que, cada algoritmo tem seus próprios parâmetros específicos e não é possível generalizar a sua aplicação. Portanto, é essencial entender o significado de cada parâmetro, pois a escolha errada de valores pode resultar em um modelo completamente diferente do que deveria ser.

- Passo 7: Geração do modelo.

Neste passo deve-se executar o experimento como especificado nas etapas anteriores, usando os dados de entrada fornecidos para o algoritmo e produzir um modelo de nicho ecológico. Muitos pacotes de software, como a ferramenta openModeller, oferece a oportunidade de executar diferentes algoritmos a partir de um conjunto de dados de entrada selecionados, com diferentes configurações de parâmetros, para um mesmo experimento.

- Passo 8: Pós-Análise automática.

Neste passo o modelo gerado é avaliado, a fim de verificar se o modelo está adequado para a espécie em estudo, por exemplo, medidas estatísticas podem ser calculadas para comparar os resultados obtidos com outros pontos de ocorrência e de ausência que ainda não foram utilizados. Ainda com o propósito de avaliação do modelo, podem ser calculadas medidas estatísticas para se obter indicações sobre a acurácia do modelo, ,por exemplo, a análise Receiver Operating Characteristic (ROC), ou curva ROC, que corresponde a uma representação gráfica da sensibilidade versus a especificidade, e a Area Under Curve (AUC), que resulta em um valor numérico para comparar a acurácia de diferentes algoritmos (PHILLIPS et al., 2006).

- Passo 9: Validação pelos pesquisadores.

Neste passo, baseado no conhecimento e na avaliação do pesquisador especialista na espécie, e principalmente, combinada com os 
resultados estatísticos para a validação do modelo, decide-se validar 0 modelo e encerrar o processo ou retornar aos passos anteriores.

O Processo destaca a possibilidade da escolha entre diversos algoritmos de Modelagem de Distribuição de Espécie, e ainda com a integração destas diferentes atividades em uma ferramenta computacional.

De acordo com Elith e Leathwick (2009b), uma Modelagem de Distribuição de Espécies inclui os seguintes passos:

Passo 1: Reunir registros das espécies e avaliar a sua adequação

Um modelo quantifica a relação entre as espécies e do seu ambiente, e a sua qualidade dependerá, portanto, a qualidade dos dados disponíveis.

As principais características dos dados de espécies que contribuem para um modelo ecologicamente sensível são: um número suficiente de registros para modelar as tendências principais; as observações que são independentes umas das outras, de confiança, registrada com precisão; a amostragem dos principais gradientes de espaço e o ambiente geográfico em momentos relevantes e sem viés, como descritos a seguir:

a) O tamanho da amostra: O número de registros exigidos depende da complexidade da relação entre as espécies e seu ambiente, com poucos registros o melhor que pode ser feito é a identificação do mais forte gradiente ambiental ou de tendências.

b) $A$ independência e cobertura: $O$ registros precisam ser independentes no sentido de que cada um traz uma nova informação para o modelo. Múltiplas observações em um local geralmente deve ser reduzido a um registro, a menos que contribuam com dados sazonais importantes, ou a longo prazo, ou fornecer informação sobre a detectabilidade, isto é, correções 
de erros de visibilidade. Os clusters de amostras podem ser espacialmente próximos que, do ponto de vista biológico, não podem ser considerados como independentes, por exemplo, quando são muito fortes as semelhanças no ambiente e dentro de distância de facil dispersão.

c) A confiabilidade, precisão e viés: Os erros típicos de dados de espécies incluem os de falhas na identificação, a incapacidade de detectar uma espécie que está presente, os erros na descrição da localização, e as questões temporais. Dessa forma, é importante investir tempo e recursos para limpeza de registros de espécies, utilizando opinião de especialistas ou o cuidadoso cruzamento de registros e investigação de outliers no espaço geográfico e ambiental. Um conjunto claro de critérios deve ser definido com antecedência para aceitar ou rejeitar dados, refletindo a utilização final desejada do modelo.

d) As pseudo-ausências: Muitas vezes, apenas os dados de presença estão disponíveis, por isso a escolha deve ser modelar apenas os dados de presença, ou comparar a sua distribuição com os ambientes da região de interesse.

Passo 2: Confrontar e pré-processar as variáveis preditoras

É difícil definir a importância de um preditor funcionalmente relevante, porque isso pode ter impactos substanciais sobre o ajuste do modelo e na capacidade de um modelo prever de forma consistente em áreas não amostrados.

A difícil e subjetiva tarefa de escolha adequada de preditores é limitada pela quantidade de dados de distribuição de espécies disponíveis, o que impõe um limite no número de indicadores que possam ser razoavelmente manipulados de forma eficiente e relevante para a espécie, como descrito a seguir: 
a) Considerações de formatação: A produção de um mapa digital prevendo uma distribuição de espécie, a partir de uma Modelagem de Distribuição de Espécie, exige que todos os preditores do modelo estejam disponíveis através de toda região de interesse. Estes preditores são normalmente armazenados em um Sistema de Informação Geográfica (GIS) . Ao utilizar-se quaisquer dados GIS, é importante garantir que as inconsistências nas projeções, datums, tamanhos de células de grade e alinhamento estejam corrigidas.

b) Correlações entre as variáveis preditoras: as correlações entre preditores podem criar problemas, tanto na interpretação dos modelos como na previsão de regiões onde a estrutura de correlação difere; de modo que correlações precisam ser identificadas e tratadas. No entanto, os modelos estatísticos podem identificar correlação, não a causa, e não há nenhuma maneira simples para decidir quais variáveis devem ser considerada e quais devem ser ignoradas.

Passo 3: Montagem do modelo

Com os dados das espécies e variáveis preditores candidatas, a primeira tarefa de modelagem é coletar os valores das variáveis preditoras em todos os locais em que há registros de espécies, considerando as seguintes questões gerais:

a) A seleção de variáveis a partir do conjunto de variáveis candidatas: Seleção de variáveis é uma parte importante do modelo em muitas técnicas de regressão, e para isso são usadas um certo número de abordagens fundamentalmente diferentes, as opções incluem: 
I. O uso das variáveis preditoras candidatas agrupadas, assumindo que o modelo pode classificar as variáveis relevantes por coeficientes de atribuição de forma confiável;

II. O uso de um algoritmo de seleção de variáveis, tais como stepwise, que é a criação de diversos modelos com diferentes subconjuntos de variáveis, seguido pela seleção dos melhores modelos, usando critérios baseados em informação, como a média dos resultados;

III. O uso de todas as variáveis preditoras, seguido pelos métodos de redução dos coeficientes globais ou locais, também chamado de regularização.

b) A complexidade do modelo e da estrutura: Independentemente do método usado, é importante abordar o conflito entre a maximização do ajuste do modelo e a minimização do erro de predição. O problema é parcialmente evitado pela restrição do número de variáveis preditoras candidatas e a complexidade dos relacionamentos modelados, de acordo com o tamanho da amostra dos dados de espécies.

c) A utilização de pesos: Muitos métodos de regressão permitir a utilização de pesos que controlam as contribuições relativas das observações de presença e ausência. Os pesos também podem ser usados de forma mais ampla para refletir certezas relativas sobre registros ou valorizar registros em regiões subamostradas.

d) A verificação do modelo: A verificação do modelo deve ser considerado uma parte indispensável do processo de montagem de um Modelo de Distribuição de Espécie. 
As projeções geralmente envolvem a aplicação do modelo a um conjunto de dados que contém os valores de variáveis de previsão dos novos locais, considerando as seguintes características:

a) Interpretação numérica: todas as previsões estão ligadas aos métodos de pesquisa utilizados para coletar 0 dados de treinamento. Apesar de sua aparência, as previsões dos modelos, equipados somente com dados de presença, não indicam a probabilidades de ocorrência, porque estes tipos de registros de espécies não dispõem de informações sobre a prevalência das espécies. Os modelos com informações apenas de presença só podem fornecer previsões da probabilidade relativa da presença da espécies em um local.

b) Aplicando limites: o planejamento da conservação é muitas vezes feito com mapas digitais que indicam locais que fornecem um habitat apropriado ou impróprio, isto é, como uma variável de 0/1, em vez de utilizar previsões contínuas de probabilidade, ou probabilidade relativa, disponível a partir de modelos de regressão. Se as previsões contínuas devem ser reduzidas para uma nível binário, um threshold ou limiar deve ser escolhido para atingir esta conversão.

c) Estimativas de incerteza: A previsão será sempre incerta, tanto porque o mecanismo intrínseco de muitos modelos fornece previsões de estimativas médias, em determinado local, e porque existem muitas fontes de erro que são inevitáveis. Muitos métodos de Modelagem de Distribuição de Espécies podem produzir intervalos de confiança estimados em torno de suas previsões, embora isso possa envolver um esforço computacional substancial, por exemplo, através de métodos de bootstrap. 
Conforme Rodrigues (2012), as três Etapas principais de um Processo de Modelagem são a Etapa de Pré-análise, Etapa de Modelagem e a Etapa de Pósanálise. As atividades em cada etapa podem então serem organizadas em fases ou subetapas descritas a seguir:

\section{Etapa de Pré-análise}

\section{Primeira Fase}

- A subetapa de definição dos objetivos, o escopo do processo de análise de desempenho que estão relacionados diretamente com as características dos algoritmos, e como essas características afetam o desempenho e a precisão dos modelos,

- A subetapa de seleção e organização dos dados, como os dados georreferenciados de localização de espécies e variáveis ambientais que influenciam a distribuição da espécie, e

- A subetapa de escolha dos algoritmos de modelagem que serão analisados e as ferramentas de modelagem, por meio de características que podem influenciar os resultados, que podem estar relacionadas ou serem dependentes umas das outras, como:

a) A estrutura interna, como parâmetros que definem sua arquitetura e são definidos empiricamente pelo usuário;

b) O princípio de funcionamento, com implementação de técnicas baseadas em diferentes estratégias de convergência, como correção de erros, otimização de restrições e otimização global;

c) O tratamento dos dados, como a utilização de pontos de ocorrência e pontos de ausência;

d) O tipo de saída produzida, como binárias ou probabilísticas, e a forma de produzir os mapas de distribuição potencial, como calculando um valor de probabilidade para ponto da região de interesse ou calculando uma distribuição para a região de interesse; 
e) O determinismo, quando o algoritmo produzirá sempre o mesmo modelo, versus o não determinismo, quando podem produzir diferentes modelos a cada execução para o mesmo conjunto de dados de entrada; $\mathrm{e}$

f) A quantidade de parâmetros, que determina a complexidade para a utilização eficiente do algoritmo.

Por exemplo, os objetivos podem ser definidos a partir de dados já disponíveis, ou os dados e os algoritmos podem ser selecionados com base nos objetivos previamente definidos, ou ainda, objetivos são estabelecidos e dados selecionados considerando a necessidade de testar ou validar determinados algoritmos.

\section{Segunda Fase}

- A subetapa de escolha das métricas que serão utilizadas para analisar o desempenho dos algoritmos, como as listadas a seguir:

a) O erro de um classificador ao rotular um conjunto de exemplos.

b) A taxa percentual de acerto do algoritmo sobre um conjunto de exemplos.

c) A taxa de erros de omissão, que ocorrem quando o algoritmo classifica exemplos da classe presença, ou seja, área habitada pela espécie.

d) A taxa de erros de sobreprevisão, que ocorrem quando o algoritmo classifica pontos considerados inadequados para a espécie como pontos de presença, ou seja, áreas potencialmente habitadas pela espécie.

e) A Area Under Curve (AUC)

Etapa de Modelagem de Distribuição de Espécies 
- A subetapa de geração dos modelos de distribuição geográficas, por meio da execução dos algoritmos e dados previamente selecionados e organizados.

\section{Etapa de Pós-análise}

\section{Quarta Fase}

- A subetapa de testes dos modelos de distribuição previamente gerados, que devem ser testados com um conjunto de dados diferente do conjunto de dados utilizados no treinamento.

\section{Quinta Fase}

- A subetapa de coleta dos resultados, como medidas estatísticas e os mapas de distribuição, que são então organizados e agrupados para produzir o máximo de elementos que auxiliem a avaliação dos resultados.

\section{Sexta Fase}

- A subetapa de avaliação dos resultados, como as técnicas apresentadas a seguir:

a) A avaliação estatística, que leva em consideração apenas os resultados estatísticos da fase de treinamento dos algoritmos e da fase de testes com os modelos de distribuição,

b) A avaliação qualitativa dos mapas de distribuição potencial, que representa a avaliação dos resultados por um especialista com conhecimento sobre a espécie, o bioma, as condições climáticas e as ambientais. 
Segundo Giannini et al. (2012a), a Modelagem de Distribuição de Espécies é um Processo complexo que compreende várias Etapas, as quais exigem o conhecimento de diversos conceitos e técnicas ligados não só à Biologia, mas também a Biodiversidade, Geografia e Clima, e ao processamento de dados requerido antes, durante e depois da obtenção do Modelo, descritas a seguir:

Etapa de tratamento dos pontos de ocorrência das espécies

Nesta primeira etapa é considerada a obtenção, avaliação e o preparo dos pontos de presença e ausência das espécies a ser modelado, o que pode incluir o georreferenciamento dos pontos e a exclusão de dados imprecisos ou duvidosos.

Etapa de tratamento e escolha das camadas ambientais

Nesta etapa as camadas ambientais são identificadas, adquiridas e convertidas. É importante também definir adequadamente a resolução das camadas ambientais, considerando a precisão dos pontos de ocorrência, as características do terreno, características da espécie e o tamanho da área geográfica a ser analisada.

Etapa de escolha dos algoritmos de modelagem

Nesta etapa a escolha do algoritmo deve ser baseada na pergunta do estudo e na disponibilidade de dados de ocorrência, considerando o número de registros e dados de presença somente ou de dados de presença e ausência. Por exemplo, o MaxEnt (Phillips et al., 2006) demonstrou um bom desempenho em geral para modelagem preditiva, e para o caso de poucos pontos de ocorrência com dados de presença somente.

Etapa de avaliação dos modelos gerados

Nesta etapa é realizada a avaliação da qualidade dos modelos gerados, também conhecido como teste externo, e consiste da confrontação de seus resultados contra dados da distribuição da 
espécie que não foram utilizados pelo algoritmo no processo de modelagem, como descritos a seguir:

a) Os erros associados aos modelos preditivos de distribuição de espécies baseados na matriz de confusão, como: erro de omissão ou subprevisão, que também podem ser um outlier para o algoritmo, ou seja, pontos com informação ambiental muito fora do padrão gerado pelos demais pontos do conjunto de treino; erros de sobreprevisão ou comissão, que consiste na previsão de ocorrência em uma área na qual não tem registro de presença da espécie.

b) A geração de um conjunto independente de dados, podendo ser feita pela coleta de novos dados em trabalho de campo ou levantamento na literatura, ou dividindo o conjunto de dados em conjunto de treino e teste antes de realizar a modelagem.

c) A medida da capacidade discriminatória de um modelo pode ser obtida pelo estabelecimento de um limite de corte, este threshold é um fator de subjetividade na interpretação do modelo.

d) A aplicação de métodos de análise, como o cálculo AUC.

e) A validação de campo da capacidade do modelo acertar a distribuição da espécie em áreas de alta e baixa adequabilidade ambiental.

f) A avaliação biológica, através de interpretação visual do especialista na espécie modelada.

Ainda segundo Giannini et al. (2012a), procedimentos pós-modelagem podem ser adotados com o objetivo de aumentar a confiabilidade dos modelos gerados, ou diminuir as incertezas. Por exemplo, as técnicas de ensemble forecasting podem ser aplicadas aos resultados da modelagem, que consiste basicamente em gerar um modelo de consenso, a partir dos resultados de diferentes algoritmos ou diferentes cenários (ARAÚJO; NEW, 2007).

\subsection{Nicho Ecológico}


O Nicho Fundamental, de acordo com o conceito definido por Hutchinson (1957), representa as condições ambientais que limitam a abundância e distribuição de uma espécie. Toda espécie é limitada por um número de fatores ambientais, em um período de tempo determinado e dentro de sua distribuição geográfica.

Desta forma, o Nicho Fundamental da espécie representa combinação de variáveis ambientais que permitem a sobrevivência individual e reprodução, e ainda, que a população mantenha o seu número de individuos. O Nicho Realizado é definido como um subconjunto do Nicho Fundamental, devido a fatores externos que impedem o desenvolvimento de todo o potencial da espécie, conforme Soberón e Peterson (2005).

Em Hutchinson (1957), o nicho é definido como "o conjunto, num espaço multidimensional, de estados do ambiente dentro do qual uma espécie é capaz de sobreviver".

No entanto, o "ambiente" de uma espécie consiste de fatores radicalmente diferentes, sendo importante fazer a distinção entre fatores que são ambientais daqueles que não são fatores ambientais. Os fatores ambientais estão ligados dinamicamente à população das espécies em foco, isto é, o espaço ambiental multivariado é baseado em variáveis que não são dinamicamente afetados pela espécie, como clima e topografia. Os fatores que não são ambientais, em contraste, são dinamicamente ligados à espécie em foco, como o consumo de recursos, ou são sujeitos a modificações pela construção ou destruição do nicho (PETERSON et al., 2011).

Conforme Leibold (1995) existem diversas interpretações do conceito de nicho, mas podemos destacar duas interpretações para o melhor entendimento da distribuição geográfica da espécie. O Nicho Grinnelliano pode ser definido fundamentalmente por variáveis ambientais abióticas, chamadas de cenopoéticas, que apresentam uma alta autocorrelação espacial e está relacionada com a fisiologia da espécie, como as variáveis climáticas, a topografia em larga escala e a radiação solar. O Nicho Eltoniano é focado nas variáveis chamadas bionômicas, isto é, as Interações bióticas e dinâmicas de consumo dos recursos, interações entre as espécies e as interações dos seus recursos locais e as outras espécies. 
Os conceitos de Nicho Grinnelliano e Nicho Eltoniano são relevantes para o entendimento da distribuição das espécies no espaço, mas o Nicho Eltoniano é mais fácil de medir em escala local, que tem maior resolução, entre $10^{-3}$ a $10^{0} \mathrm{~km}^{2}$, que é a característica da maioria das pesquisas ecológicas. O Nicho Grinnelliano se encaixa melhor às escalas maiores, com resolução mais baixa, entre $10^{-1}$ a $10^{2} \mathrm{~km}^{2}$, nas quais as áreas de distribuições são tipicamente definidas (SOBERON, 2007; SOBERON; NAKAMURA, 2009; PETERSON, 2011).

Segundo Brown e Lomolino (1998) e o trabalho de Anderson e MartínezMeyer (2004), um modelo de distribuição pode ser elaborado a partir das localidades determinadas por um conjunto de dados georreferenciados de ocorrência da espécie e variáveis como a temperatura média, a precipitação média e a elevação do terreno. Estas variáveis foram medidas ou estimadas na área geográfica de interesse e descrevem alguns dos fatores que influenciam a adequabilidade do ambiente.

De acordo com Cox e Moore (2005), a área geográfica de uma espécie não é sempre determinada pela presença de barreiras topográficas que restrigem o seu espalhamento completo. A distribuição de uma espécie pode também ser limitada por um Fator em particular, que influência a sua habilidade de sobreviver ou de se reproduzir adequadamente.

\subsection{Distribuição de Espécie}

Conforme Soberón e Peterson (2005), a área de distribuição da espécie é a expressão de sua ecologia e histórico evolucionário (BROWN, 1995 apud SOBERÓN; PETESON, 2005) , determinado por diversos fatores que operam em diferentes intensidades nas diferentes escalas (GASTON, 2003; PEARSON; DAWSON, 2003 apud SOBERÓN; PETESON, 2005).

O diagrama BAM, Figura 1, indica que a espécie poderá estar presente em um determinado ponto onde três condições são satisfeitas: na região $(A)$ as 
condições abióticas devem ser favoraveis; na região (B) uma combinação de espécies, como hospedeiros, plantas e polinizadores, devem estar presentes e outras devem estar ausentes, como competidores, doenças e predadores especializados; e na região (M) a espécie poderá estar presente somente se for acessível, considerando a capacidade de dispersão da espécie a partir de áreas de distribuição onde a espécie esta estabelecida. $A$ área de intersecção entre a região (B) e a região (A) é a expressão geográfica do Nicho Realizado, e finalmente com a interseção desta área com a região $(\mathrm{M})$ é obtido a Distribuição Geografica da Espécie (SOBERÓN; PETESON, 2005).

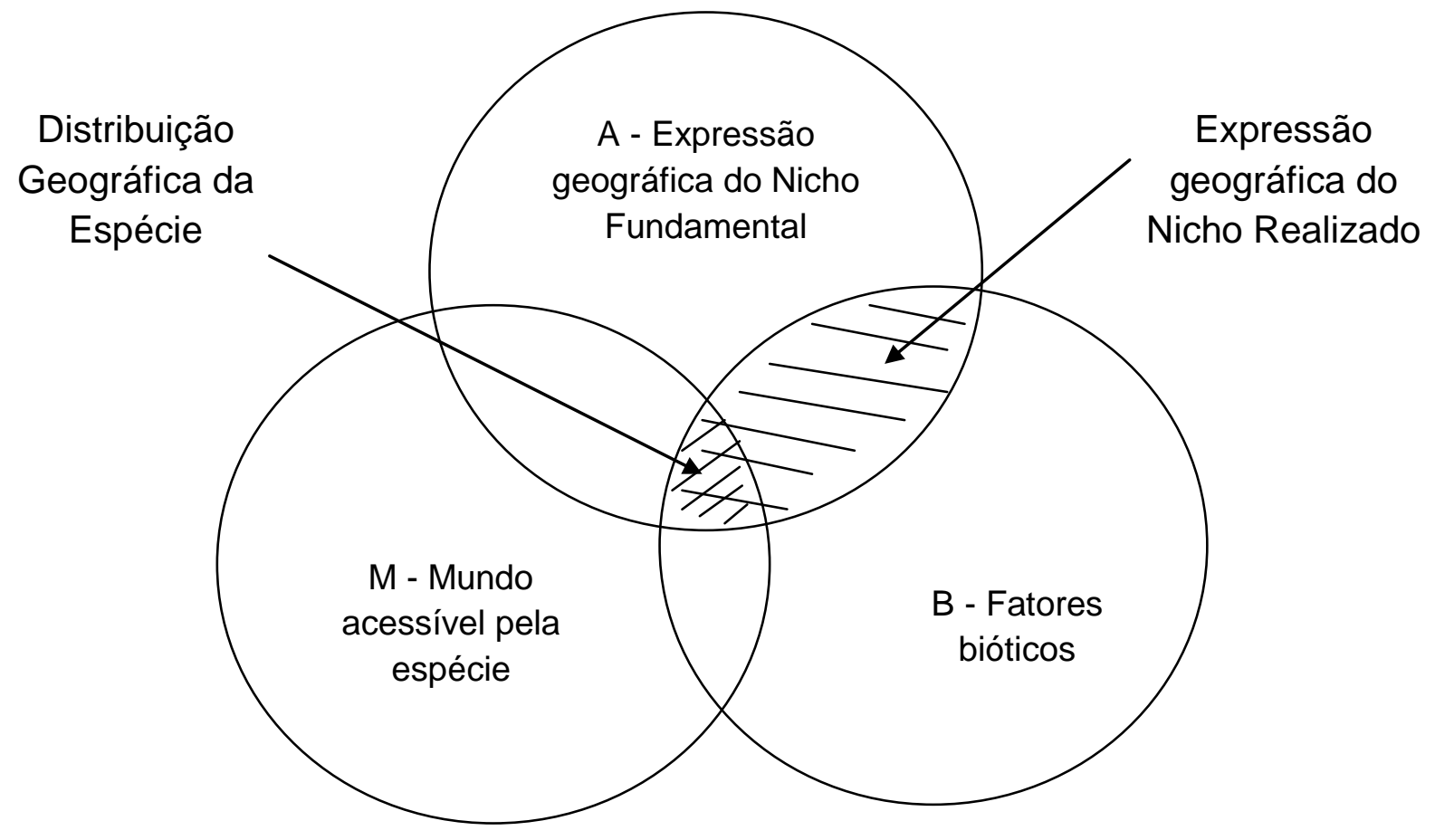

Figura 1: O Diagrama de BAM apresenta região equivalente à distribuição geográfica da espécie, que tem a combinação adequada dos fatores bióticos, abióticos e ainda é acessível pela espécie. 
Conforme Soberón e Peterson (2005), esses fatores podem ser divididos em classes, que juntas determinam a área na qual a espécies pode ser encontrada:

- Fatores Abióticos:

Os Fatores Abióticos, ou Variáveis Cenopoéticas, impõe limites fisiológicos sobre a habilidade da espécie persistir na área, o que inclui aspectos do clima e ambiente físico.

- Fatores Bióticos:

Os Fatores Bióticos, ou Variáveis Bionômicas, são o conjunto de interações com outras espécies que modificam a capacidade da espécie de manter populações. Essas interações podem ser positivas, como polinizadores e distribuidores de sementes, ou negativa, como predadores e competidores.

- Habilidade de Dispersão da Espécie:

As regiões que são acessíveis, para dispersão da espécie, a partir de alguma área original. Este fator é utilizado para distinguir a distribuição real da espécie de sua distribuição potencial, com base na configuração da paisagem e habilidades de dispersão da espécie.

- Capacidade Evolutiva das Populações de Espécies:

Considera a hipótese climática "niche conservatism", que postula que as espécies habitam ambientes mais produtivos ou mais quente, pois a maioria é originaria em tais ambientes, e restrições evolutivas limitam a ocupação de regiões mais frias ou mais áridas (WIENS et al., 2010).

Segundo Soberon e Peterson (2005), os fatores interagem de forma dinâmica como as condições abióticas, os fatores bióticos, as regiões que são acessíveis e a capacidade evolucionária das populações para se adaptarem, com forças diferentes 
e em diferentes escalas para produzir uma entidade complexa e fluída, chamada de distribuição geográfica das espécies.

Mas, segundo Hortal et al. (2010) e Soberón (2010), pode ser necessário diferenciar entre os fatores biogeográficos e aqueles fatores relacionados à Dinâmica de Ocupação.

Os Fatores Biogeográficos têm um efeito significativo sobre os processos em grande escala, que determinam o tamanho e forma dos intervalos de distribuição de espécies, por exemplo, um dos padrões biogeográficos mais notáveis observados na riqueza de espécies em diferentes ecossistemas refere-se ao aumento do número de espécies em regiões tropicais e equatoriais (HORTAL et al., 2010; PINTOCOELHO, 2007).

A Dinâmica de Ocupação é o resultado de uma série de processos que afetam a demografia das populações e os movimentos de seus indivíduos, incluindo a Dinâmica de Metapopulação, dispersão de pequena distância e distúrbios localizados. Metapopulação é definida como um conjunto de populações conectadas por indivíduos que se movem entre elas, por exemplo, cada população ocorrendo em um fragmento de mata. O termo Dinâmica de Metapopulações refere-se não ao ganho e perda de indivíduos dentro de cada uma das populações, mas ao ganho e à perda de populações dentro da metapopulação. Por exemplo, em uma metapopulação, populações podem ser ganhas por colonização de manchas vazias de habitat e podem ser perdidas por extinção local (HANSKI, 1991; HANSKI; GILPIN, 1997).

Segundo Philips, Anderson e Schapire (2006), a tarefa de uma técnica de modelagem é predizer a adequação ambiental para uma espécie como uma função de variáveis ambientais.

Note-se que essas variáveis ambientais podem ser relacionadas a algo importante para a espécie de interesse. Os Modelos de Adequabilidade de Habitat (HSM) (RUSHTON; ORMEROD; KERBY, 2004), visam definir, para quaisquer espécies escolhidas, o "envelope" que melhor descreve os seus limites espaciais 
alcançados, através da identificação das variáveis ambientais que limitam a sua distribuição, conforme Hirzel e Lay (2008) e BRAUNISCH (2008).

Ainda, conforme Thuiller e Mümkemüller (2010), o Modelo de Adequabilidade de Habitat (HSM) considera que as variáveis ambientais podem exercer efeitos diretos ou indiretos sobre as espécies.

\subsection{Dados de presença-ausência de espécie}

É importante destacar que a presença de uma espécie é uma função de probabilidade. Esta função de probabilidade é afetada principalmente pela abundância da espécie e sua capacidade de ser detectada (BROTONS, 2004).

Segundo Peterson (2011), a existência de registros de ausência ou presença de uma espécie está associada a diversos fatores, que são descritos a seguir:

a) A área pode ser inadequada, e por essa razão a espécie não está presente.

b) A área pode ser inadequada, mas a espécie está presente devido à dispersão a partir de áreas adequadas.

c) A área pode ser adequada, mas a espécie não tem sido capaz de alcançar a área por meio de sua capacidade de dispersão.

d) A área era adequada e foi ocupada pela espécie em um momento, mas a espécie foi extirpada da área desde então.

e) A área adequada pode ser ocupada pela espécie, mas não tem um pesquisador que já visitou o local para provar.

f) A área adequada pode ser ocupada e pode ter sido visitada e amostrada por pesquisadores, mas eles não detectam as espécies.

g) A área adequada pode ser ocupada e pode ter sido visitada e amostrada, e as espécies podem também ter sido detectada, mas o registro não está disponível.

h) A área adequada pode ser ocupada e pode ter sido visitada e amostrada, as espécies foram detectadas, e um registro está disponível para o pesquisador. 
Segundo Elith et al. (2011), os registros de presença também são impactados por muitos dos fatores que também afetam os registros de ausências: se uma espécie está ausente em uma área ambientalmente adequada, devido a alguma perturbação no passado que causou a extinção local, o sinal da ausência será encontrado na distribuição dos registros de presença, isto é, não haverá registros de presença na área perturbada.

Desta forma, independentemente de serem utilizados registros de ausência no algoritmo de Modelagem de Distribuição de Espécies, o padrão de distribuição nos registros de presença irá sugerir que a área é inadequada, conforme Elith et al. (2011).

Similarmente, a facilidade na detecção da presença de determinada espécie pode variar, de um local para outro local, o que poderá resultar em alguns registros de ausências falsos. Esta variação na facilidade de detecção da presença também afeta o padrão dos registros de presença, conforme Elith et al. (2011).

Assim, a simples supressão de registros de ausência não soluciona as limitações nos registros de presença, causadas pelo fato de que as espécies não são perfeitamente detectáveis e não podem ocupar toda a área do habitat adequado, conforme Elith et al. (2011).

Outra limitação nos registros de presença é que o viés de seleção da amostra. Neste caso, algumas áreas da paisagem são amostradas de forma mais intensa do que outras. O viés de seleção tem um efeito mais forte em modelos que utilizam somente registros de presença do que em modelos que utilizam os registros de presença e os registros de ausência, conforme Philips et al., (2009) e Wisz, Guisan (2009).

Uma abordagem mais direta para resolver este problema de uma amostra espacialmente enviesada seria a manipulação dos dados de ocorrência, a fim de remover a polarização. Por exemplo, desfazer-se ou baixar o peso do conjunto de registros de uma região super amostrada. No entanto, tais manipulações são prejudicadas pela falta de informação sobre a distribuição do esforço de amostragem, conforme (DUDIK; SCHAPIRE; PHILLIPS, 2006; PHILIPS et al., 2009). 
Em um modelo baseado em dados ambientais, uma amostra espacialmente enviesada não causaria problema, se estiver proporcionalmente distribuída em toda a gama de ambientes da área de interesse. No entanto, se o desvio não é contabilizado, um modelo ajustado pode estar mais perto de um modelo do esforço de levantamento do que de um modelo da verdadeira distribuição da espécie, conforme Soberón e Nakamura (2009) e Philips et al. (2009).

De acordo com Philips et al. (2009), a maioria dos métodos de modelagem de distribuição de espécies a partir de registros de ocorrência exigem dados adicionais que representam o conjunto de condições disponíveis no meio ambiente das espécies na região modelada. Estes dados, chamados de dados de background ou pseudo-ausências, são oferecidos por uma amostra de pontos da área de interesse, por exemplo, as pseudo-ausências são geralmente escolhidas de forma aleatória e com distribuição uniforme. Isto caracteriza a gama de ambientes na região, mas não provoca o viés de seleção amostral (PHILIPS; DUDIK, 2008).

Assim, uma amostra dos pontos de background pode ser escolhida puramente ao acaso, ou por vezes excluindo os locais com registros de presença, conforme Graham et al. (2004).

É importante destacar também que, por definição, as pseudo-ausências nunca indicam que um determinado local é realmente inadequado à sobrevivência das espécies, como é assumido com os dados reais de ausência (PHILLIPS et al., 2006; WISZ; GUISAN, 2009; LOBO; JIMENÉZ-VALVERDE; HORTAL, 2010).

\subsection{As abordagens de algoritmos para modelagem}

Conforme (SEGURADO; ARAÚJO, 2004), os modelos que exploram o relacionamento entre ocorrências de espécies e um conjunto de variáveis preditoras produzem:

a) A estimativa da probabilidade da espécie ocorrer em uma dada região não amostrada;

b) A estimativa de uma área adequada para a espécie. 
A estimativa da probabilidade de ocorrência pode ser interpretada como a estimativa da probabilidade da espécie poder encontrar um habitat adequado em uma dada área.

Segundo Liu, White e Newell (2011) e Elith et al. (2006), podemos classificar as diversas abordagens para modelagem de distribuição de espécies em relação ao tipo de dado que é utilizado. Vários métodos têm sido utilizados para a modelagem de distribuição de espécies considerando somente as informações de presença para obter um modelo. Outras técnicas utilizam de dados de presença e dados de background.

O método de modelagem Bioclimatic Envelope (BIOCLIM) prevê as condições adequadas de um "envelope bioclimático", constituído por uma região retilínea no espaço ambiental representando o intervalo de presença observado em cada dimensão ambiental (BUSBY, 1986; NIX, 1986).

Do mesmo modo, o método de modelagem DOMAIN utiliza uma similaridade métrica, onde um índice de adequação predito é dado pelo cálculo da distância mínima no espaço ambiental para qualquer registro de presença (CARPENTER et al., 1993).

Os métodos estatísticos de uso geral como Generalized Linear Models (GLM) (McCULLAGH; NELDER, 1989) e Generalised Additive Models (GAM) (HASTIE; TIBSHIRANI, 1990; YEE; MITCHELL, 1991) são comumente usados para modelagem com conjuntos de dados de presença e de ausência, e também tem sido aplicados a situações com dados de presença somente (FERRIER; WATSON, 1996; FERRIER et al., 2002)

O Genetic Algorithm for Rule-set Production (GARP) usa uma estrutura de inteligência artificial chamada algoritmo genéticos (STOCKWELL; PETERS, 1999; ANDERSON; LEW; PETERSON, 2003). O GARP é baseado na definição de limites relacionados a variáveis ambientais através de regras para a seleção, evolução, teste, incorporação ou rejeição a fim de produzir um conjunto de regras que caracterize os requisitos ecológicos da espécie. As regras são favorecidas no algoritmo de acordo com a sua significância, em comparação com a previsão 
aleatória, com base em uma amostra de pontos de background e os pontos de presença.

A Ecological-Niche Factor Analysis (ENFA) utiliza localidades de presença juntamente com dados ambientais para toda a região estudada, sem requerer dados de background a ser tratada como ausências, conforme Hirzel et al. (2002). É semelhante à Principal Component Analysis (PCA) (LEGENDRE; LEGENDRE, 1998), envolvendo uma transformação linear do espaço ambiental. A adequação ambiental é então modelada como uma distância Manhattan no espaço transformado.

A Entropia Máxima é um método para estimar a distribuição através de um espaço geográfico, isto é, comparar a densidade de probabilidade em um espaço covariado. Este algoritmo utiliza uma amostra de dados de background no cálculo da distribuição de Entropia Máxima (PHILLIPS; ANDERSON; SCHAPIRE, 2006; PHILIPS; DUDIK; SCHAPIRE, 2004).

\subsection{As ferramentas para modelagem}

Atualmente, vários métodos de modelagem podem ser executados a partir de scripts e pacotes em linguagem $R$ (www.rproject.org), como o pacote BIOMOD (THUILLER; LAFOURCADE; ARAUJO, 2009) e DISMO (ELITH et al., 2011). Os algoritmos podem também ser executados a partir de ferramentas dedicadas, como o MaxEnt (PHILLIPS; ANDERSON; SCHAPIRE, 2006; PHILIPS; DUDIK; SCHAPIRE, 2004; PHILIPS; DUDÍK, 2008) e o openModeller Desktop (MUÑOZ et al., 2009).

Algumas ferramentas computacionais, como o openModeller Desktop, buscam a integração de algumas das atividades do processo de modelagem e diversos métodos de modelagem de distribuição de espécie baseado no conceito de nicho ecológico (CORRÊA et al., 2011).

O objetivo principal do projeto openModeller foi desenvolver um ambiente computacional integrado de modelagem para facilitar o trabalho dos pesquisadores 
para prever distribuição das espécies em diferentes cenários. O projeto foi apoiado pela Fapesp e envolveu três instituições: Centro de Referência de Informação Ambiental (CRIA), Escola Politécnica da Universidade de São Paulo (USP) e Instituto Nacional de Pesquisas Espaciais (INPE) (CANHOS et al., 2006; CANHOS et al., 2007; CANHOS et al., 2008; CANHOS et al., 2009)

\subsection{Considerações Finais}

Neste Capítulo foram apresentados os trabalhos correlatos sobre o desenvolvimento do Processo de Modelagem de Distribuição de Espécies, bem como as suas Fases, Etapas e Atividades.

Além disso, foram discutidos os aspectos relevantes que envolvem a seleção das variáveis preditoras, como o conceito de nicho ecológico, a escolha do Algoritmo de Modelagem adequado e a utilização de dados enviesados. 


\section{PROCESSO DE MODELAGEM DE DISTRIBUIÇÃO DE ESPÉCIES}

Neste Capítulo é apresentado o Processo de Modelagem de Distribuição de Espécie com suas Fases, Etapas e Atividades. Na Seção 3.1, é apresentado o Processo geral de Modelagem de Distribuição de Espécie proposto. Na Seção 3.2, são apresentadas as Fases do Processo de Modelagem de Distribuição de Espécie. $\mathrm{Na}$ Seção 3.3, são apresentadas as Etapas do Processo de Modelagem de Distribuição de Espécie. Na Seção 3.4, são apresentadas as Atividades do Processo de Distribuição de Espécie. Na Seção 3.5, são apresentas as considerações finais deste Capítulo.

\subsection{Processo de modelagem de distribuição de espécies proposto}

A Figura 3 apresenta um Framework teórico que combina os diversos Fatores que influênciam a Modelagem de Distribuição de Espécies, usando como notação um Profile UML com a Extensão de Negócios Eriksson-Penker (PRESSMAN, 2010; ERIKSSON, PENKER, 1999).

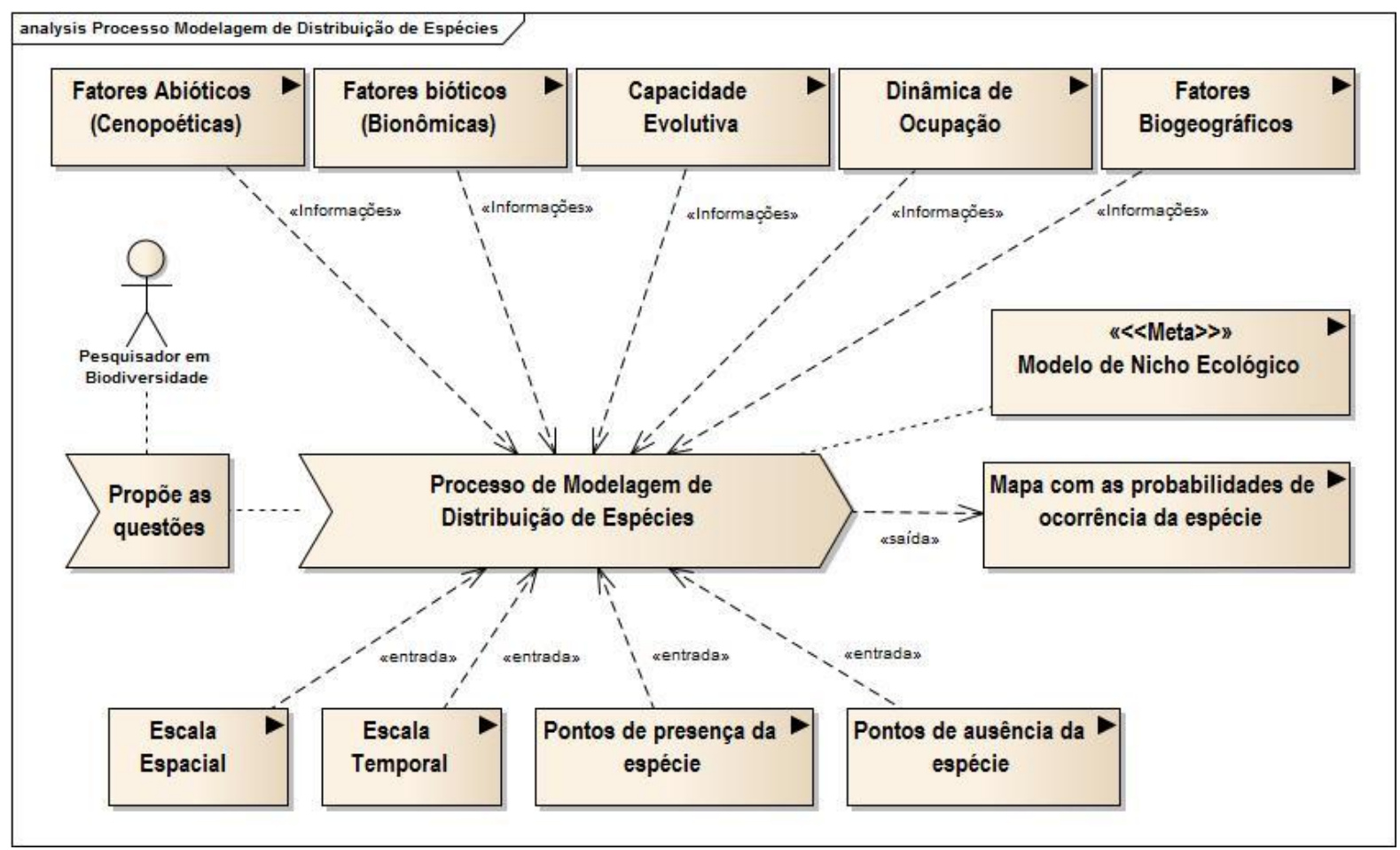

Figura 2: Framework teórico para Modelagem de Distribuição de Espécies 
Conforme o Framework teórico apresentado, o Pesquisador em Biodiversidade define as questões ecológicas que a modelagem de distribuição de espécies deve ajudar a responder, conforme Santana et al. (2008) e Giannini (2011).

Ainda neste Framework teórico, conforme Soberón e Peterson (2005) e Hortal et al. (2010), o pesquisador em biodiversidade usa informações sobre:

- Fatores Abióticos ou variáveis Cenopoéticas, que são as características ambientais, por exemplo, como temperatura e precipitação média anual;

- Fatores Bióticos ou variaveis Bionômicas, que correspondem às interações entre a espécie e outros que ocupam o mesmo ambiente e a dinâmica de consumo de recursos, por exemplo, como predadores e competidores;

- Dinâmica de Ocupação e Dispersão, que são os movimentos espaciais dos indivíduos e populações, por exemplo, com base na configuração da paisagem;

- Fatores Biogeográficos, que determinam o tamanho e forma dos espaços na distribuição de espécies, por exemplo, o Gradiente Latitudinal.

- Capacidade Evolutiva, onde as espécies habitam os ambientes mais produtivos, por exemplo, restrições evolutivas limitam a ocupação de regiões mais frias.

Este Framework teórico faz referência às informações que devem ser fornecidas. O pesquisador em biodiversidade deve selecionar a escala espacial e temporal desejada para a pesquisa ecológica. Estas escalas determinam a importância relativa dos fatores e quais aspectos moldariam a distribuição nessa escala, conforme Hortal et al. (2010) e Peterson et al. (2011). 


\section{Tabela 1: Atividades do Processo de Distribuição de Espécies}

\begin{tabular}{|c|c|}
\hline \multicolumn{2}{|c|}{ Fase I: Construção da Hipótese Científica } \\
\hline \multirow{5}{*}{ Etapa 1: Definir a pesquisa ecológica } & $\begin{array}{l}\text { Atividade 1.1: Definir o problema da pesquisa } \\
\text { ecológica }\end{array}$ \\
\hline & Atividade 1.2: Definir as hipóteses científicas \\
\hline & Atividade 1.3: Definir as hipóteses estatísticas \\
\hline & Atividade 1.4: Planejar a pesquisa ecológica \\
\hline & $\begin{array}{l}\text { Atividade 1.5: Revisão do problema da } \\
\text { pesquisa ecológica }\end{array}$ \\
\hline \multirow{2}{*}{ Etapa 2: Coletar dos dados } & $\begin{array}{l}\text { Atividade } 2.1 \text { : Coletar os dados de registro de } \\
\text { presença e registros de ausência }\end{array}$ \\
\hline & $\begin{array}{l}\text { Atividade } 2.2: \text { Selecionar as variáveis } \\
\text { preditoras candidatas }\end{array}$ \\
\hline \multicolumn{2}{|c|}{ Fase II: Pré-Análise dos Dados } \\
\hline \multirow{3}{*}{$\begin{array}{l}\text { Etapa 3: Análise dos dados em } \\
\text { relação às variáveis preditoras } \\
\text { candidatas e a posição } \\
\text { georreferenciada }\end{array}$} & Atividade 3.1: Análise dos dados \\
\hline & Atividade 3.2: Testar as hipóteses estatísticas \\
\hline & Atividade 3.3: Analisar os resultados \\
\hline \multicolumn{2}{|c|}{ Fase III: Modelagem } \\
\hline \multirow{2}{*}{$\begin{array}{c}\text { Etapa 4: Selecionar as variáveis } \\
\text { preditoras }\end{array}$} & $\begin{array}{l}\text { Atividade 4.1: Selecionar as variáveis } \\
\text { preditoras numéricas }\end{array}$ \\
\hline & $\begin{array}{l}\text { Atividade 4.2: Selecionar as variáveis } \\
\text { preditoras qualitativas (categóricas) }\end{array}$ \\
\hline \multirow{3}{*}{$\begin{array}{l}\text { Etapa 5: Selecionar e executar o } \\
\text { algoritmo de modelagem de } \\
\text { distribuição de espécie }\end{array}$} & $\begin{array}{l}\text { Atividade 5.1: Selecionar o algoritmo de } \\
\text { modelagem }\end{array}$ \\
\hline & $\begin{array}{l}\text { Atividade 5.2: Executar o algoritmo de } \\
\text { modelagem de distribuição de espécie }\end{array}$ \\
\hline & $\begin{array}{l}\text { Atividade 5.3: Avaliar o desempenho do } \\
\text { modelo de distribuição de espécie }\end{array}$ \\
\hline \multicolumn{2}{|c|}{ Fase IV: Predição } \\
\hline \multirow{3}{*}{$\begin{array}{l}\text { Etapa 6: Estimar a distribuição da } \\
\text { espécie para as novas condições }\end{array}$} & $\begin{array}{l}\text { Atividade } 6.1 \text { : Selecionar a área de interesse e } \\
\text { a resolução para a predição }\end{array}$ \\
\hline & $\begin{array}{l}\text { Atividade 6.2: Selecionar as condições } \\
\text { climáticas }\end{array}$ \\
\hline & $\begin{array}{l}\text { Atividade 6.3: Executar e Analisar os } \\
\text { resultados da predição }\end{array}$ \\
\hline \multicolumn{2}{|c|}{ Fase V: Validação da Hipótese Científica } \\
\hline \multirow{2}{*}{$\begin{array}{c}\text { Etapa 7: Analisar o conjunto de } \\
\text { predições de distribuição de espécies }\end{array}$} & $\begin{array}{l}\text { Atividade 7.1: Combinar os modelos de } \\
\text { distribuição de espécie e predições }\end{array}$ \\
\hline & $\begin{array}{l}\text { Atividade } 7.2: \text { Validar a hipótese científica com } \\
\text { análise das predições das espécies de } \\
\text { interesse em conjunto. }\end{array}$ \\
\hline
\end{tabular}


Em escalas globais e continentais, os fatores abióticos e biogeográficos seriam os mais importantes; nas escalas intermediárias, os quatro fatores atuariam conjuntamente; e nas escalas menores, os fatores bióticos e dinâmica de ocupação e dispersão seriam os mais atuantes, conforme Hortal et al. (2010) e Austin (2007).

Os pontos são coordenadas georreferenciadas, com a latitude e longitude da posição. Estes pontos indicam a existência comprovada da espécie naquela coordenada, e os pontos de ausência representam a inexistência da espécie em um determinado ponto georreferenciado, conforme Elith et al. (2011).

O Processo de Distribuição de Espécie proposto atende este Framework teórico, organizado em Fases, Etapas e Atividades, apresentado na Tabela 1.

\subsection{Fases do Processo de Modelagem de Distribuição de Espécies}

O Processo de Modelagem de Distribuição de Espécies foi definido em cinco Fases: 1) Construção da hipótese científica; 2) Pré-Análise dos dados; 3) Modelagem; 4) Predição; 5) Validação da hipótese científica.

A sequência de Fases do Processo de Modelagem de Distribuição de Espécies é representada por um Diagrama de Atividade UML, apresentado na Figura 3. As Fases são representadas por elementos da linguagem UML denominados atividades estruturadas, que representam um conjunto de ações não elementares (PRESSMAN, 2010; BOOCH, RUMBAUGH, JACOBSON, 2000).

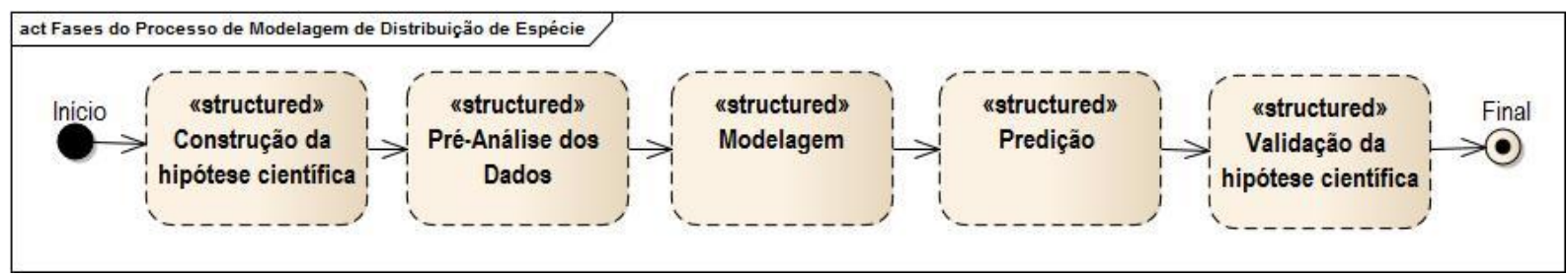

Figura 3: Apresentação das Fases relacionadas ao Processo de Modelagem de Distribuição de Espécies 


\subsubsection{Fase de construção da hipótese científica}

A Hipótese Científica da Distribuição Geográfica da espécie é o ponto de partida para sua demonstração e comprovação (UNDERWOOD, 1997; ZAR, 2010). O objetivo da Fase de construção da hipótese científica é que a questão ecológica relacionada à distribuição de espécie esteja clara e explicitamente colocada.

O resultado desta Fase é a determinação da questão ecológica ou variável a ser investigada. As questões ecológicas que devem ser variáveis de causa e não de efeito. O problema agora é decidir o que afeta esta variável e de que maneira (Peterson et al., 2011). Por exemplo, os métodos de regressão, como GLMs, modelam o relacionamento entre a resposta, também chamada de variável dependente, isto é, os dados da espécie, as presenças e pseudo-ausências, presença e ausência; e uma ou mais variáveis preditoras, também chamada de variáveis exploratórias ou independentes; a equação que relaciona a resposta (y) aos preditores $(X)$ é dada por $y \sim f(X)$ e os valores para os coeficientes ou parâmetros do modelo e o termo de erro, também chamados de variações não explicadas, são estimados; sendo $f(X)$ chamado de preditor linear e inclui todas as variáveis selecionadas e seus coeficientes (ELITH; LEATHWICK, 2009b).

Segundo Underwood (1997) e Hulbert (1984), podem ocorrer problemas na lógica que relaciona as hipóteses propostas e as pesquisas ecológicas que são realizadas.

Conforme Tukey (1980), para evitar esses problemas devem ser respondidas algumas perguntas. Por exemplo:

a) Como são geradas as questões ecológicas?

b) Como é orientado o planejamento do experimento?

c) Como é realizada a coleta de dados?

d) Como será o procedimento de análise dos resultados? 


\subsubsection{Fase de Pré-Análise dos Dados}

O objetivo da fase de Pré-análise dos Dados é investigar e validar os pontos de registro de ocorrências e de ausências da espécie (VELOZ, 2009; DUDIK; SCHAPIRE; PHILIPS, 2006). As variáveis preditoras candidatas são avaliadas em relação à área geográfica de interesse (HORTAL, 2010; SOBERÓN; NAKAMURA, 2009).

Os resultados desta Fase são as variáveis preditoras candidatas e os dois grupos de pontos para o treinamento do modelo e para o teste do modelo. O grupo para o treinamento do modelo e grupo de teste deve ser independente para evitar a autocorrelação espacial, conforme Peterson et al. (2011) e Veloz (2009).

Como exemplo de uma técnica que pode ser usada na Fase de Pré-Análise de Dados é o Gradiente Latitudinal (PIANKA, 1966). Este tipo de análise permite a identificação de outliers que não seriam identificados em um simples diagrama de dispersão.

\subsubsection{Fase de Modelagem}

O objetivo da Fase de Modelagem é selecionar o algoritmo e os parâmetros de configuração mais adequados à questão ecológica, executar algoritmo selecionado e testar o desempenho do modelo obtido (PETERSON et al., 2011).

O resultado obtido é o modelo de distribuição da espécie e as medidas de desempenho do modelo (ALLOUCHE; TSOAR; KADMON, 2006).

Segundo Soberón e Nakamura (2009), a técnica de modelagem de distribuição de espécie é usada para estimar áreas de distribuição reais ou potenciais, ou conjuntos de habitats favoráveis para uma dada espécie, com base em registros de sua presença e ausência. 
Como exemplo, pode-se selecionar o algoritmo de Entropia Máxima para a modelagem de distribuição de espécie, para estimar uma quantidade proporcional à probabilidade de presença da espécie, utilizando somente os registros de presença e pontos de background uniformemente distribuídos na área de interesse, conforme Soberón e Nakamura (2009) e Elith et al. (2011).

\subsubsection{Fase de Predição}

O objetivo da Fase de Predição é obter uma estimativa da distribuição de espécie em uma nova área, diferente da área utilizada na Fase de Modelagem, ou em um cenário específico de mudança climática (BROENNIMANN, 2012; PETERSON et al., 2011).

O resultado desta fase é a estimativa de distribuição da espécie, de acordo com o algoritmo utilizado, na nova área de interesse ou cenário específico de mudança climática.

Por exemplo, pode-se utilizar o modelo criado na Fase de Modelagem, pelo algoritmo de Entropia Máxima, e fazer uma extrapolação no espaço ambiental com as variáveis preditoras relacionadas à nova área ou ao cenário específico de mudança climática para calcular a estimativa de distribuição de espécies, conforme Elith et al. (2009).

\subsubsection{Fase de validação da hipótese científica}

O objetivo da Fase de validação da hipótese científica é validar as questões ecológicas formuladas. As estimativas de distribuição de espécies, obtidas na Fase de Predição, podem ser combinadas ou refinadas. Nesta Fase as predições são avaliadas por um biólogo especialista nas espécies de interesse da pesquisa ecológica (PETERSON et al., 2011). 
O resultado esperado é a apresentação de resultados que permitem a confirmação, a rejeição ou a adequação do modelo ecológico proposto.

Por exemplo, pode-se utilizar a técnica de ensemble forecasting para combinar os resultados da modelagem oriunda de diferentes algoritmos de modelagem de distribuição de espécies ou de diferentes cenários de mudanças climáticas (ARAÚJO; NEW, 2007; THUILLER et al., 2009).

\subsection{Etapas do Processo de Modelagem de Distribuição de Espécies}

As etapas do Processo de Modelagem de Distribuição de Espécies proposto podem ser sintetizadas:

Fase I - Construção da Hipótese Científica

- Etapa 1: Definir a pesquisa ecológica.

Nesta Etapa é estabelecida a hipótese científica a ser testada; a definição das espécies que farão pare da pesquisa ecológica; a definição da área geográfica de interesse; definição da escala espacial e temporal; seleção das variáveis preditoras candidatas pela identificação dos fatores relevantes.

- Etapa 2: Coleta dos dados.

Nesta Etapa são definidos os pontos de ocorrência das espécies, os pontos de ausência ou pseudo-ausências, ou ainda os pontos de background, que serão utilizados no Processo de Modelagem de distribuição de Espécies, de acordo com os algoritmos de modelagem selecionados. Selecionar as variáveis preditoras candidatas, de acordo com as características da área de estudo. 
Fase II - Pré-Análise dos Dados

- Etapa 3: Análise dos dados em relação às variáveis preditoras candidatas e a posição georreferenciada.

Nesta Etapa é aplicada a técnica de análise exploratória de dados aos registros de ponto de ocorrência e pontos de ausência, em conjunto com os valores das variáveis preditoras obtidas pela posição georeferenciada desses pontos de ocorrência e pontos de ausência.

Fase III - Modelagem

- Etapa 4: Seleção das variáveis preditoras.

Nesta Etapa as variáveis preditoras são selecionadas para reduzir a quantidade de variáveis preditoras, por exemplo, por meio da análise da correlação das variáveis na área de estudo.

- Etapa 5: Selecionar e executar o algoritmo de modelagem de distribuição de espécie.

Nesta Etapa o algoritmo de modelagem de distribuição de espécie é selecionado de acordo com a hipótese científica definida; os parâmetros do algoritmo modelagem de distribuição de espécie são definidos; o modelo de distribuição de espécie é gerado e são realizados os testes do modelo.

Fase IV - Predição

- Etapa 6: Estimar a distribuição da espécie para as novas condições.

Nesta Etapa a área para a predição de distribuição da espécie é definida. As condições ambientais corrente, passada ou futuras para a predição são definidas. A estimativa de distribuição de espécie é 
calculada a partir do modelo de distribuição de espécie obtido na Fase de Modelagem. A predição da distribuição de espécie resultante é validada por um biólogo especialista na espécie em estudo.

\section{Fase V - Validação da hipótese científica}

- Etapa 7: Análise de um conjunto de predições de distribuição de espécies.

Nesta Etapa o pesquisador combina os resultados das predições, a fim de validar as questões ecológicas propostas.

\subsection{Considerações finais}

Neste Capítulo foi apresentado o Processo geral de Modelagem de Distribuição de Espécies proposto.

No Capítulo seguinte são aplicados o Processo apresentado em Santana et al. (2008) e o novo Processo geral de Modelagem de Distribuição de Espécie proposto, na realização de um experimento de Modelagem de Distribuição de Espécie.

Neste experimento, são apresentadas as Atividades de cada Etapa do novo Processo de Modelagem de Distribuição de Espécie proposto, com ênfase nas técnicas estatísticas disponíveis para realizar as atividades.

No Capítulo 5, é realizada a discussão dos resultados da análise comparativa dos experimentos realizados. 


\section{Estudo de Caso do Processo de Modelagem de Distribuição de Espécies}

O Processo de Modelagem de Distribuição de Espécie proposto é aplicado na modelagem de distribuição geográfica de espécie da Centris hyptidis, na região nordeste brasileira.

O experimento de modelagem de distribuição da espécie Centris hyptidis foi realizado da seguinte maneira:

a) Inicialmente realizada a modelagem de distribuição de espécies considerando o Processo de modelagem apresentado em Santana et al. (2008), como uma referência para a análise dos resultados.

b) Posteriormente foi realizada a modelagem de distribuição de espécies considerando o Processo de Modelagem de Distribuição de Espécie proposto.

Cada passo do Processo de Modelagem de Distribuição de Espécies aplicado no experimento é descrito nos subitens subsequentes, e os resultados obtidos são analisados e discutidos no Capítulo 5.

\subsection{Modelagem de Distribuição da Espécie Centris hyptidis com openModeller Desktop}

Nesta primeira fase, o experimento de modelagem de distribuição da espécie Centris hyptidis é realizada com o auxilio da ferramenta de modelagem openModeller Desktop, versão 1.2.

Conforme Santana et. al. (2008), o Processo de Modelagem de Distribuição de Espécies foi subdividido em nove passos, descrito nos subitens a seguir. 


\subsubsection{Definição do problema}

A questão ecológica a ser respondida é a distribuição potencial da espécie Centris hyptidis, para as condições climáticas atuais e com a resolução de 30 segundos de arco ( $1 \mathrm{~km})$.

Foram considerados todos os pontos de ocorrência coletados na modelagem de distribuição da espécie Centris hypitidis.

As 19 camadas bioclimáticas do WorldClim (www.worldclim.org/) foram utilizadas como camadas ambientais neste experimento. O WorldClim é uma base de dados climáticos globais (HIJMANS et al., 2005), nesta base de dados, os dados de clima atual correspondem aos dados de observação representativos de 1950 a 2000 e que foram interpolados para a resolução de 30 segundos de $\operatorname{arco~}(\sim 1 \mathrm{~km})$.

\subsubsection{Tratamento dos pontos de ocorrência}

Os dados de pontos de ocorrência utilizados nestes experimentos de modelagem de distribuição de espécies são provenientes das pesquisas sobre a interação da espécie de abelha Centris hyptidis e plantas oleaginosas da espécie Angelonia campestris e Angelonia cornigera, na região nordeste do Brasil, publicadas em Giannini et al. (2012b) e Giannini; Saraiva e Alves-dos-Santos (2010).

Neste experimento, foram utilizados inicialmente 41 pontos de ocorrência da espécie Centris hyptidis. Não foram utilizados pontos de ausência neste experimento.

Os pontos de ocorrência foram listados em um arquivo texto, em conformidade com o padrão de arquivo para a ferramenta de modelagem openModeller Desktop.

Existem funções específicas para as técnicas de limpeza de dados no openModeller Desktop, versão1.1.0, como a remoção da repetição de pontos de ocorrência para uma mesma coordenada geográfica e a remoção da repetição de 
pontos de ocorrência com o mesmo conjunto de valores nas camadas ambientais, também chamadas de variáveis preditoras.

Desta forma, foram excluídos os pontos de ocorrência que não passaram no tratamento de limpeza de dados.

\subsubsection{Tratamento de dados ambientais}

As camadas bioclimáticas foram obtidas a partir dos arquivos de alta resolução, com 30 segundos de arco $(\sim 1 \mathrm{~km})$, do site AMBDATA - Variáveis ambientais para modelagem de distribuição de espécies (www.dpi.inpe.br/ambdata/index.php) do Grupo de Modelagem para Estudos de Biodiversidade da Divisão de Processamento de Imagens do INPE.

\subsubsection{Análise da viabilidade dos dados}

A viabilidade dos dados é validade pela limitação das variáveis preditoras e registros de pontos de ocorrência pela área de interesse do experimento. Desta forma, o recorte para o Brasil foi utilizado, delimitado pelas coordenadas de $05^{\circ} 16^{\prime}$ $16,5^{\prime \prime} \mathrm{N}$ de latitude e $73^{\circ} 59^{\prime} 16,5^{\prime \prime} \mathrm{W}$ de longitude para o limite superior e as coordenadas $33^{\circ} 45^{\prime} 13,5^{\prime \prime} \mathrm{S}$ de latitude e $32^{\circ} 23^{\prime} 16,5^{\prime \prime} \mathrm{W}$ de longitude para o limite inferior, que cobre toda a região de Caatinga e as coordenadas dos pontos de ocorrência da espécie.

\subsubsection{Escolha do algoritmo}

O algoritmo de Entropia Máxima foi selecionado para a análise comparativa, pois é frequentemente utilizado por pesquisadores em biodiversidade (ELITH et al., 2011) e utiliza somente os pontos de ocorrência da espécie. 
Além disso, este algoritmo de modelagem é escolhido pela disponibilidade do algoritmo nas duas ferramentas de modelagem utilizadas neste experimento, o openModeller Desktop e os scripts em linguagem R.

Para o openModeller Desktop, foi utilizada a implementação do algoritmo de Entropia Máxima na versão 0.2 (RODRIGUES, 2012).

\subsubsection{Definição dos parâmetros do algoritmo}

Os algoritmos disponíveis na ferramenta openModeller Desktop estão com os parâmetros configurados com os valores default, para cada algoritmo, fornecidos por seus autores. O usuário pode alterar esses padrões, com o gerenciador de algoritmo, para tornar a execução do algoritmo mais adequada às necessidades específicas.

Neste experimento foram utilizados os parâmetros default para o algoritmo de Máxima Entropia.

\subsubsection{Geração do modelo}

Neste passo o algoritmo escolhido é executado, com os parâmetros selecionados, para a geração de Modelos de Distribuição de Espécies baseados na teoria de nicho ecológico.

\subsubsection{Pós-Análise automática}

No openModeller Desktop, uma grande variedade de técnicas de pósprocessamento, como ,por exemplo, a "Area Under the Curve" (AUC). A AUC é tomada como uma medida de acurácia do modelo e caracteriza o seu desempenho (PHILLIPS et al., 2006), apresentada na Tabela 2. 
Após a criação do Modelo de Distribuição de Espécie, o openModeller Desktop calcula automaticamente as estatísticas da matriz de confusão, tais como erros de omissão, precisão e comissão, e realiza a análise "Receiver Operating Characteristic" (ROC). A "Area Under the Curve" (AUC) é tomada como uma medida de acurácia do modelo e caracteriza o seu desempenho (PHILLIPS et al., 2006), apresentada na Tabela 2.

Tabela 2: Relatório de modelagem do openModeller Desktop

\begin{tabular}{|c|c||}
\hline Algoritmo & $\begin{array}{c}\text { Maximum Entropy } \\
\text { (versão 0.2) }\end{array}$ \\
\hline \hline Filtro de ocorrências & Ambientalmente único \\
\hline \hline $\begin{array}{c}\text { Teste Interno } \\
\text { Total Area Under Curve (AUC): }\end{array}$ & 0.984748 \\
\hline
\end{tabular}

\subsubsection{Validação pelos pesquisadores}

Aqui o usuário define o nome do arquivo de base para os arquivos de saída do modelo e o diretório de destino dos arquivos gerados pela ferramenta. A ferramenta openModeller Desktop irá produzir uma imagem no padrão Geographic Tagged Image File Format (GeoTIFF), e um arquivo de imagem tipo Portable Network Graphics (PNG) com gradiente de cor, para a visualização inicial do Mapa de Distribuição Potencial de Espécies pelo usuário.

O GeoTIFF é um padrão de metadados que permite embutir informações das coordenadas geográficas em um arquivo TIFF, sendo adequado para uso na maioria dos pacotes de Geographic Information System (GIS).

A ferramenta openModeller exibe barras de progresso durante a execução do algoritmo de modelagem, com o objetivo de informar ao usuário sobre o andamento da criação do modelo e projeção do modelo. Uma vez que o assistente concluiu a tarefa, uma nova janela é aberta mostrando a saída do modelo, uma imagem PNG de um mapa com gradiente de cor proporcional a um valor da distribuição potencial 
da espécie. Como exemplo, a janela de saída com o Mapa da Distribuição Potencial da Espécie Centris hyptidis gerado no openModeller é apresentado na Figura 4.

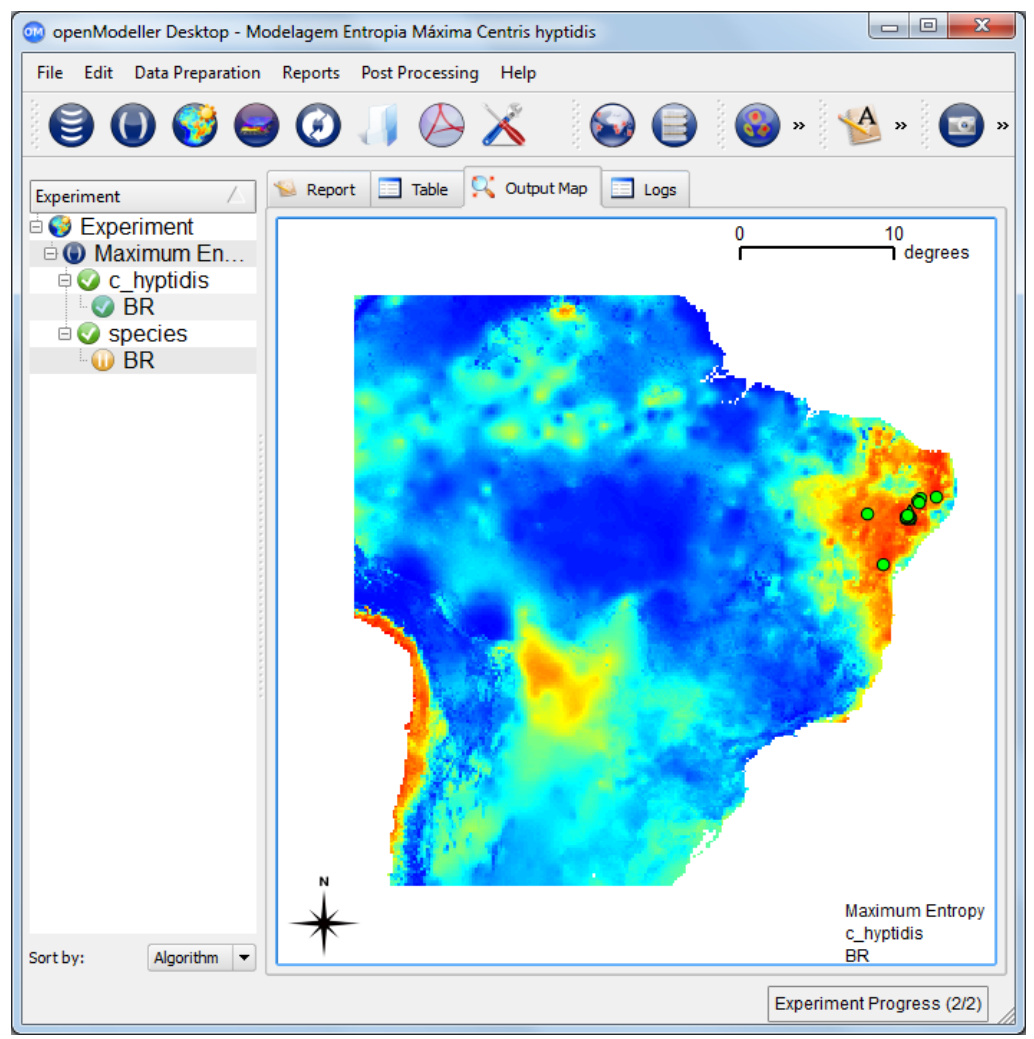

Figura 4: Mapa da Distribuição Potencial da Espécie Centris Hyptidis e os pontos de ocorrências gerado com o openModeller.

Neste Mapa de Distribuição Potencial da Espécie Centris Hyptidis as regiões com melhor adequabilidade de habitat apresentam as cores mais escuras (cor vermelha) e as regiões com menor adequabilidade com cores clara (cor azul), de acordo com o algoritmo de modelagem Entropia Máxima e as variáveis preditoras selecionados. Os pontos de ocorrência são exibidos no mapa na forma de círculos (cor verde). 


\subsection{Modelagem de Distribuição da Espécie Centris hyptidis considerando a interação com Angelonia cornigera e Angelonia campestris}

Nesta segunda fase, o experimento de modelagem de distribuição da espécie Centris hyptidis é realizada com o auxílio de scripts em linguagem R. Estes scripts foram desenvolvidos para produzir as análises estatísticas e gráficas utilizados no Processo de Modelagem de Distribuição de Espécie proposto.

Conforme o Processo de Modelagem de Distribuição de Espécie proposto, esta modelagem considera os fatores bióticos que podem impactar a distribuição das espécies.

As Etapas do Processo de Modelagem de Distribuição de Espécies proposto foram decompostas em atividades, com a finalidade de ressaltar os relacionamentos entre as diversas atividades.

Na Figura 5, um Diagrama de Atividades UML é apresentado com as atividades do Processo de Modelagem de Distribuição de Espécies proposto. As atividades são elementos da linguagem UML que representam um conjunto de ações não elementares, denominados atividades estruturadas (PRESSMAN, 2010; BOOCH, RUMBAUGH, JACOBSON, 2000). 


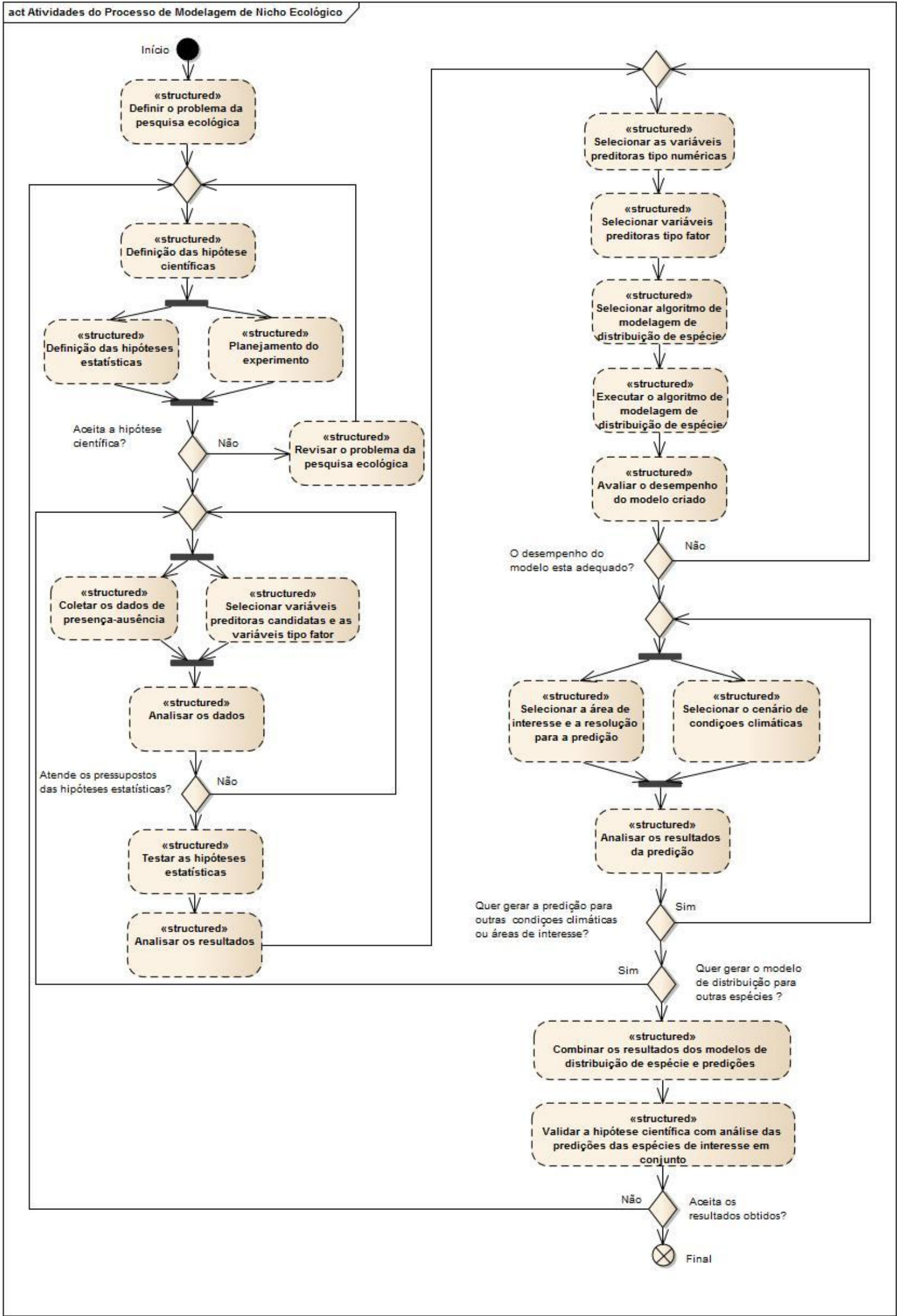

Figura 5: Diagrama de atividades UML com o detalhe dos relacionamentos entre as atividades do Processo de Modelagem de Distribuição de Espécies proposto. 
Nesta fase do experimento, a fim de facilitar o entendimento, os detalhes de cada atividade e as técnicas estatísticas utilizadas serão apresentados nos subitens a seguir.

\subsubsection{Definir a Hipótese inicial}

Nesta etapa do processo de distribuição de espécie proposto, foram coletados os pontos de ocorrência, na área de caatinga na região Nordeste do Brasil, para a modelagem de distribuição de espécies de plantas Angelonia campestris e Angelonia cornigera e o polinizador Centris hypitidis.

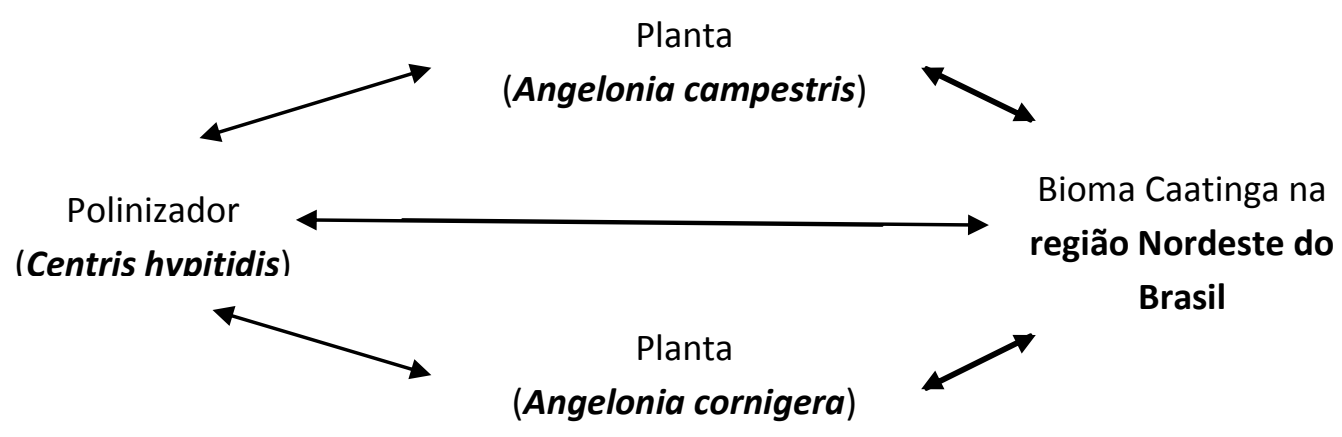

Figura 6: Apresentação da hipótese inicial simplificada para o exemplo de modelagem de distribuição de espécies.

Na Figura 6, a hipótese inicial de estudo é representada por um diagrama, conforme Mourão e Magnusson (2005) e Turkey (1980).

As interações entre as abelhas e as flores em um sistema de restinga, na Bahia, são apresentadas na pesquisa de Gimenes, Oliveira e Almeida (2002). Ainda neste sentido, a pesquisa de Machado, Vogel e Lopes (2002) apresenta a polinização da Angelonia cornigera por abelhas coletoras de óleo no nordeste do Brasil, e a pesquisa de Aguiar et al. (2003) apresenta as plantas visitadas pela abelha Centris. 


\subsubsection{Coletar os dados}

Nesta Etapa deve ser observada que a representatividade da amostra não é o mesmo que amostra aleatória (HURLBERT, 1984). Uma amostra aleatória é aquela em que todo membro de toda uma população tem chance igual e independente de ter sido amostrado.

Segundo Underwood (1998) e Hulbert (1985), muitos trabalhos ecológicos têm demonstrado a existência de gradientes e o efeito de patchiness, distribuição horizontal heterogênea, na distribuição de animais e plantas. O problema da não representatividade das amostras é o grau em que a amostra esta enviesada, isto é, o grau que ela superestima ou subestima o parâmetro que está sendo investigado.

Neste estudo de caso, foram levantados 41 pontos de ocorrência da espécie Centris hypitidis, 90 pontos de ocorrência da espécie Angelonia campestris e 384 pontos de ocorrência da espécie Angelonia cornigera, apresentados na Figura 7.

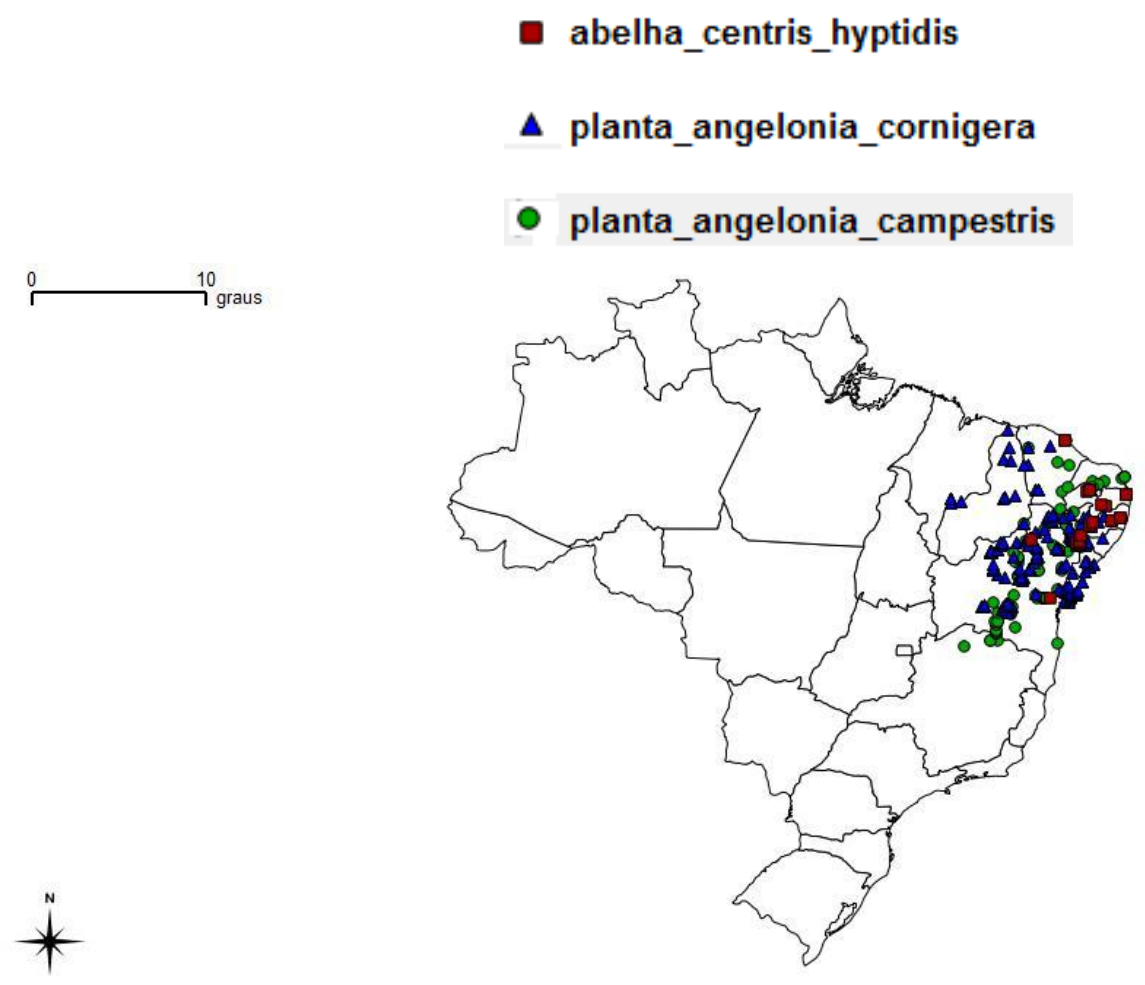

Figura 7: Apresentação dos pontos de ocorrência para o exemplo de modelagem de distribuição de espécies. 
O problema de representatividade das amostras pode ser reduzido com a aplicação das técnicas de design de experimento para segmentar uma área heterogênea de estudo em unidade amostrais (HULBERT, 1985). A amostragem aleatória é apropriada quando não existe alternativa ou quando puder ser evitada uma amostra enviesada (UNDERWOOD, 1998).

As informações ambientais utilizadas neste experimento são grades projetadas no sistema de coordenadas geodésicas de projeção Latitude/Longitude, Datum WGS-84, com resolução espacial de 30 arc-segundos, ou aproximadamente $1 \mathrm{~km}$.

\section{Tabela 3: Lista das 19 variáveis bioclimáticas utilizadas como variáveis preditoras candidatas}

\begin{tabular}{|c|c|c|}
\hline $\mathrm{BIO1}$ & Temperatura média anual $\left({ }^{\circ} \mathrm{C} * 10\right)$ & Observações \\
\hline $\mathrm{BIO} 2$ & Oscilação térmica diária $\left({ }^{\circ} \mathrm{C} * 10\right)$ & Média mensal (Tmax-Tmin) \\
\hline Bio3 & Isotermalidade (\%) & $(\mathrm{BIO} 2 / \mathrm{BIO} 7)\left({ }^{*} 100\right)$ \\
\hline $\mathrm{BIO} 4$ & Sazonalidade da Temperatura (Desvio padrão * 100) & \\
\hline $\mathrm{BIO5}$ & Temperatura máxima de mês mais quente $\left({ }^{\circ} \mathrm{C}{ }^{*} 10\right)$ & \\
\hline $\mathrm{BIO6}$ & Temperatura mínima do mês mais frio $\left({ }^{\circ} \mathrm{C} * 10\right)$ & \\
\hline $\mathrm{BIO}$ & Amplitude térmica anual $\left({ }^{\circ} \mathrm{C} * 10\right)$ & $(\mathrm{BIO} 5-\mathrm{BIO})$ \\
\hline $\mathrm{BIO} 8$ & Temperatura media na estação mais úmida $\left({ }^{\circ} \mathrm{C} * 10\right)$ & \\
\hline $\mathrm{BIO9}$ & Temperatura media na estação mais seca $\left({ }^{\circ} \mathrm{C} * 10\right)$ & \\
\hline $\mathrm{BIO} 10$ & Temperatura media na estação mais quente $\left({ }^{\circ} \mathrm{C}{ }^{*} 10\right)$ & \\
\hline $\mathrm{BIO} 11$ & Temperatura media na estação mais fria $\left({ }^{\circ} \mathrm{C} * 10\right)$ & \\
\hline $\mathrm{BIO} 12$ & Precipitação anual (mm) & \\
\hline $\mathrm{BIO} 13$ & Precipitação do mês mais úmido $(\mathrm{mm})$ & \\
\hline $\mathrm{BIO} 14$ & Precipitação do mês mais seco (mm) & \\
\hline $\mathrm{BIO} 15$ & Sazonalidade Precipitação (Coeficiente de variação) & \\
\hline $\mathrm{BIO} 16$ & Precipitação na estação mais úmida (mm) & \\
\hline $\mathrm{BIO} 17$ & Precipitação na estação mais seca (mm) & \\
\hline $\mathrm{BIO18}$ & Precipitação na estação mais quente (mm) & \\
\hline $\mathrm{BIO19}$ & Precipitação na estação mais fria (mm) & \\
\hline
\end{tabular}

A distribuição potencial da espécie foi obtida com base nas 19 variáveis bioclimáticas do projeto WorldClim (HIJMANS et al., 2005), disponível online (http://www.worldclim.org). O recorte espacial para a região de interesse foi estabelecido de acordo com a coordenadas limites do Brasil, a longitude de $73^{\circ} 59^{\prime}$ 
$16,5^{\prime \prime} \mathrm{W}$ a $32^{\circ} 23^{\prime} 16,5 \mathrm{~W}$ e a latitude de $5^{\circ} 16^{\prime} 16,5^{\prime \prime} \mathrm{N}$ a $33^{\circ} 45^{\prime} 13,5 \mathrm{~S}$, estimada em uma resolução espacial de 30 segundos de arco ,aproximadamente $1 \mathrm{~km}$ no equador, apresentadas na Tabela 3.

Da mesma forma que no experimento anterior, as camadas bioclimáticas foram obtidas no site AMBDATA - Variáveis ambientais para modelagem de distribuição de espécies (www.dpi.inpe.br/ambdata/index.php) do Grupo de Modelagem para Estudos de Biodiversidade da Divisão de Processamento de Imagens do INPE.

\subsubsection{Análise dos dados em relação às variáveis preditoras candidatas e a posição georreferenciada}

Segundo Houglin, Mosteller e Turkey (2000), a análise de dados pode ser dividida em duas fases: a fase exploratória e a fase confirmatória. A análise exploratória de dados isola os padrões e características dos dados e revela estes com força para o analista. A análise confirmatória de dados valida a reprodutibilidade dos padrões observados ou efeitos.

\subsubsection{Análise dos Dados}

A estimativa de média e variância de uma população é a preocupação de muitos estudos de Biologia e Ecologia. Entretando, outros parâmetros de frequência de distribuição são úteis sobre o processo ecológico, conforme Underwood (1998).

A seguir são apresentadas técnicas que podem ser utilizadas na fase exploratória de dados.

a) Síntese numérica dos dados

A área de estudos pode ser sintetizada pelas medidas estatísticas de posição e de dispersão das variáveis preditoras e pontos de registro de ocorrência (SOKAL; ROHLF, 1995).

Os dados podem ser sintetizados com o cálculo das medidas de posição e dispersão: 
- Medidas de tendência central, como a Média Amostral ( $\overline{\mathbf{x}})$, a Moda e a Mediana.

- Medidas de dispersão ou variabilidade, como o Desvio Padrão ( $\mathbf{S}$ ) e a Variância $\left(\mathbf{S}^{2}\right)$.

- Medidas de Assimetria, como por exemplo, o Coeficiente de Assimetria de Pearson para valores; o Coeficiente Quartílico de Assimetria para Ordem; e o Coeficiente do Momento de Assimetria para Momentos.

- Medidas de Curtose ou do achatamento da distribuição, como por exemplo, o Coeficiente Percentílico de Curtose e o Coeficiente do Momento de Curtose.

As medidas de posição foram calculadas para cada variável preditora em relação à área de estudo, por exemplo, são apresentadas as medidas calculadas para a variável preditora temperatura média anual (Bio1), na Tabela 4.

Tabela 4: Medidas para a variável preditora temperatura média anual (Bio1)

\begin{tabular}{|l|l|}
\hline Temperatura média anual (Bio1) & $\left({ }^{\circ} \mathrm{C}\right)$ \\
\hline Mínimo & 20,10 \\
\hline Primeiro quartil & 22,70 \\
\hline Mediana & 25,20 \\
\hline Média & 24,31 \\
\hline Terceiro quartil & 25,70 \\
\hline Máxima & 26,50 \\
\hline
\end{tabular}

As medidas de posição e dispersão podem também ser exibidas em gráficos, como exemplo, o Gráfico Box-plot, da espécie Centris hyptidis em relação à Temperatura Média Anual (Bio1), apresentada na Figura 8.

O gráfico oferece a medida da posição central dos dados através da mediana. O Gráfico Box-plot também dá uma ideia da dispersão, ou contrariamente, da concentração dos valores, através da distância interquartílica (75\% (Q3)-25\% (Q1)).

No Gráfico Box-plot, o comprimento das caudas é dado pelas linhas contínuas que vão da "caixa" (retângulo) aos valores mais afastados que não sejam outliers. 
Os outliers, ou valores atípicos, são representados por pequenos círculos vazios. O gráfico oferece também a medida da posição central dos dados através da mediana. (SOKAL; ROHLF, 1995).

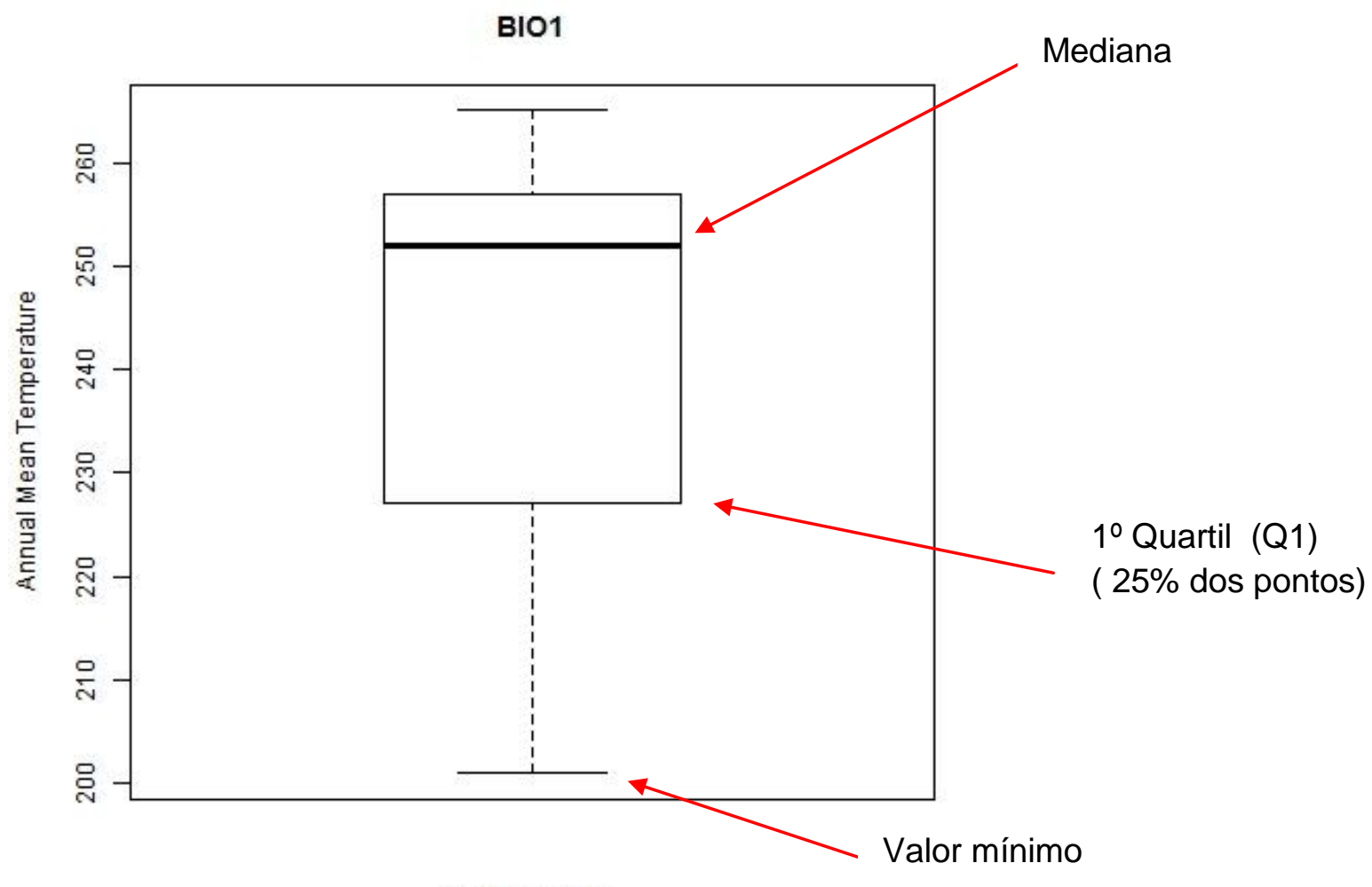

Centris hyptidis

Figura 8: Gráfico Box-plot da espécie Centris hyptidis em relação à Temperatura Média Anual (Bio1).

O gráfico Box-plot pode também ser utilizado para uma comparação preliminar das distribuições das espécies em estudo, por exemplo, podemos observar os gráficos Box-plot, das espécies Angelonia campestris, Angelonia cornigera e Centris hyptidis em relação à Precipitação Anual (Bio12), apresentado na Figura 9. 


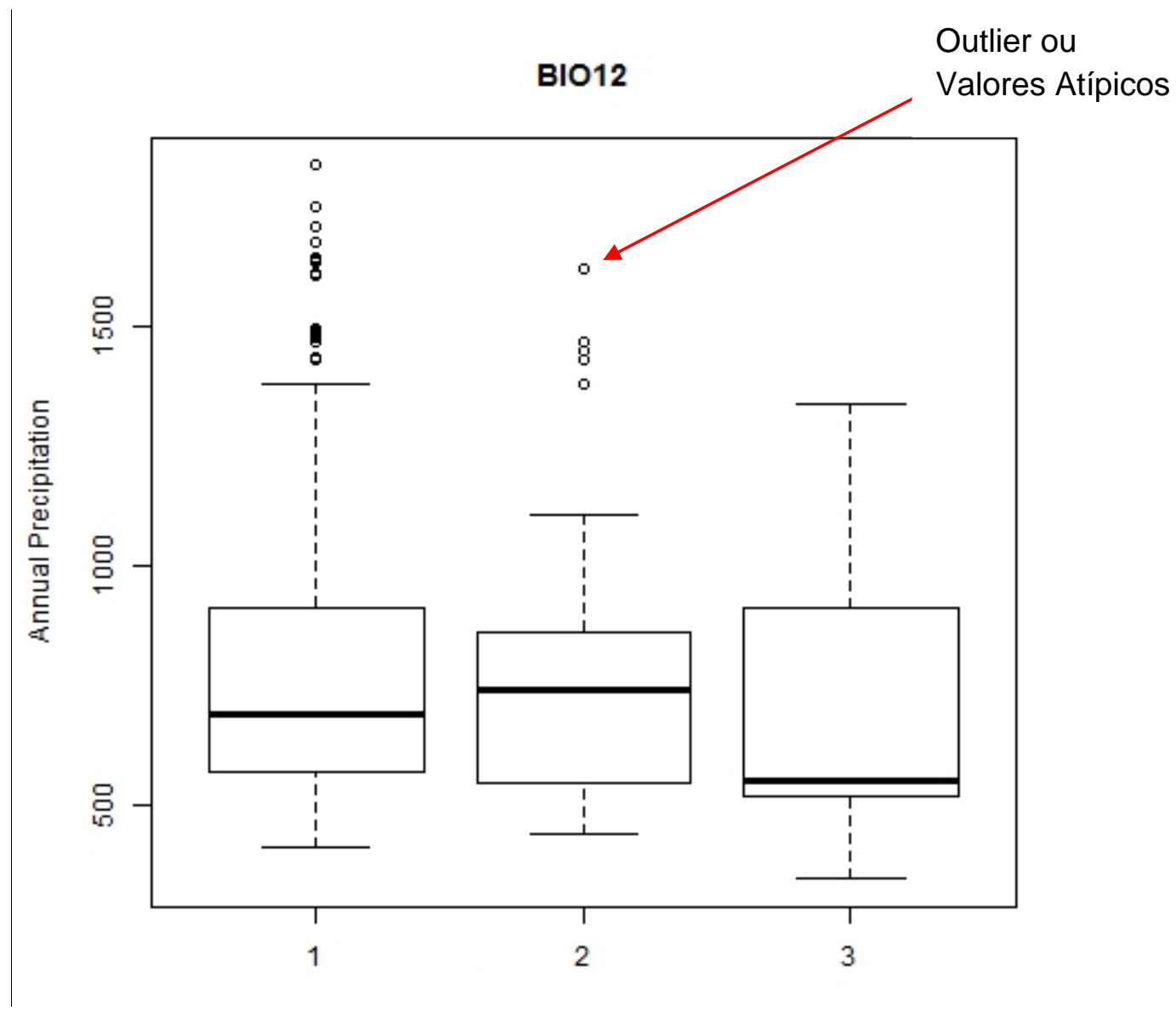

Figura 9: Gráfico Box-plot das espécies: 1- Angelonia campestris, 2- Angelonia cornigera e 3- Centris hyptidis em relação à Precipitação Média Anual (Bio12).

Na figura 9, são apresentados em um mesmo Gráfico Box-plot os valores da variável preditora Precipitação Média Anual (Bio12) para os pontos de ocorrência da Centris hyptidis, Angelonia campestris e Angelonia cornigeras para facilitar a análise comparativa por meio de uma inspeção visual.

Dessa forma, pode-se observar que a maioria da faixa de valores dos dados da Centris hyptidis é coberta pela faixa de valores dos dados da Angelonia cornigera ou pela faixa de valores dos dados da Angelonia campestris, que corrobora a hipótese científica inicial. Neste experimento, o mesmo procedimento foi adotado para todas as variáveis preditoras candidatas. 
a) Análise do Gradiente Latitudinal da Espécie

O Gráfico de Gradiente Latitudinal é construído a partir dos dados de ocorrência, de cada espécie para cada variável preditora em relação à latitude, como exemplo, o Gráfico de Gradiente Latitudinal da espécie Centris hyptidis em relação à Temperatura Média Anual (Bio1) é apresentado na Figura 10.

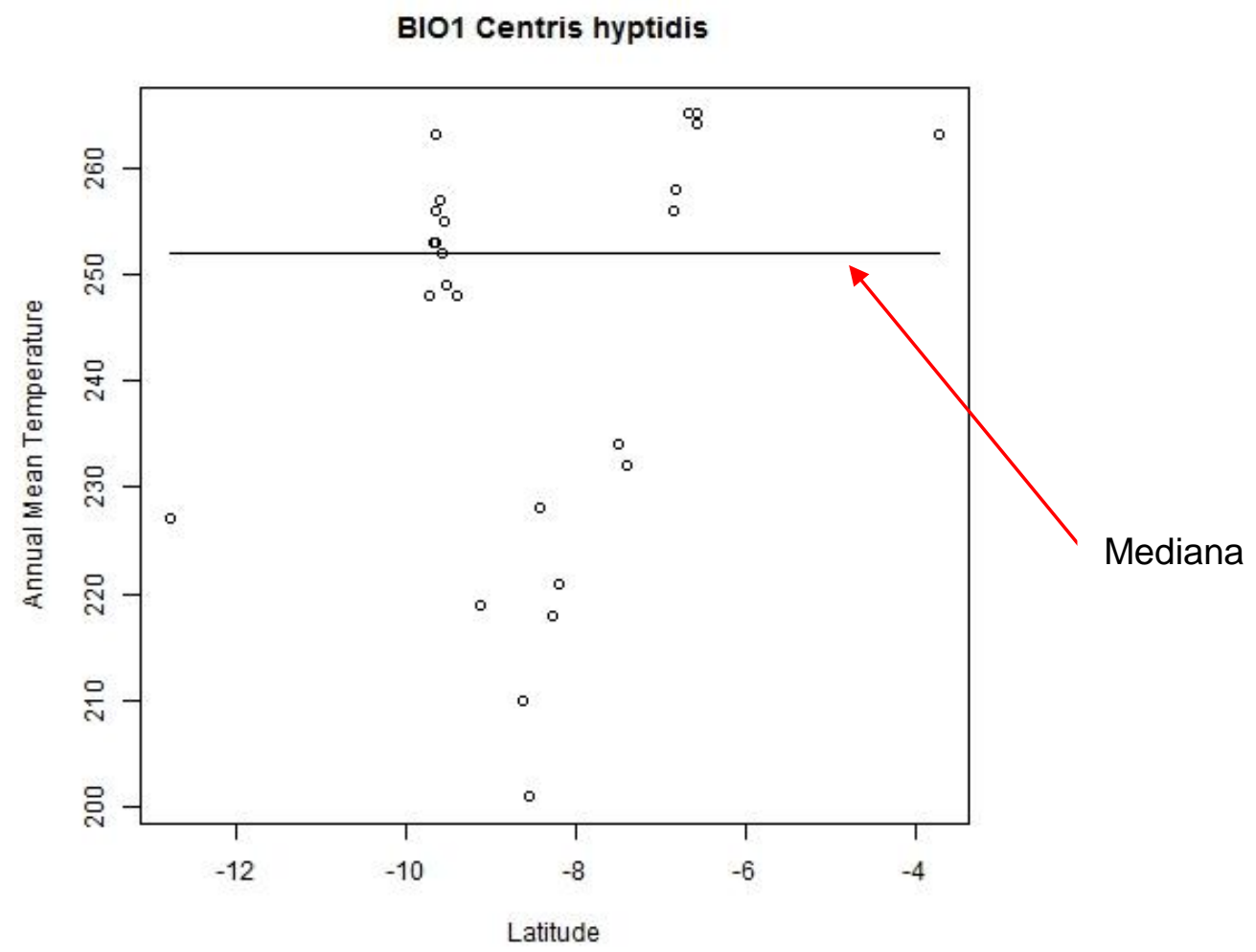

Figura 10: Diagrama de gradiente latitudinal espécie Centris hyptidis em relação à Temperatura Média Anual (Bio1).

Segundo Pianka (1966), as comunidades mudam à medida que ocorre variação dos fatores bióticos ao longo de uma gradiente espacial, como em relação à latitude onde a riqueza de espécies tende a aumentar das latitudes maiores em direção às menores.

b) Avaliar o espaço do nicho

No estudo de caso, pode-se analisar o impacto das variáveis preditoras, como no gráfico da Precipitação Anual (Bio12) em relação à Temperatura Média Anual (Bio1), apresentada na Figura 11. 


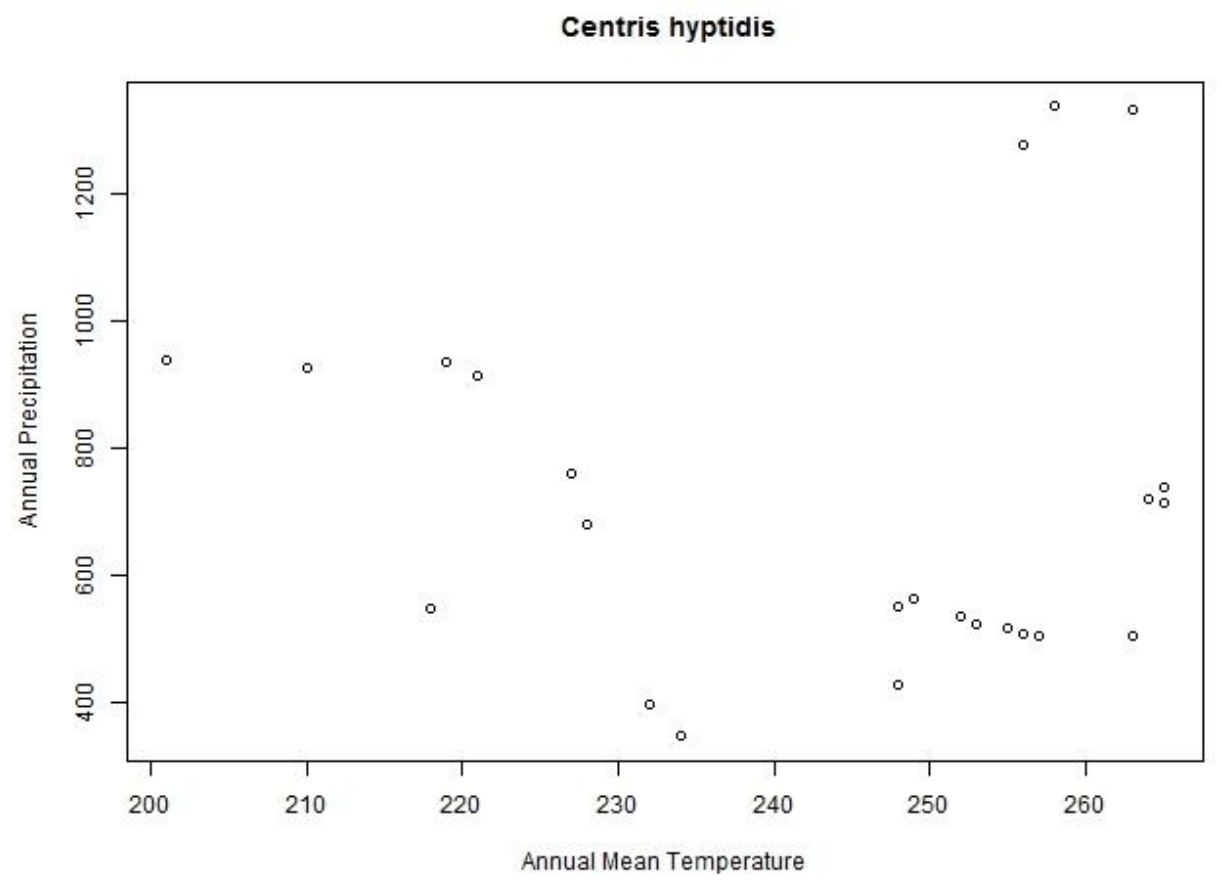

Figura 11: Gráfico da espécie Centris hyptidis de impacto da Precipitação Anual (Bio12) em relação à Temperatura Média Anual (Bio1).

$\mathrm{Na}$ figura 11, o gráfico da relação entre as médias anuais de temperatura e precipitação, para os valores das variáveis preditoras nos pontos de ocorrência da espécie, indica como as principais formadoras do clima podem influenciar na distribuição da espécie.

Segundo Peterson (2011), deve ser feita a seleção de variáveis ambientais abióticas, ou cenopoéticas, para definir espaços de nicho. O espaço de nicho pode ser definido com base nas variáveis que influenciam as taxas de crescimento de uma espécie, em uma determinada escala geográfica.

\subsubsection{Testar as hipóteses estatísticas}

Os outliers ou valores discrepantes, que representam pontos de ocorrência das espécies verdadeiros, porém devem ser removidos do processo de construção do modelo. 
Assim, para testar a existência de valores outliers são utilizadas técnicas para o reconhecimento de outliers relativos aos valores numéricos das variáveis preditoras nos pontos de ocorrência da espécie, como por exemplo:

a) Inspeção visual para detecção de outliers em gráficos unidimensional, como os gráficos Box-plot, gráficos de distribuição normal e gráficos de histogramas, com os valores das variáveis preditoras obtidos em cada ponto de ocorrência,

b) Detecção de outliers com a aplicação do critério numérico, baseado no desvio padrão.

A aplicação somente de técnicas para a remoção dos outliers, ou valores discrepantes, em uma única dimensão (marginal), pode revelar-se inadequado, se as observações são outliers em um sentido multidimensional, conforme Faber e Kadmon (2003).

A aplicação da técnica de detecção de outliers baseada em desvio padrão nos pontos de ocorrência da espécie Centris hyptidis não identificou, entre 41 pontos de ocorrências, pontos de ocorrências com valor superior ao limite aceitável. O valor numérico do limite aceitável é determinado pela técnica estatística aplicada, por exemplo, na técnica do exame crítico de escores normais os valores limites são $Z<-3,9$ e $Z>3,9$.

Assim, no Gráfico Gradiente Latitudinal da Variação Diurna Média de Temperatura (Bio2) da espécie Centris hyptidis pode ser observado o valor discrepante da maioria dos outros valores, mas não poderia ser descartado como outlier, Figura 12. 


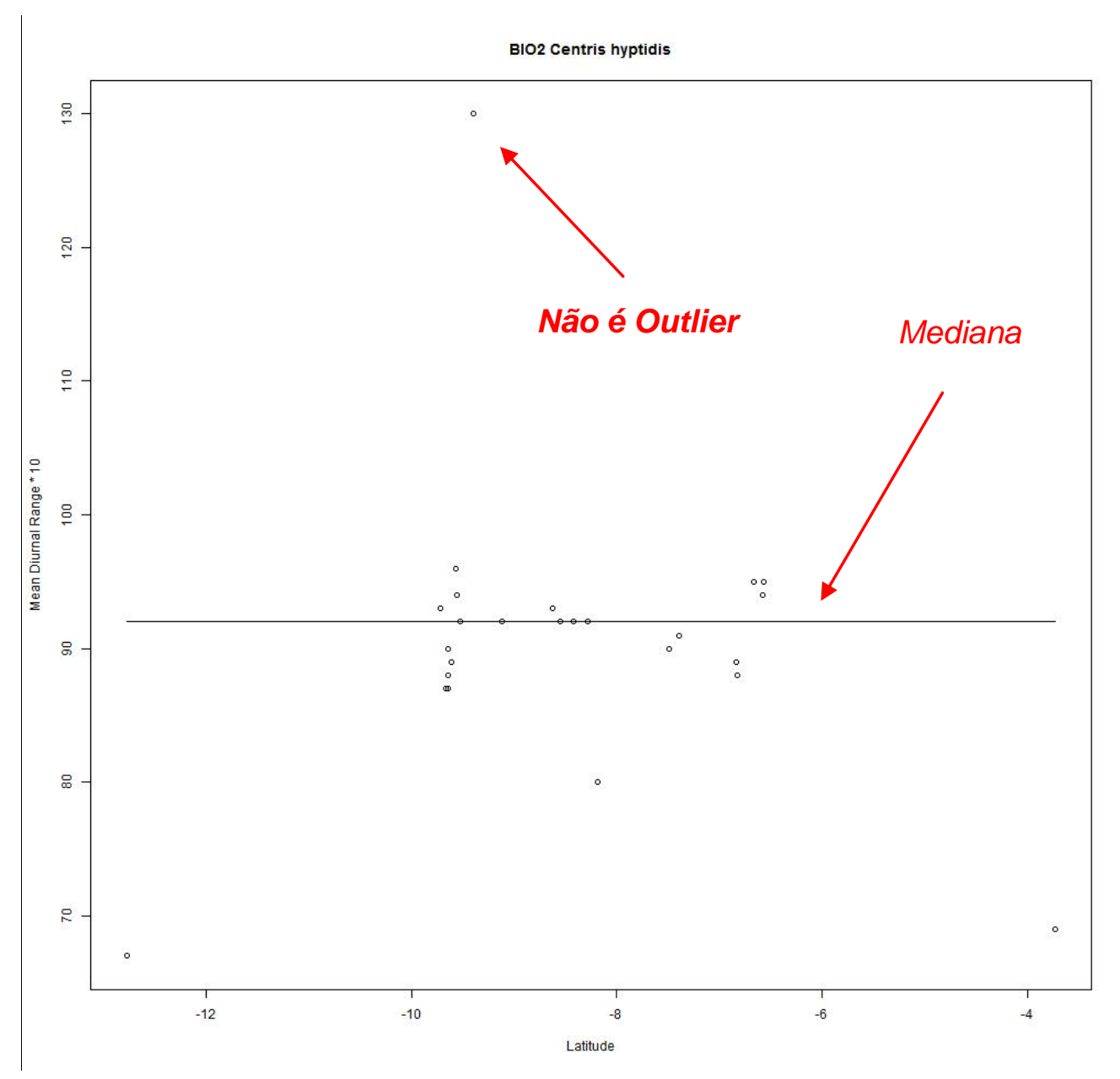

Figura 12: Gráfico de Gradiente Latitudinal da espécie Centris hyptidis relativo à Variação Diurna Média de Temperatura (Bio2).

A aplicação da técnica de detecção de outliers baseada em desvio padrão nos pontos de ocorrência da espécie Angelonia campestris identificou, entre 90 pontos de ocorrências, pontos de ocorrência com valor superior ao limite aceitável no teste de outlier baseados no desvio padrão.

Assim, no Gráfico do Gradiente Latitudinal da Precipitação do mês mais seco (Bio14) da espécie Angelonia campestris pode ser observado um valor discrepante da maioria dos outros valores (outlier), conforme apresentado na Figura 13. 


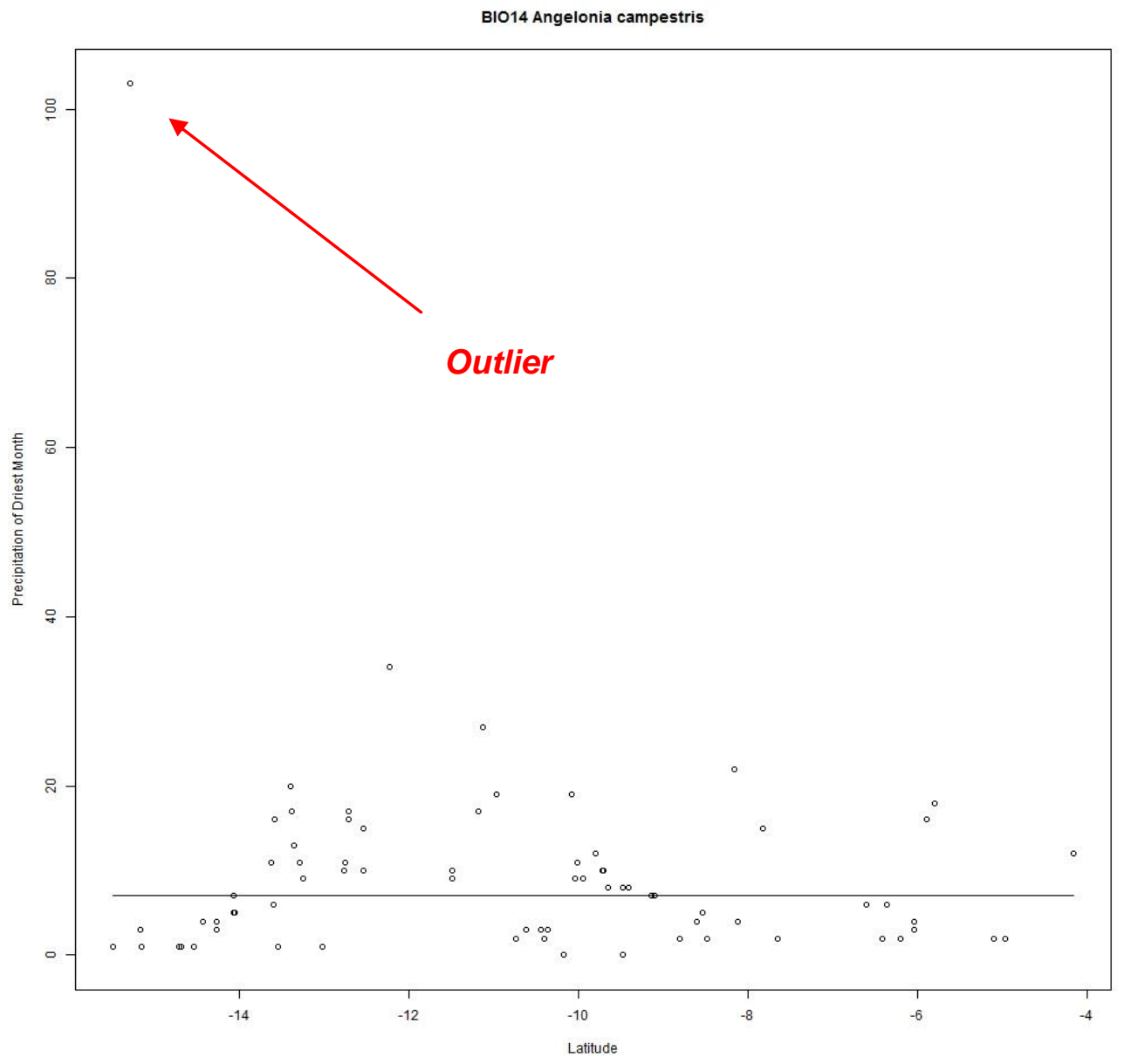

Figura 13: Gráfico de Gradiente Latitudinal da espécie Angelonia campestris relativo à Precipitação do mês mais seco (Bio14).

Na espécie Angelonia campestris, pode também ser observado o impacto do outlier no Gráfico de Histograma dos valores dos pontos de ocorrência relativos à Precipitação do mês mais seco (Bio14), apresentado na Figura 14.

Este comportamento apresentado no histograma é característico de ocorrência de outliers. Desta forma, a nuvem de pontos se comporta como dois pontos isolados, de um lado o outlier e no outro extremo o restante da nuvem de pontos de ocorrência, formando uma reta. 


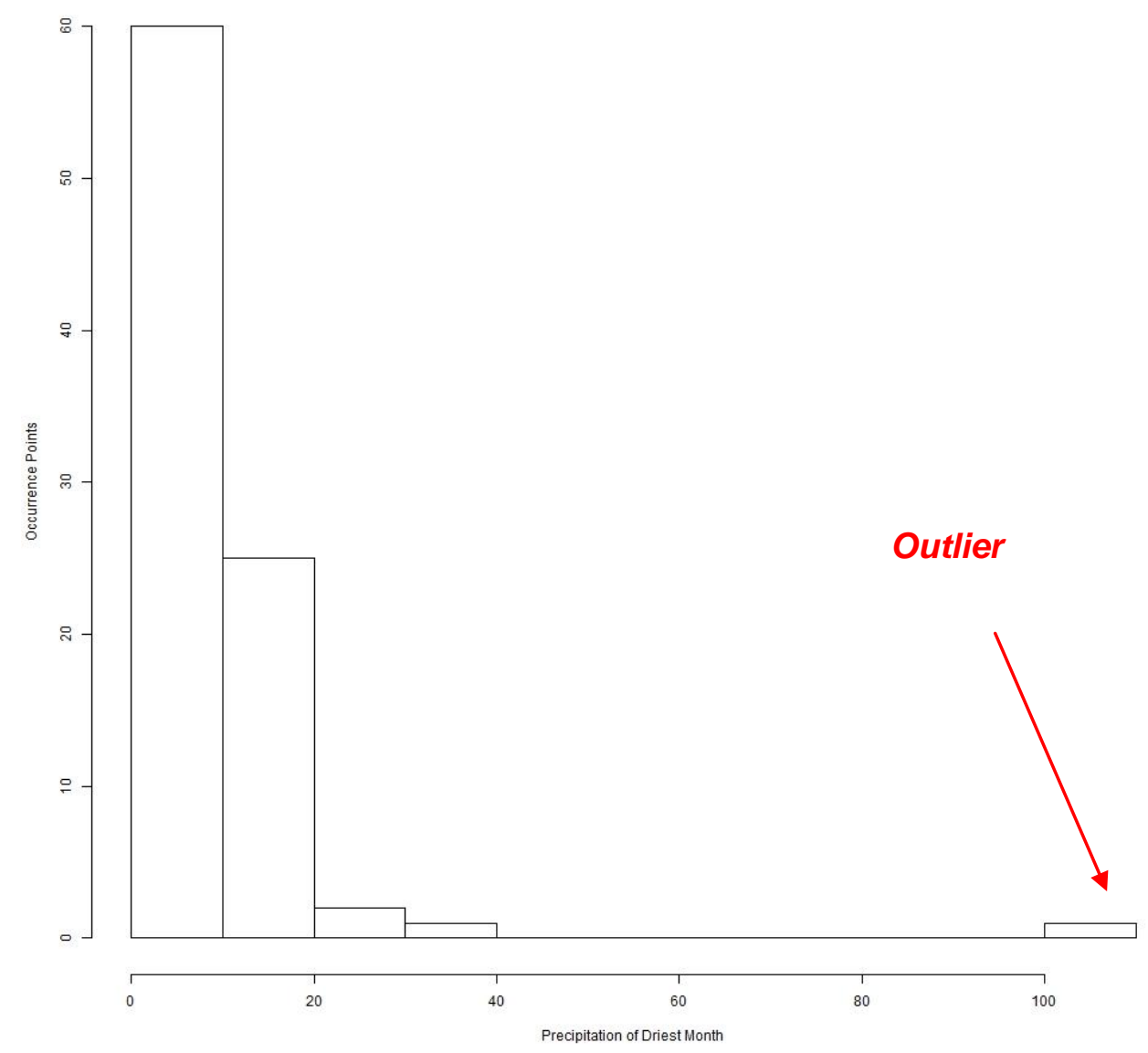

Figura 14: Gráfico de Histograma da espécie Angelonia campestris relativo à Precipitação do mês mais seco (Bio14).

Os pontos de ocorrência que foram identificados como outliers são removidos do grupo de pontos de ocorrência utilizados na modelagem de distribuição de espécies. Os detalhes da técnica de detecção de outliers utilizada são apresentados no Capitulo 5, na discussão dos resultados.

\subsubsection{Analisar os resultados}

Segundo Phillips et al. (2009) e Hurlbert (1984), registros de ocorrência podem apresentar viés espacial quando a distribuição das espécies só foi amostrada num subconjunto não aleatório da área total onde a espécie ocorre, tais como 
apenas áreas que são facilmente acessíveis. Este viés pode resultar em má calibração do modelo.

Por outro lado, esforços de amostragem podem ser espacialmente autocorrelacionados. Neste caso, os locais de amostragem são muito mais próximos do que seria esperado.

Assim, mesmo que todos os locais sejam visitados aleatoriamente, estes ainda podem conduzir a uma imprecisão na predição e avaliação do modelo, mesmo se não houver outros desvios (VELOZ, 2009).

Segundo Peterson et al. (2011) e Hijmans (2012), a autocorrelação espacial prejudica a separação em grupos independentes de pontos de registro de ocorrência para treinamento e teste do modelo de distribuição de espécie.

A aplicação das técnicas de análise da autocorrelação e seleção dos pontos que podem ser utilizados no estudo não foram utilizadas neste experimento.

\subsubsection{Selecionar as variáveis preditoras}

Segundo Austin (2002), suposições sobre a forma da resposta das espécies a uma variável ambiental, denominado um gradiente ambiental, são fundamentais para qualquer esforço de modelagem preditiva e usualmente a resposta é apresentada como um unimodal, a curva simétrica em forma de sino. A teoria de nicho é baseada nesta premissa e também inclui as seguintes premissas:

a) Os nichos fundamental e realizado de uma espécie são curvas simétricas em forma de sino.

b) A concorrência com outras epécies restringe a amplitude de nicho.

c) A abundância máxima ocorre no ponto ótimo para o nicho fundamental.

d) Os máximos das espécies são igualmente espaçados ao longo do gradiente.

e) Os máximos das espécies são de igual amplitude. 
f) As propriedades coletivas de espécies, por exemplo, riqueza de espécies, dominância ou abundância não mostram padrões de resposta ao longo do gradiente.

Assim, de acordo com Austin (2002) e Elith et al. (2006), os dados ambientais ou variáveis preditoras, utilizados no Processo de Modelagem de Distribuição de Espécies de cada região de interesse, devem ser selecionados pela sua relevância para a espécie a ser modelada..

\subsubsection{Selecionar as variáveis preditoras numéricas}

A redução da quantidade de variáveis preditoras, na prática, impede que padrões aleatórios espúrios sejam incorporados ao modelo construído. È também comum o interesse em se analisar o comportamento de duas ou mais variáveis quantitativas, para obter uma medida estatística que indique se existe ou não relação entre as duas variáveis; e se existe relação e qual a sua magnitude e sinal.

Em trabalhos como Elith, Kearney e Philips (2010), foi utilizada à medida do coeficiente de correlação linear de Pearson, para selecionar as variáveis preditoras.

O coeficiente linear de Pearson é utilizado para quantificar a correlação entre duas variáveis quantitativas. Índica o quanto a nuvem de pontos aproxima-se de uma reta ascendente ou descendente (ZAR, 2010).

Entretanto as duas variáveis podem apresentar uma associação curvilínea, ao invés de linear. Neste caso, podemos utilizar o coeficiente de correlação nãoparamétrico de Spearman (ZAR, 2010).

Pode-se também montar a matriz de correlação, para todo par de variáveis preditoras numéricas. Se necessário, pode ser aplicado os testes de normalidade em cada variável preditora para determinar o tipo de correlação (ZAR, 2010): 
a) Teste de normalidade Chi-Quadrado $\left(\chi^{2}\right)$;

b) Teste de normalidade de Kolmogorov-Smirnov;

c) Teste da normalidade de Shapiro-Wilk (W).

Caso as variáveis preditoras apresentem desvios significativos à normalidade, podemos utilizar o teste $U$ de Mann-Whitney, para testar diferenças nas medianas, e o teste de Kolmogorov-Smirnov de duas amostras, para comparar a distribuição de frequências em cada classe, para cada variável preditora quantitativa (ZAR, 2010).

Além destas técnicas, a Análise de Componentes Principais (PCA) (PEARSON, 1901) pode ser utilizada para reduzir o número de variáveis preditoras candidatas (ROBERTSON; CAITHNESS; VILLET, 2001).

A PCA é um método estatístico multivariado que encontra os autovalores e autovetores da matriz de covariância dos dados. Com esse resultado pode-se realizar a redução dimensional dos dados relacionados à área de interesse e analisar os padrões principais de variabilidade presentes.

Cada componente principal é uma combinação linear de todas as variáveis originais que melhor representa a distribuição dos dados. Nestas combinações, cada variável terá uma importância ou peso diferente.

\subsubsection{Selecionar as variáveis preditoras qualitativas}

As variáveis preditoras qualitativas, ou variáveis categóricas, permitem a separação dos dados em grupos de pontos de ocorrência formados pelos fatores de interesse. 
Pontos de ocorrências

Centris hyptidis

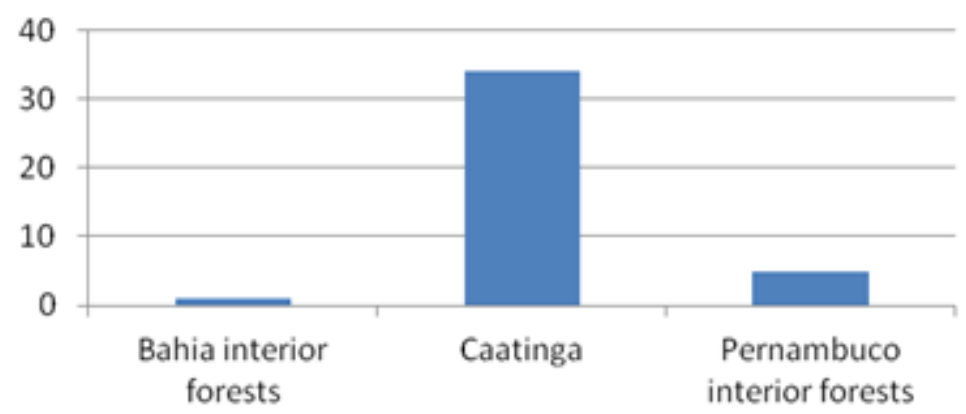

Figura 15: Categorização dos pontos de ocorrência de Centris hyptidis pelo Bioma.

Os pontos de ocorrência podem ser categorizados em relação ao Bioma, como por exemplo, a categorização dos pontos de ocorrência de Centris hyptidis apresentado na Figura 15.

As técnicas de Análise de Variância Paramétrica (ANOVA) ou a Análise de Variância Não-Paramétrica de Kruskal-Wallis podem ser utilizadas para comparação de dois ou mais grupos de pontos de ocorrências (ZAR, 2010).

\subsubsection{Selecionar e executar o algoritmo de modelagem de distribuição de espécie}

O algoritmo selecionado para este experimento foi o algoritmo de Entropia Máxima (Phillips et al., 2006). A versão do algoritmo de Entropia Máxima utilizada foi a 3.3.3k implementada no software MaxEnt (PHILLIPS; DUDÍK; SCHAPIRE, 2004), disponível online (HTTP://www.cs.princenton.edu/ schapire/maxent).

A sua escolha foi devido ao seu melhor desempenho em estudos comparativos (ELITH et al., 2011), mesmo para uma pequena quantidade de pontos de ocorrências (HERNANDEZ et al., 2006; WISZ et al., 2008). 
O algoritmo de Entropia Máxima do MaxEnt, disponível no Pacote "Dismo" (HIJMANS, 2011), foi executado a partir de scripts desenvolvidos na linguagem $R$ ( $R$ Development Core Team, 2009). Estes scripts em linguagem $R$ foram escritos para este experimento, com a finalidade de implantar os detalhes do Processo de Modelagem de Distribuição de Espécie proposto e fornecer os dados para a análise comparativa dos resultados.

O desempenho preditivo do modelo é analisado pelo teste AUC (Area Under the receiver operating characteristic Curve), que mede a habilidade do modelo de discriminar entre a omissão de áreas com registros e a sobreprevisão de áreas não ocupadas (ELITH et al., 2006). Os valores do teste AUC acima de 0,9 indicam um excelente desempenho do modelo, por exemplo, o Gráfico do resultado do teste AUC da Modelagem de Distribuição Potencial da espécie Centris hyptidis é apresentado na Figura 16.

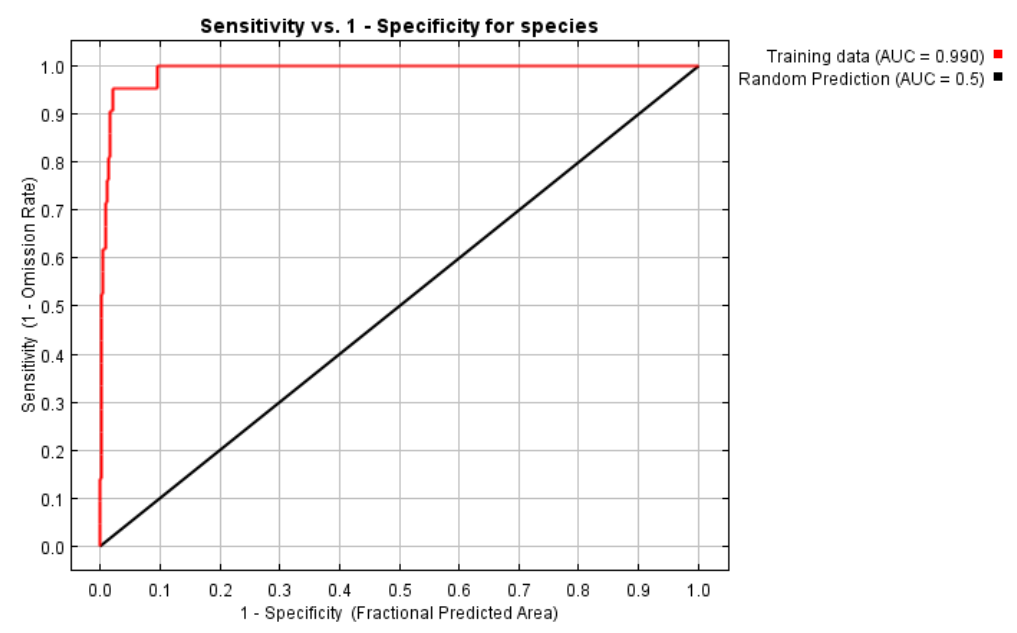

Figura 16: Gráfico com o resultado do teste AUC da Modelagem de Distribuição Potencial da espécie Centris hyptidis com o algoritmo de Entropia Máxima.

Os erros de comissão e omissão são avaliados com o Gráfico da Matriz de Confusão (FIELDING; BELL, 1997), por exemplo, o Gráfico do resultado do teste erros de omissão e comissão da Modelagem de Distribuição Potencial da espécie Centris hyptidis é apresentado na Figura 17. 


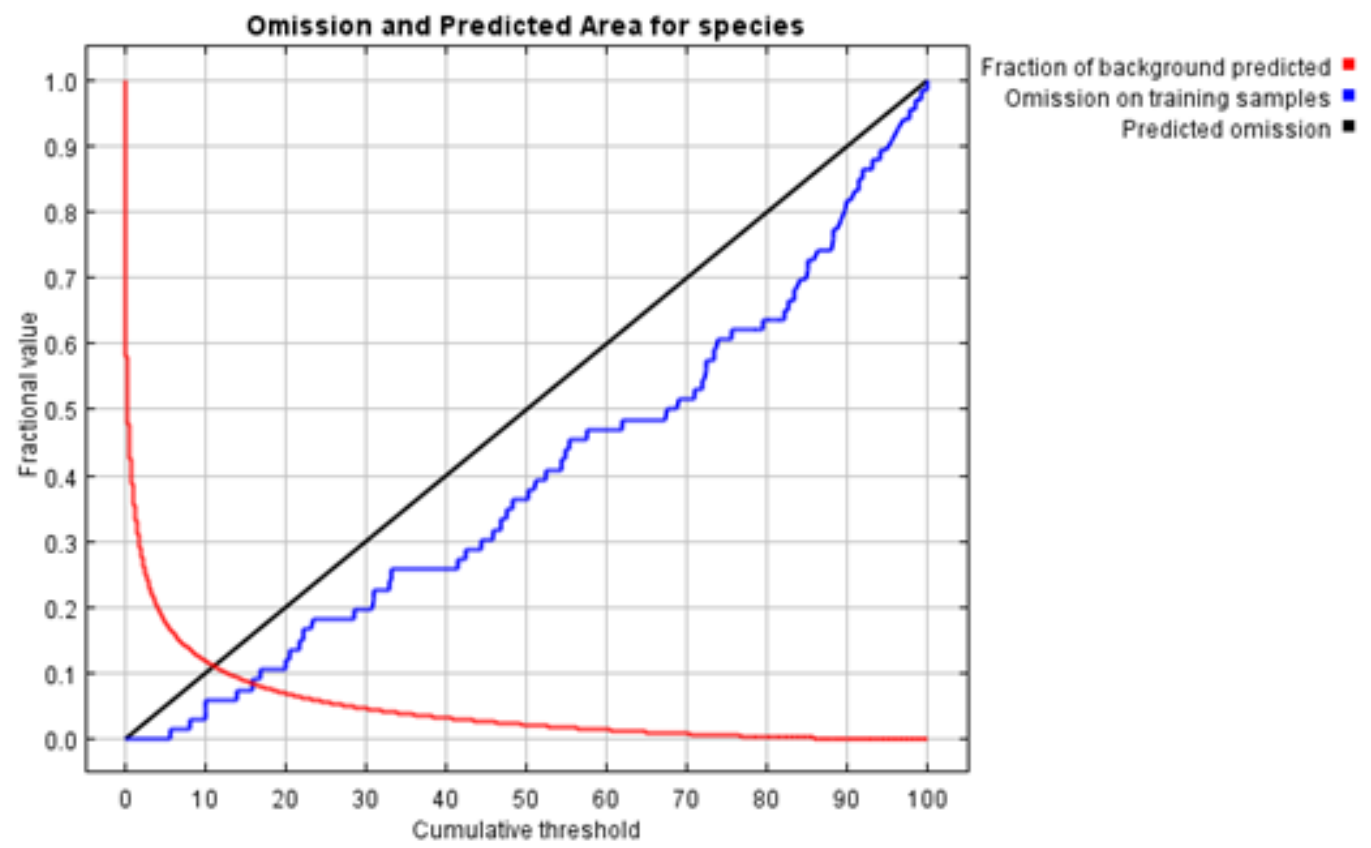

Figura 17: Gráfico com o resultado do teste de Erro de Comissão e Omissão da Modelagem de Distribuição Potencial da espécie Centris hyptidis com o algoritmo de Entropia Máxima.

O teste Jackknife mede a importância das variáveis, estimando o ganho quando a variável é aplicada isolada e a perda quando é omitida (QUENOUILLE, 1956; EFRON, 1979). Assim, as variáveis preditoras podem ser classificadas de acordo com sua contribuição relativa para a elaboração do modelo.

A Figura 18 apresenta o Gráfico com os resultados da avaliação de Jackknife acerca da importância relativa das variáveis preditoras. A importância é quantificada em um percentual para o modelo sem a variável preditora, em azul claro, com apenas a variável, em azul escuro, e com todas as variáveis, em vermelho. 


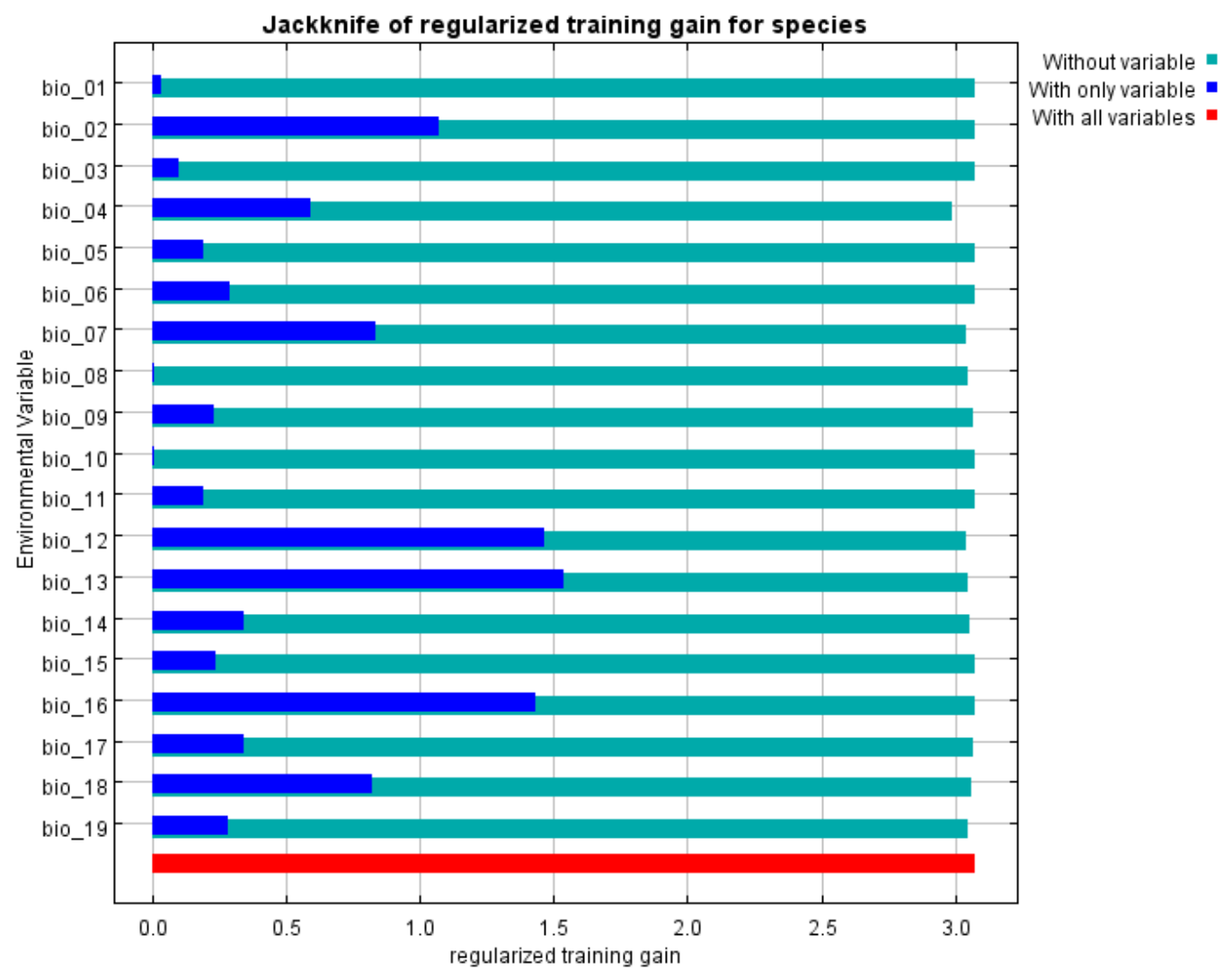

Figura 18: Gráfico com os resultados do teste de Jackknife da Modelagem de Distribuição Potencial da espécie Centris hyptidis com o algoritmo de Entropia Máxima.

Neste exemplo, podem-se observar em destaque as contribuições individuais das variáveis de Precipitação anual (B12), Precipitação do mês mais chuvoso (BIO13), Precipitação na estação mais chuvosa (BIO16) e a Variação diurna média da Temperatura (Bio2), Amplitude térmica anual (BIO7) e Precipitação na estação mais quente (BIO18). Isto pode indicar que além das condições de Temperatura, a Distribuição Potencial desta espécie é também determinada por uma forte correlação com as condições de Precipitação.

\subsubsection{Predição da distribuição de espécie na área de interesse}

Segundo Peterson (2011), os modelos de nicho oferecem o potencial para prever áreas potenciais de distribuição de espécies em condições climáticas correntes ou em condições especificas de cenários futuros de mudanças climáticas, 
baseados nos Special Report on Emissions Scenarios (SRES) do Intergovernmental Panel on Climate Change (IPCC).

O resultado é um Mapa com a estimativa de Distribuição Potencial da Espécie para uma área de interesse, com valores em escala logística entre 0 e 1, onde 1 seria a máxima adequabilidade do habitat às condições de ocorrência da espécie. Por exemplo, o Mapa de Distribuição Potencial da espécie Centris hyptidis obtido a partir do algoritmo de Entropia Máxima é apresentado na Figura 19.

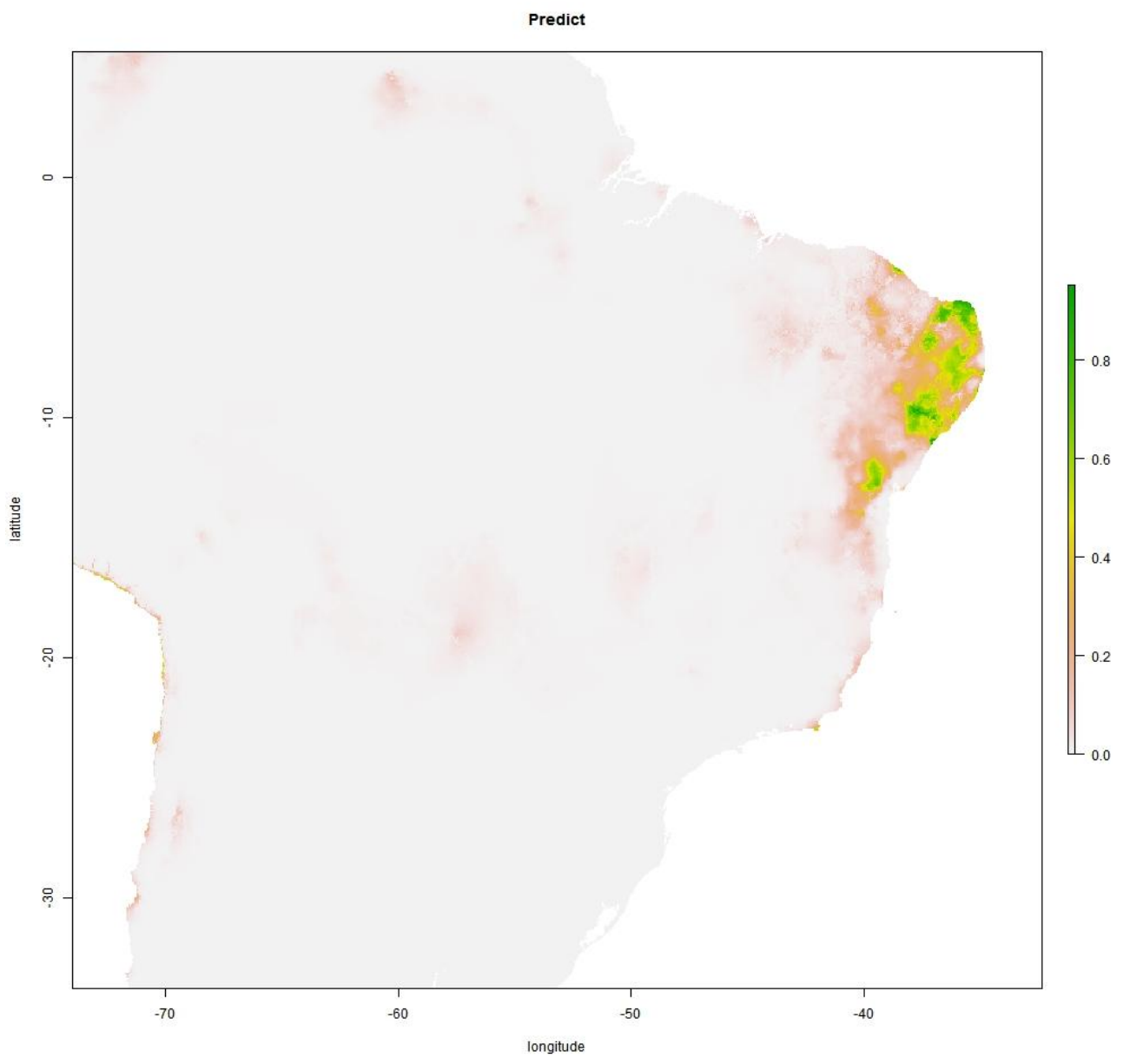

Figura 19: Mapa da Modelagem de Distribuição Potencial da espécie Centris hyptidis com o algoritmo de Entropia Máxima. 


\subsubsection{Validar a hipótese científica com a análise de um conjunto de predições de distribuição de espécies}

A hipótese cientifica pode ser analisada por meio da inspeção visual dos Mapas das predições, ou projeções, das Modelagens de Distribuição de Espécie, por Pesquisadores Especialistas nas Espécies, a fim de verificar se os modelos gerados são consistentes com as informações sobre a distribuição empiricamente determinada.

Além dessa inspeção visual, essa análise pode também utilizar-se os dados de interação para melhorar a acurácia e o desempenho da Modelagem de Distribuição de Espécie, conforme Giannini (2011). O Processo de Modelagem de Distribuição de Espécie proposto destaca nas Atividades desta Etapa análise comparativa dos resultados, como por exemplo, da Modelagem de Distribuição das espécies Centris hyptidis, Angelonia campestris e Angelonia Cornigera.

Além disso, as informações sobre como cada variável preditora afeta a espécie em estudo pode contribuir significativamente para avaliação dos resultados no Processo de Modelagem de Distribuição de Espécie.

Estas informações auxiliam na compreensão dos fatores que levaram a determinadas áreas não serem classificadas como um habitat adequado para a espécie em estudo, e também na compreensão de como este Modelo poderá ser afetado em cenários de mudanças climáticas, conforme Elith, Kearney e Philips (2010).

A seguir é apresentada a técnica de inspeção visual para análise do conjunto de modelagens de distribuição de espécies.

\subsubsection{Análise utilizando a Inspeção Visual}

A inspeção visual pode ser utilizada para a análise do Mapa de Distribuição Potencial de uma Espécie ou analisar comparativamente os resultados da 
Modelagem de Distribuição de mais de uma espécie, por exemplo, uma inspeção visual dos Mapas com os resultados da Modelagem de Distribuição Potencial das espécies Centris hyptidis, Angelonia Campestris e Angelonia Cornigera, apresentados na Figura 20, 21 e 22.

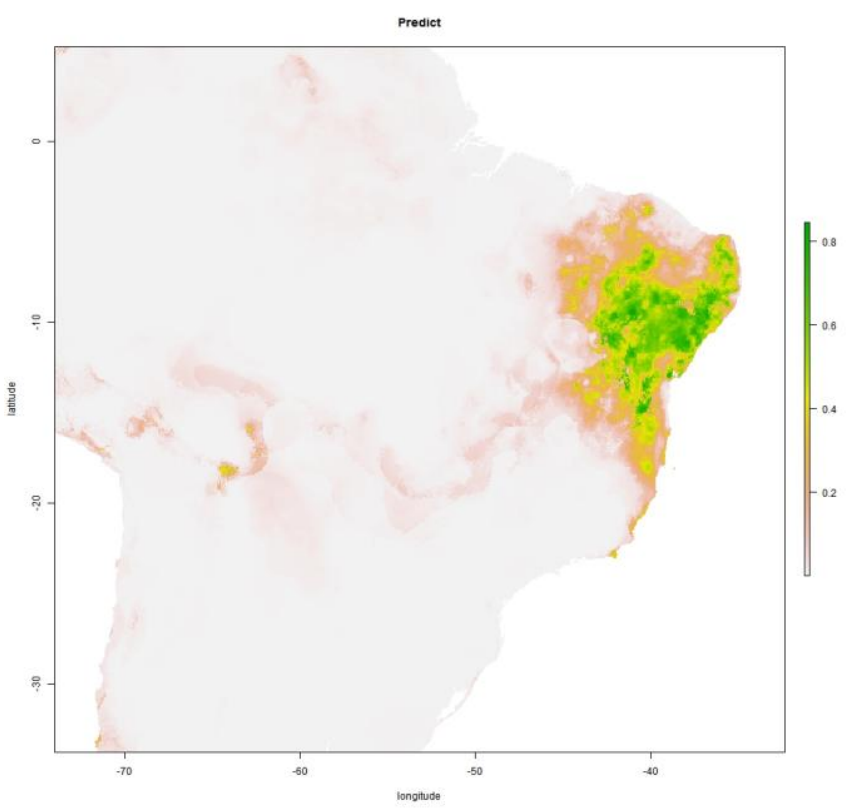

Figura 20: Mapa com o resultado da Modelagem de Distribuição Potencial da espécie Angelonia campestris utilizando o algoritmo de Entropia Máxima

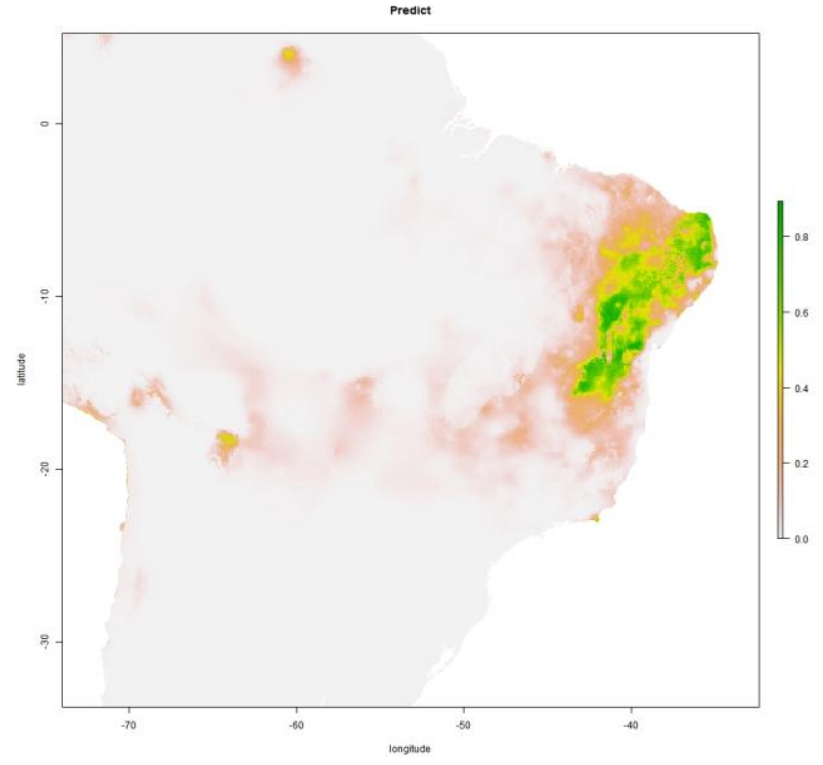

Figura 21: Mapa com o resultado da Modelagem de Distribuição Potencial da espécie Angelonia cornigera utilizando o algoritmo de Entropia Máxima 


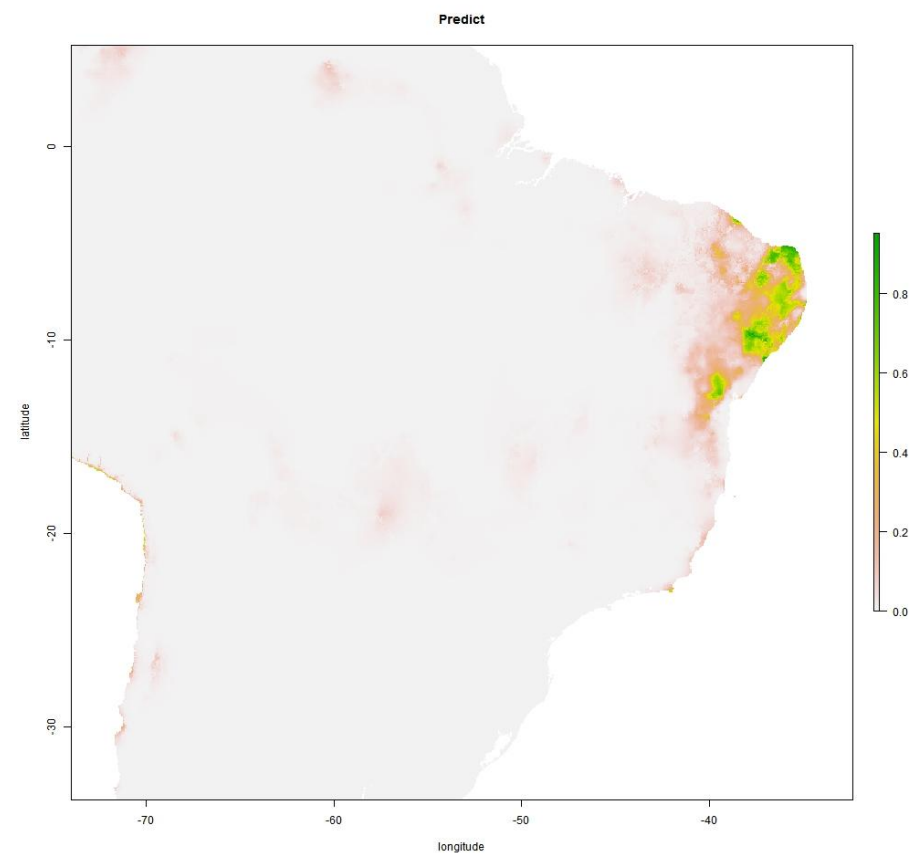

Figura 22: Mapa com o resultado da Modelagem de Distribuição Potencial da espécie Centris hyptidis utilizando o algoritmo de Entropia Máxima

Nesta análise com a inspeção visual, pode-se observar que a área de maior potencial de distribuição da espécie Centris hypitidis está sob o Bioma de Caatinga, a região representada pela cor verde, confirmando a hipótese cientifica inicial.

De acordo com Giannini et al. (2012b) e Giannini, Saraiva e Alves-dos-Santos (2010), nos trabalhos sobre a interação da espécie de abelha Centris hyptidis e plantas oleaginosas da espécie Angelonia campestris e Angelonia cornigera, na região nordeste do Brasil, a maior parte das regiões com valor alto de adequabilidade de habitat no Mapa da Distribuição Potencial da espécie Centris hypitidis, as regiões com a cor verde, coincidem com regiões com valor alto de adequabilidade de habitat no Mapa da Distribuição Potencial da espécie Angelonia cornigera, ao norte, e com regiões com valor alto de adequabilidade de habitat no Mapa da Distribuição Potencial da espécie Angelonia campestris, ao sul.

Este resultado é uma corroboração das conexões entre as espécies Centris hyptidis e as plantas oleaginosas da espécie Angelonia campestris e Angelonia cornigera, prevista na hipótese apresentada neste experimento de interação entre as espécies.

Também de acordo com Giannini et al. (2012b), pode-se observar nos Mapas com os resultados da Modelagem de Distribuição Potencial das espécies Angelonia cornigera e Angelonia campestris uma área maior, mais espalhada. 


\subsection{Considerações finais}

Neste Capítulo foi apresentado o estudo de caso da Modelagem de Distribuição da espécie Centris hyptidis. Com a finalidade gerar dados para a análise comparativa do Processo de Modelagem de Distribuição de Espécie, foi inicialmente utilizado o processo de baseado em Santana et al. (2008) e em seguida foi aplicado o novo Processo de Modelagem de Distribuição de Espécie proposto, que permitiu apresentar detalhadamente as atividades.

Na Etapa de Pré-Análise, os fatores bióticos foram utilizados para analisar a qualidade dos pontos de ocorrência e variáveis preditoras, como apresentado na análise dos dados de registros de ocorrências das plantas oleaginosas Angelonia campestris e Angelonia cornigera em conjunto com os dados de registros de ocorrência da Centris hyptidis.

O novo Processo de Modelagem de Distribuição de Espécie proposto foi detalhado em Atividades. Em cada atividade foram apresentadas algumas das principais técnicas estatísticas disponíveis. Entretanto, somente algumas técnicas foram utilizadas na adaptação do novo Processo de Modelagem de Distribuição de Espécie para realização deste experimento em específico.

Dessa mesma forma, o pesquisador poderá também adaptar o novo Processo de Modelagem de Distribuição de Espécie proposto, de acordo com as características específicas de sua pesquisa.

No Capítulo seguinte é apresentada a discussão da análise comparativa e dos resultados obtidos na realização dos experimentos de Modelagem de Distribuição de Espécie. 


\section{Discussão dos resultados obtidos}

As análises comparativas a seguir visam explorar os principais aspectos que surgiram durante a aplicação Processo de Modelagem de Distribuição de Espécies proposto.

Conforme apresentado no Capítulo 4, o experimento de Modelagem de Distribuição das Espécies Centris hyptidis, Angelonia campestris e Angelonia cornigera foi subdividido em três fases:

a) $\mathrm{Na}$ primeira fase, foi realizada a Modelagem de Distribuição de Espécies considerando o Processo de Modelagem de Distribuição de Espécies proposto em Santana et al. (2008), como uma referência para a análise dos resultados.

b) $\mathrm{Na}$ segunda fase deste experimento, foi realizada a Modelagem de Distribuição de Espécies considerando o Processo de Modelagem de Distribuição de Espécies proposto com a aplicação de filtro de outliers.

c) $\mathrm{Na}$ terceira e última fase foi realizada a análise comparativa e discutidos os resultados obtidos.

A discussão da análise comparativa foi subdividida diferentes aspectos:

- Análise comparativa da estrutura e organização do Processo de Modelagem de Distribuição de Espécie.

- Análise comparativa do impacto no desempenho do Modelo de Distribuição de Espécies em relação à Fase de Pré-Análise dos dados com a utilização de filtro de outliers.

- Análise comparativa do desempenho do Modelo de Distribuição de Espécies em relação às curvas de resposta das variáveis preditoras.

- Análise comparativa dos resultados do Processo de Modelagem de Distribuição de Espécies proposto em relação à contribuição de cada variável preditora no Modelo.

Assim, os subitens seguintes apresentam a discussão de cada um destes aspectos. 


\subsection{Estrutura e organização do Processo de Modelagem de Distribuição de Espécies}

Como pode ser observado no estudo de caso apresentado no Capitulo anterior, o Processo de Modelagem de Distribuição de Espécie apresentado em Santana et al. (2008) foi aplicado em um experimento de Modelagem de Distribuição da Espécie Centris hyptidis.

Conforme descrito em Santana et al. (2008), o experimento foi realizado seguindo os passos sugeridos e com o auxilio da ferramenta de Modelagem openModeller.

O foco do processo é produzir o Mapa de Distribuição Potencial da Espécie a partir de qualquer um dos algoritmos disponíveis na ferramenta, considerando os pontos de ocorrência, pontos de ausência e as variáveis preditoras disponíveis para o projeto do experimento.

Existem ainda diversos passos que reforçam a necessidade de configuração dos parâmetros do Algoritmo de Modelagem de Distribuição de Espécie e da realização automática dos testes de desempenho do Modelo, como o teste AUC.

O Processo de Modelagem de Distribuição de Espécie proposto é subdividido em Fases, Etapas e Atividades. O pesquisador pode adaptar o Processo de Modelagem de Distribuição de Espécie de acordo com as características especificas de sua pesquisa.

As Fases definidas para o Processo de Modelagem de Distribuição de Espécie proposto servem para guiar o pesquisador durante o tratamento dos dados utilizados e as principais necessidades de tratamento desses dados, por exemplo, na Fase de Pré-análise dos Dados existe a necessidade de Data Clearing e recorte das variáveis preditoras para a área de interesse. 
As Etapas são utilizadas na gestão efetiva do Processo de Modelagem de Distribuição de Espécie como um todo, incluindo todos os Modelos necessários para atender a Hipótese científica definida, de tal forma a ficar claro o estágio da pesquisa e as principais preocupações, por exemplo, na Etapa de Selecionar e Executar o Algoritmo de Modelagem de Distribuição de Espécie deve-se, além de executar o teste do modelo, avaliar os problemas de esforço amostral e outliers.

As Atividades são necessárias para identificar quais os procedimentos utilizados na realização do experimento, quais as técnicas aplicadas e considerações adotadas na adaptação do Processo de Modelagem de Distribuição de Espécie.

A descrição das Etapas neste nível de detalhe facilita a repetição do experimento por outros pesquisadores. Portanto, permite que se busque, de forma sistemática, o aprimoramento da metodologia utilizada na pesquisa.

Assim, os Modelos das três espécies em estudo, a Centris hyptidis e as plantas oleaginosas Angelonia campestris e Angelonia cornigera, puderam ser produzidos e analisados por especialistas nas espécies em estudo dentro de um mesmo contexto, como destacado na Fase de Validação da Hipótese Científica.

A Fase de Modelagem e Projeção abstraiu toda a complexidade de seleção, configuração e execução do algoritmo de Modelagem de Distribuição de Espécie, mas ainda manteve a forte conexão com a Hipótese Científica definida.

A Fase de Construção da Hipótese Científica e a Fase de Pré-Análise de Dados se mostraram muito interligadas, favorecendo um ambiente onde possam ser analisados os diferentes aspectos que envolvem a Modelagem de Distribuição de Espécies, por exemplo, o esforço amostral e outliers.

\subsection{Técnica de filtragem para remoção de outliers}

$\mathrm{Na}$ fase de Pré-Análise, a modelagem de distribuição da espécie Angelonia campestris é realizada com a aplicação de filtro de outlier, que utiliza para 
identificação de outliers a técnica do exame critico de escores normais $(Z<-3,9$ e Z>3,9).

Onde:

$$
Z_{i}=\left\{\frac{X_{i}-\bar{X}}{s}\right\}
$$

Sendo:

$$
\bar{X}=\text { média aritmética } \quad \bar{X}=\frac{\sum_{i=\mathbf{1}}^{n} X_{i}}{n}
$$

$s=$ desvio padrão

$$
s=\sqrt{\frac{\sum_{i=1}^{n}\left(X_{i}-\bar{X}\right)^{2}}{n-1}}
$$

(3)

$$
\begin{aligned}
& x_{i}=\text { dado } i \\
& n=\text { número total de dados }
\end{aligned}
$$

Esta técnica foi aplicada a todos os pontos de ocorrência em relação aos valores extraídos das variáveis preditoras nos pontos de ocorrência. Por exemplo, os resultados da aplicação desta técnica na análise dos pontos de ocorrência da espécie Angelonia campestris, relativos à Precipitação do mês mais seco (Bio14), confirmou o outlier indicado no Gráfico de Gradiente Latitudinal e Gráfico de Histograma, apresentados nas Figuras 13 e 14 respectivamente.

\subsection{Resultados da aplicação do filtro outliers nas curvas de resposta das variáveis preditoras}

Nesta fase de Pré-análise dos Dados, os pontos de ocorrência são analisados em diferentes aspectos na atividade de Data Clearing, por exemplo, a confiabilidade 
do processo de coleta de dados, além da existência de georeferenciamento dos pontos de ocorrência.

Deve-se ainda considerar que frequentemente existem poucos pontos de ocorrência disponíveis, especialmente para as espécies raras ou ameaçadas, por exemplo, as espécies que constam na IUCN Red List (IUCN, 2008).

Entretanto, a permanência dos pontos de ocorrência considerados outliers traz graves consequências, como observado nas curvas de resposta da espécie em ralação a variável preditora, apresentadas nas Figuras 23 e 24 .

As curvas de resposta da espécie em relação a variável preditora mostram como cada variável preditora afeta a previsão do Algoritmo de Entropia Máxima. As curvas mostram como cada variável preditora é variada, mantendo todas as outras variáveis preditoras em seu valor médio. Em outras palavras, as curvas mostram o efeito marginal de mudar exatamente uma variável, enquanto que o modelo pode tirar vantagem de mudança de todo um conjunto de variáveis.

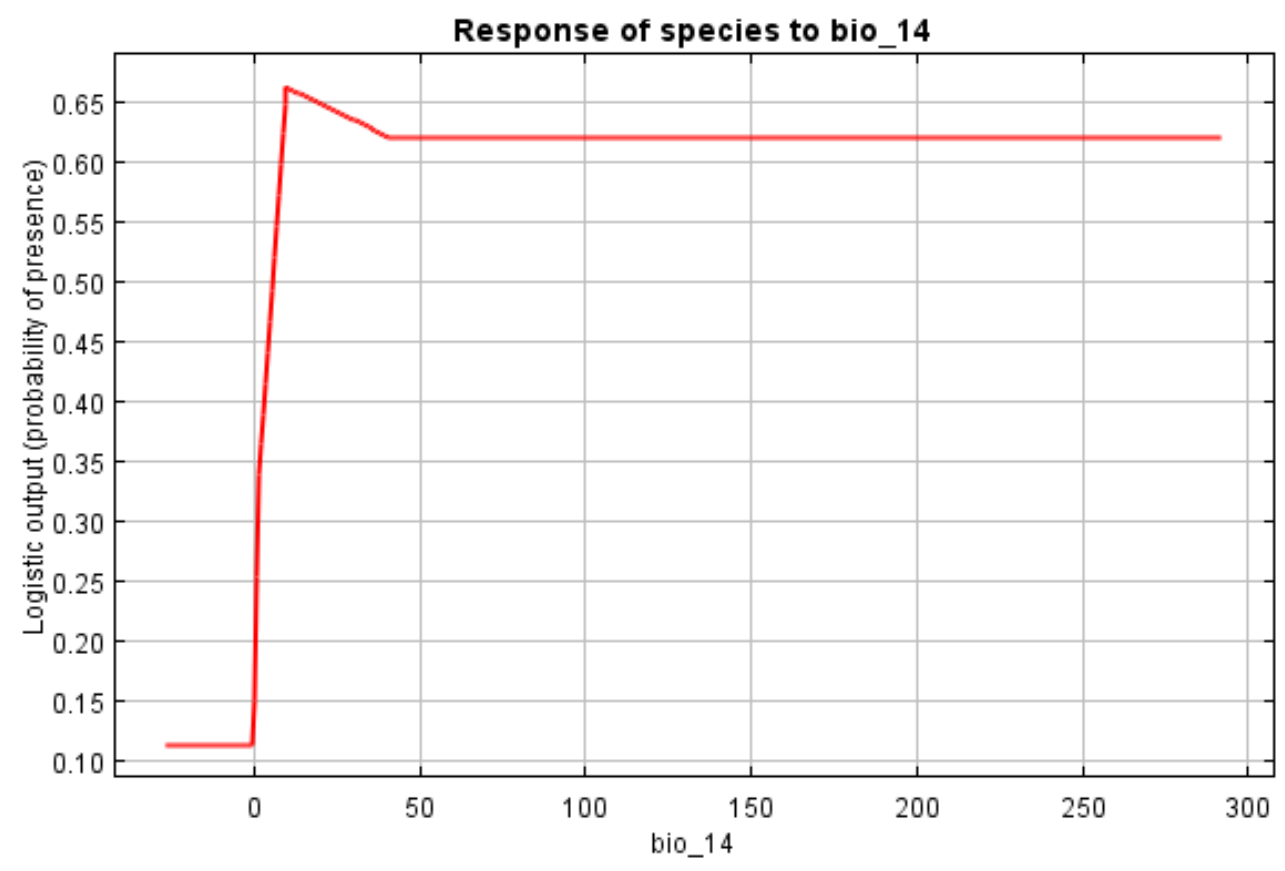

Figura 23: Curva de resposta da espécie Angelonia campestris em relação a variável preditora Precipitação do mês mais seco (Bio14) com o outlier 


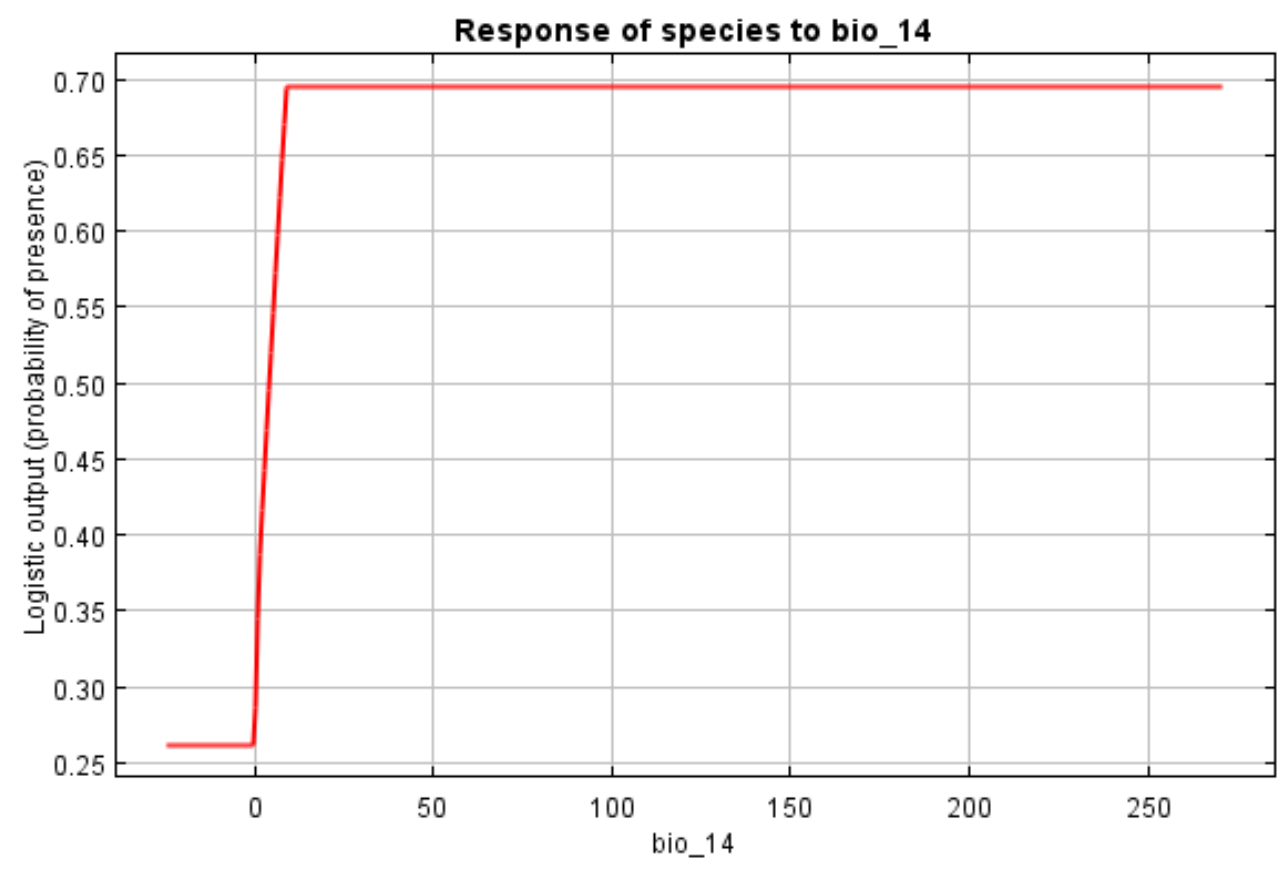

Figura 24: Curva de resposta da espécie Angelonia campestris em relação a variável preditora Precipitação do mês mais seco (Bio14) com a aplicação do filtro para a remoção do outlier

\subsection{Resultados da aplicação do filtro outliers no peso das contribuições das variáveis preditoras no Modelo}

Além disso, observa-se que os pesos relativos das variáveis preditora são alterados no Modelo, por exemplo, como observado nos Modelos criado para a espécie Angelonia campestris, apresentados na Tabela 5.

$\mathrm{Na}$ tabela 5, pode-se também observar a alteração da contribuição da variável preditora Precipitação do mês mais seco (Bio14). Por conseguinte, ocorrem também alterações na contribuição das outras variáveis preditoras que compõem o Modelo. 
Tabela 5: Comparação do impacto na contribuição das variáveis preditoras ao Modelo com a aplicação do filtro para remoção de outliers

\begin{tabular}{|c|c|c|c|c|c|}
\hline \multicolumn{3}{|c|}{\begin{tabular}{|c|} 
Contribuição das variáveis preditoras com \\
Outliers
\end{tabular}} & \multicolumn{3}{|c|}{\begin{tabular}{|c|}
$\begin{array}{c}\text { Contribuição das variáveis preditoras com } \\
\text { aplicação do Filtro de Outliers }\end{array}$ \\
\end{tabular}} \\
\hline $\begin{array}{c}\text { Variável } \\
\text { Preditora }\end{array}$ & \begin{tabular}{|c|} 
Percentual de \\
contribuição
\end{tabular} & \begin{tabular}{|c|} 
Importância na \\
Permutação
\end{tabular} & \begin{tabular}{|c|} 
Variável \\
Preditora \\
\end{tabular} & \begin{tabular}{|l|} 
Percentual de \\
contribuição
\end{tabular} & $\begin{array}{c}\text { Importância na } \\
\text { Permutação }\end{array}$ \\
\hline Bio_12 & 34.6 & 60.3 & Bio_12 & \begin{tabular}{|l|}
38.8 \\
\end{tabular} & 30 \\
\hline Bio_7 & 32.5 & 3.8 & Bio_7 & 29.1 & 1.3 \\
\hline Bio_4 & 17.5 & 4.4 .4 & Bio_4 & 16.2 & 5 \\
\hline Bio_17 & 5.6 & 6 & Bio_17 & 6.4 & 36.1 \\
\hline Bio_14 & 2.4 & 4.3 & Bio_14 & 2 & 2.3 \\
\hline Bio_2 & 1.6 & 0.7 & Bio_18 & 1.8 & 3.2 \\
\hline Bio_18 & 1.4 & 2 & Bio_3 & 1.7 & 3.9 \\
\hline Bio_3 & 1.1 & 1.2 & Bio_2 & 1.4 & 4.3 \\
\hline Bio_19 & 0.8 & 2.1 & Bio_19 & 0.7 & 3.7 \\
\hline Bio_6 & 0.7 & 11.8 & Bio_5 & 0.6 & 0 \\
\hline Bio_16 & 0.5 & 1.1 & Bio_13 & 0.5 & 4.3 \\
\hline Bio_11 & 0.3 & 1.5 & Bio_9 & 0.3 & 0 \\
\hline Bio_5 & 0.3 & 0 & Bio_6 & 0.2 & 5.5 \\
\hline Bio_9 & 0.2 & 0 & Bio_16 & 0.1 & 0.2 \\
\hline Bio_13 & 0.2 & 0.7 & Bio_11 & 0.1 & 0 \\
\hline Bio_10 & 0.2 & 0.3 & Bio_8 & 0 & 0.1 \\
\hline Bio_8 & 0 & 0 & Bio_10 & 0 & 0 \\
\hline Bio_15 & 0 & 0 & Bio_15 & 0 & 0 \\
\hline Bio_1 & 0 & 0 & Bio_1 & 0 & 0 \\
\hline
\end{tabular}

\subsection{Considerações finais}

Neste Capítulo foram avaliados os resultados obtidos na analise comparativa do Processo proposto em Santana et al. (2008) e o Processo de Modelagem de Distribuição de Espécies proposto.

A aplicação do filtro de outliers contribuiu para a remoção de distorções que foram analisadas em diferentes aspectos, como o impacto nas curvas de resposta da espécie em relação a variável preditora e na contribuição da variável preditora no Modelo. : 


\section{CONCLUSÂO}

O Processo de Modelagem de Distribuição de Espécies foi revisado, atualizado e estendido para atender aos novos desafios da Modelagem de Distribuição de Espécies e ferramentas de Biodiversity Informatics.

As Atividades do Processo de Modelagem de Distribuição de Espécie proposto foram detalhadas no estudo de caso. Os resultados obtidos foram analisados comparativamente com o Processo de Modelagem de Distribuição apresentado em Santana et al. (2008).

Neste estudo de caso foi utilizado o Algorítmico de Entropia Máxima, que é um método de modelagem baseado em apenas pontos de presença, para criar um Modelo de Distribuição Geográfica da Espécie, pelo seu bom desempenho e ser largamente utilizados por pesquisadores da área.

Conforme os resultados obtidos na análise comparativa realizada, as atividades estabelecidas no Processo de Modelagem de Distribuição de Espécies proposto, dentro da Etapa de Pré-Análise dos Dados, podem ser utilizadas para identificar problemas relativos ao esforço amostral, como dados de ocorrência enviesados pela falta de representatividade de subespécies nos pontos de ocorrência, ou pela super amostragem de regiões específicas.

Além disso, a aplicação do filtro de outliers contribuiu para a remoção de distorções no Modelo que afetariam a seu desempenho preditivo. Estas distorções foram analisadas em diferentes aspectos, como o impacto nas curvas de resposta da espécie em relação a variável preditora e na contribuição da variável preditora no Modelo.

Desta forma, os problemas podem ser identificados e corrigidos, em um ciclo de melhoria continua dentro do Processo de Modelagem de Distribuição de Espécies proposto.

O Processo de Modelagem de Distribuição de Espécie proposto é subdividido em Fases, que servem para guiar o pesquisador durante o tratamento dos dados, 
Etapas, que são utilizadas na gestão, e as Atividades, que são necessárias para identificar quais os procedimentos utilizados na realização do experimento.

O pesquisador pode adaptar, de acordo com as características específicas de sua pesquisa, o Processo de Modelagem de Distribuição de Espécie proposto, pois este não é restrito a uma Ferramenta de Modelagem ou Algoritmo de Modelagem de Distribuição de Espécie em específico.

Como diferencial deste trabalho, a proposta de Processo de Modelagem de Distribuição de Espécie também estabelece um procedimento comum para diferentes algoritmos de modelagem de distribuição de espécies. Entretanto, cada Etapa do Processo de Modelagem de Distribuição de Espécie deve permitir a troca de informações com outras ferramentas. A padronização do formato utilizado para troca dessas informações favorece a interoperabilidade entre as ferramentas de Biodiversity Informatics.

O Processo geral de Modelagem de Distribuição de Espécie proposto também se diferencia dos demais por abranger a análise integrada com os resultados de outros modelos de distribuição de espécies, com o objetivo de facilitar a transformação dos dados em informação e a geração de conhecimento em biodiversidade.

Foram apresentadas as Etapas de Pré-Análise dos Dados e a Seleção das Variáveis Preditoras em uma nova proposta, revisada e atualizada, com o foco na visão do biólogo ou ecólogo especialista na espécie, onde os pontos de ocorrência e pontos de ausência da espécie podem ser analisados em conjunto com as variáveis preditoras.

O Processo de Modelagem de Distribuição de Espécie proposto foi aplicado em um Estudo de Caso de Modelagem de Distribuição da Espécie da Centris hyptidis, na região nordeste brasileira.

Neste estudo de caso também foi utilizado o conceito de interação entre abelha Centris hypitdis e as duas espécies de plantas oleaginosas especializadas, a 
Angelonia cornigera e Angelonia campestris, de acordo com visão do biólogo ou ecólogo especialista na espécie.

Nesta nova proposta do Processo de Modelagem de Distribuição de Espécie, os pontos de ocorrência e ausência das espécies, as variáveis preditoras e os Mapas de Distribuição Potencial de Espécies gerados podem então ser analisados dentro de um mesmo contexto por Especialistas nessas espécies, a fim de verificar se estão consistentes com as informações sobre a Distribuição Potencial da Espécie empiricamente determinada.

Além disso, a análise dos resultados por especialista nas espécies de interesse, na Fase de Validação da Hipótese Cientifica, podem revelar inconsistências nos Modelos iniciais. Estas inconsistências podem ser relativas à falta de variáveis preditoras ou problemas de esforço amostral, que impedem a caracterização adequada do Mapa de Distribuição Potencial da Espécie em estudo em comparação com os dados obtidos em campo.

As atividades de Seleção das Variáveis Preditoras foram analisadas na Fase de Pré-Análise dos Dados, na Fase de Modelagem e Fase de Predição. Esta análise também contribui para identificar os gaps, erros de comissão e omissão, que podem indicar a ausência de variáveis preditoras, que ainda podem impactar a distribuição da espécie ou justificar a existências desses gaps.

Os problemas relativos ao esforço amostral, como dados de ocorrência enviesados pela falta de representatividade de pontos de ocorrência de subespécies e a super amostragem de regiões específicas, podem ser identificados na Fase de Pré-análise dos Dados do novo Processo de Modelagem de Distribuição de Espécie.

Na Fase de Pré-Análise dos Dados, também foi destacada a importância da aplicação de filtros para remoção dos outliers ou valores discrepantes, que apesar de representarem pontos de ocorrência das espécies verdadeiros, não atendem os pressupostos das técnicas de Modelagem de Distribuição de Espécies utilizadas.

Entretanto, estes pontos de ocorrência, considerados outliers, ainda podem ser posteriormente utilizados para avaliar o Modelo de Distribuição de Espécie construído. 


\subsection{Contribuições e trabalhos futuros}

Os resultados deste projeto de Mestrado em Ciências serão importantes para uma maior compreensão e melhoria do Processo de Modelagem de Distribuição de Espécies.

Com esta visão detalhada das atividades do Processo de Modelagem de Distribuição de Espécies surgem novos requisitos de software para o desenvolvimento de novas ferramentas para Biodiversity informatics.

O desenvolvimento de novas ferramentas para Biodiversity informatics que possam compartilhar os dados da modelagem de distribuição de espécie, deve permitir a flexibilidade necessária para que o Processo de Modelagem de Distribuição de Espécies possa atender às questões ecológicas complexas.

Entre as principais contribuições deste trabalho foram à apresentação de um Processo de Modelagem de Distribuição de Espécie revisado que permite buscar sistematicamente a melhoria da metodologia utilizada e a análise da Hipótese Científica dentro de um mesmo contexto integrado.

A identificação de técnicas estatísticas que podem ser utilizadas nas diversas Etapas do Processo de Modelagem de Distribuição de Espécies e o detalhamento do relacionamento entre as diversas atividades podem ser utilizados na definição de novos requisitos de software para as ferramentas de Modelagem de Distribuição de Espécies.

Assim, além da técnica de inspeção visual utilizada, outras técnicas estatísticas podem ser utilizadas na análise dos resultados da Modelagem de Distribuição Potencial de Espécies, como por exemplo, a Modelagem Hierárquica na escala espacial, temporal e da organização (ROYLE; DORAZIO, 2008) e a Análise Canônica (LEGENDRE; LEGENDRE, 1998).

Também foi identificada necessidade de aprimorar as técnicas para a redução dos efeitos de um esforço amostral enviesada, por exemplo, uma super amostragem 
de uma determinada área, e de técnicas para seleção das varáveis preditoras aplicadas na Modelagem de Distribuição de Espécies de ampla distribuição.

Além disso, da proposta de Projeto de Pesquisa FAPESP para a criação de uma nova geração da ferramenta openModeller pode-se destacar entre os desafios científicos a ser atendido pelas futuras ferramentas de Modelagem de Distribuição de Espécies, o aprimoramento de técnicas que preparem adequadamente os pontos a serem utilizados na criação e testes dos Modelos. · 


\section{REFERÊNCIAS}

AGUIAR, C.M.L., ZANELLA, F. C. V., MARTINS, C. F., CARVALHO, C. A. L. Plantas visitadas por Centris spp. (Hymenoptera: Apidae) na Caatinga para obtenção de recursos florais. Neotropical Entomology v. 32. p. 247-259. 2003.

ANDERSON, R. P.; MARTÍNEZ-MEYER, E. Modeling species' geographic distributions for preliminary conservation assessments: an implementation with the spiny pocket mice (Heteromys) of Ecuador. Biological Conservation v. 116, p. 167179. 2004.

ANDERSON, R. P.; LEW, D.; PETERSON, A. T. Evaluating predictive models of species distributions: criteria for selecting optimal models. Ecological Modelling. V. 162 p. 211-232. 2003.

ALLOUCHE, O.; TSOAR, A.; KADMON, R. Assessing the accuracy of species distribution models: prevalence, kappa and the true skill statistic (TSS). Journal of Applied Ecology. v. 43 p.1223-1232. 2006.

ARAÚJO, M. B.; NEW, M. Ensemble forecasting of species distributions. Trends in Ecology and Evolution. v.22. p.42-47. 2007.

AUSTIN, M. P. Spatial prediction of species distribution: an interface between ecological theory and statistical modelling. Ecological Modelling. v. 157 p. 101-118. 2002.

AUSTIN, M. P. Species distribution models and ecological theory: a critical assessment and some possible new approaches. Ecological Modeling. v. 200, 2007.

BARVE, N.; BARVE, V.; JIMÉNEZ-VALVERDE, A.; LIRA-NORIEGA, A.; MAHER, S. P.; PETERSON, A. T.; SOBERÓN, J. ; VILLALOBOS, F. The crucial role of the accessible area in ecological niche modeling and species distribution modeling. Ecological Modelling. v. 222 p. 1810-1819 2011.

BOOCH, G.; RUMBAUGH, J.; JACOBSON, I. UML, Guia do Usuário: tradução; Fábio Freitas da Silva, Rio de Janeiro, Ed.Campus , 2000.

BROWN, J. H.; LOMOLINO, M. V.; Biogeography, $2^{\text {nd }}$ edition, Sinauer Associates, Sunderland, MA, 1998.

BRAUNISCH, V.; BOLLMANN, K.; GRAF, R. F., HIRZEL, A. H. Living on the edge Modelling habitat suitability for species at their fundamental niche. Ecological Modelling. v. 214, p.153-167, 2008.

BROENNIMANN, O.; FITZPATRICK, M. C.; PERAMAN, P. B.; PETITPIERRE, B.; PELLISSIER, L., YOCCOZ, N. G.; THUILLER, W.; FORTIN, M.; RANDIN, C.; ZIMMERMANN, N. E.; GRAHAM, C. H.; GUISAN, A. Measuring ecological niche 
overlap from occurrence and spatial environmental data. Global Ecology and Biogeography. v. 21, p. 481-497, 2012.

BROTONS, L.; THUILER, W.; ARÀUJO, M. B.; HIRZEL, A. H. Presence-absense versus presence-only modeling methods for predicting bird habitat suitability. Ecography. v. 27, p. 437-448, 2004.

CANHOS, V. P. et al. Report OM-FAPESP, openModeller - A framework for species modeling. Partial Report No 1. Campinas, SP, 2006.

CANHOS, V. P. et al. Report OM-FAPESP, openModeller - A framework for species modeling. Partial Report No 2. Campinas, SP, 2007.

CANHOS, V. P. et al. Report OM-FAPESP, openModeller - A framework for species modeling. Partial Report No 3. Campinas, SP, 2008.

CANHOS, V. P. et al. Report OM-FAPESP, openModeller - A framework for species modeling. Partial Report No 3. Campinas, SP, 2009.

CAO, H.; RECKNAGEL, F.; KIM, B. TAKAMURA, N. Hybrid evolutionary algorithm for rule set discovery in time-series data to forecast and explain algal population dynamics in two lakes different in morphometry and eutrophication. Ecological Informatics. 2th editon. Springer-Verlag. New York. 2006.

CAPENTER, G.; GILLISON, A.N.; WINTER, J.; DOMAIN: a flexible modeling procedure for mapping potential distributions of plants, animals. Biodiversity and Conservation. London. v. 2 p. 667-680. 1993.

CHAPMAN, A. D. Principles and Methods of Data Cleaning - Primary Species and Species-Occurrence Data, version 1.0. Report for the Global Biodiversity Information Facility, Copenhagen. 2005.

CHAPMAN, A. D. Principles of Data Quality, version 1.0. Report for the Global Biodiversity Information Facility, Copenhagen. 2005.

CHAPMAN, A. D. Uses of Primary Species-Occurrence Data, version 1.0. Report for the Global Biodiversity Information Facility, Copenhagen. 2005.

CORRÊA, P. L. P.; CARVAlHAES, M. A.; SARAIVA, A. M.; RODRIGUES, F. A.; RODRIGUES, E. S. C.; ROCHA, R. L. A. Computational techniques for biologic species distribution modeling.. p. 308-325, 2011. DOI: 10.4018/978-1-61692-8711.ch015.

COX, C. B.; MOORE, P. D. Biogeography: An ecological and evolutionary approach. 7th Edition. Blackwell Publishing. Malden, MA. 2005.

DUDIK, M.; PHILLIPS, S. J.; SCHAPIRE, R. E. Correcting sample selection bias in maximum entropy density estimation. Advances in neural information processing systems. MIT Press. USA. v. 18. p. 323-330. 2006. 
EFRON, B. Bootstrap methods: Another look at the jackknife. The Annals of Statistics, v. 7, n. 1, p. 1-26, 1979.

ELITH, J.; LEATHWICK, J. R. Species distribution models: Ecological Explanation and prediction across space and time. Annual Review of Ecology, Evolution, and Systematics. v. 40, p. 677-697, 2009.

ELITH, J.; LEATHWICK, J.R.. Conservation prioritization using species distribution models. In Spatial Conservation Prioritization: Quantitative Methods and Computational Tools, ed. A Moilanen, KA Wilson, HP Possingham. Oxford: Oxford Univ. Press. pp 70-93 2009.

ELITH, J.; GRAHAM, C. H.; ANDERSON, R. P.; DUDIK, M.; FERRIER, S.; GUISAN, A.; HIJMANS, R. J.; HUETTMANN, F.; LEATHWICK, J. R.; LEHMANN, A.; LI, J.; LOHMANN, L. G.; LOISELLE, B. A.; MANION, G.; MORITZ, C.; NAKAMURA, M.; NAKAZAWA, Y.; OVERTON, J.M.; PETERSON, A. T.; PHILIPS, S.J.; RICHARDSON, K.; SCACHIETTI-PEREIRA, R.; SCHAPIRE, R. E.; SOBERÓN,J.; WILLIANS, S.; WISZ,M.S.; ZIMMERMANN, N.E. Novel methods improve prediction of species' distributions from occurrence data. Ecography. v. 29 p. 129-151. 2006.

ELITH,J.; PHILIPS, S. J.; HASTIE, T; DUDIK, M.; CHEE, Y. E.; YATES, C. J. A statistical explanation of maxent for ecologists. Diversity and Distributions. v. 17, p. 43-57, 2011.

ERIKSSON, H.; PENKER, M. Business Modeling with UML: Business Patterns at work. Wiley \& Sons, Fall 1999.

FABER, O.; KADMON, R. Assessment of alternative approaches for bioclimatic modeling with special emphasis on the Mahalanobis distance. Ecological Modelling. v. 160 p. 115-130. 2003.

FIELDING, A. H.; BELL, J. F. A review of methods for the assessment of prediction errors in conservation presence / absence models. Environmental Conservation. v. 24 p. 38-49 1997.

GIANNINI, T. C. Distribuição geográfica de abelhas e plantas associadas através de modelagem. 2011. 140p. Tese (Doutorado) - Instituto de Biociências, Universidade de São Paulo, São Paulo, 2011.

GIANNINI, T. A.; Lira-Saade, R.; Ayala, R.; Saraiva, A. M., Alves-dos-Santos, I. Ecological niche similarities of Peponapis bees and non-domesticated Cucurbita species. Ecological Modelling v. 222, p. 2011-2018, 2011.

GIANNINI, T. C.; SARAIVA, M.; ALVES-DOS-SANTOS, I. A. Ecological niche modeling and geographical distribution of pollinator and plants: a case study of Peponapis fervens (Smith, 1879) (Eucerini: Apidae) and Cucurbita species (Cucurbitaceae). Ecological Informatics. v. 5, p. 59-66, 2010. 
GIANNINI, T.C.; SIQUEIRA, M. F.; ACOSTA, A.L.; BARRETO, F.C.C.; SARAIVA, A.M.; ALVES-DOS_SANTOS, I. Desafios atuais da modelagem preditiva de distribuição de espécies, Rodriguésia. v. 63 n.3 p. 733-749. 2012.

GIANNINI, T. C. ; ACOSTA, A. L. ; GARÓFALO, C. A. ; SARAIVA, A. M. ; ALVESDOS-SANTOS, I.; IMPERATRIZ-FONSECA, V. L. Pollination services at risk: bee habitats will decrease owing to climate change in Brazil. Ecological Modelling. v. 244 p. 127-1312012.

GIMENES, M., OLIVEIRA, P., ALMEIDA, G. F. Estudo das interações entre as abelhas e as flores em um ecossistema de restinga na Bahia. Anais 5th Encontro sobre Abelhas de Ribeirão Preto. Universidade de São Paulo, Ribeirão Preto, pp. 117-121 2002.

HAMPE, A. Bioclimatic models: what they detect and what they hide. Global Ecology and Biogeography. v. 11 p. 469-471. 2004.

HANSKI, I. A. Single-species metapopulation dynamics: concepts, models and observations. Biological Journal of the Linnean Society. v.42. p.17-38. 1991.

HANSKI, I.A.; GILPIN, M.E. Metapopulation biology: Ecology, genetics, and evolution. Academic Press, San Diego, California. 1997.

HASTIE, T.J. ; TIBSHIRANI R. Generalised Additive Models. Chapman \& Hall, London. 1990.

HIJIMANS, R. J. Cross-validation of species distribution models: removing spatial sorting bias and calibration with a null model. Ecology. v. 93 p. 679-688. 2012.

HIJIMANS, R. J.; CAMARON, S.; PARRA, J.; JONES, P.G.; JARVIS, A. Very highresolution interpolated climate surfaces for global land areas. International Journal of Climatology. v.25 p.1965-1978. 2005.

HIJMANS, R.J., PHILLIPS, S., LEATHWICK, J., and ELITH, J. 2011. "dismo", ver. 0.6-3, package for R. http://cran.r-project.org/.

HIRZEL, A. H.; LAY, G. L. Habitat suitability modeling and niche theory. Journal of Applied Ecology. v. 45, p. 1372-1381, 2008.

HORTAL, J.; ROURA-PASCUAL, N.; SANDERS, N. J.; RAHBEK, C. Understanding (insect) species distributions across spatial scales. Ecography. v. 33, p. 51-53, 2010.

HUTCHINSON, G. E. Conclusion Remarks. Cold Spring Harbour Symposium. Quantitative Biology. v. 22, n. 8, p. 2554-2558, 1957.

IUCN. IUCN Red List of threatened species. 2008. URL http://www.iucnredlist.org

JAYNES, E. T. Information theory and statistical mechanics. Physical review. v.106, n. 4, p. 620-630, 1957. 
JIMENÉZ-VALVERDE, A.; LOBO, J. M.; HORTAL, J. Not as good as they seem: the importance of concepts in species distribution modeling. Diversity and Distributions. v.14 p. 885-890. 2008.

LEGENDRE, P.; LEGENDRE, L.; Numerical ecology, Elsevier. 2th Edition. New York. 1998. p. 853.

LEIBOLD, M. A. The niche concept revisited: mechanistic models and community context. Ecology. v. 76. p 1371-1382. 1995.

LIU, C.; WHITE, M.; NEWELL, G. Measuring and comparing the accuracy of species distribution models with presence-absence data. Ecography. v. 34, p. 232-243, 2011.

LOBO, J. M.; JIMENÉZ-VALVERDE, A.; HORTAL, J. The uncertain nature of absences and their importance in species distribution modelling. Ecography. p. 103114, 2010.

McCULLAGH, P. ; NELDER, J.A. Generalized Linear Models, 2nd ed. Chapman \& Hall, London. 1989.

MACHADO, I. C., VOGEL, S., LOPES, A. V. Pollination of Angelonia cornigera Hook. (Scrophulariaceae) by long-legged oil-collecting bees in NE Brazil. Plant Biology v. 4 p. 352-359. 2002.

MENKE, S. B.; HOLWAY, D. A.; FISHER, R. N.; JETZ, W. Characterizing and predicting species distributions across environments and scales: Argentine ant occurrences in the eye of the beholder. Global Ecology and Biogeography v. $18 \mathrm{p}$. 50-63. 2009.

MUÑOZ, M.E.S., GIOVANNI, R., SIQUEIRA, M.F., SUTTON, T., BREWER, P., SCACHETTI, R.S., CANHOS, D.A.L.; CANHOS, V.P. (2009) "openModeller: a generic approach to species' potential distribution modelling". Geolnformatica. DOI: 10.1007/s10707-009-0090-7.

PEARSON, K. On lines and planes of closest fit to systems of points in space.Philosophical Magazine v.2 p. 559-572. 1901.

PETERSON, A. T. Uses and requirements of ecological niche models and distributional models. Biodiversity Informatics.v. 3. p. 59-72. 2006.

PETERSON, A. T.; KNAPP, S.; GURALNICK, R.; SOBERÓN, J.; HOLDER, M. Perspective: The big question for biodiversity informatics. Systematics and Biodiversity. v. 8. p. 159-168. 2010.

PETERSON, A. T.; SOBERÓN, J. Interpretation of models of fundamental ecological niches and species' distributional areas. Biodiversity Informatics. v. 2. p. 1-10. 2005. 
PETERSON, A. T.; SOBERÓN, J.; PEARSON, R. G. ANDERSON, R. P.; MARTÍNEZ-MEYER, E.; NAKAMURA, M.; ARAÚJO, M. B. Ecological Niches and Geographic Distributions. ISBN 978-0-691-13686-8. PRINCETON UNIVERSITY PRESS. United Kingdom. 2011. 328p.

PHILLIPS, S. J.; ANDERSON, R. P.; SCHAPIRE, R. E. Maximum entropy modeling of species geographic distributions. Ecological Modelling. v. 190, p. 231-259, 2006.

PHILIPS, S. J.; DUDIK, M. Modeling of species distributions with Maxent: new extensions and a comprehensive evaluation. Ecography, 31:161-175. 2008.

PHILIPS, S. J.; DUDIK, M.; SCHAPIRE, R. E. A Maximum Entropy Approach to Species Distribution Modeling. proceedings of the twenty-First International Conference on Machine Learning. Banff. Canada. p. 655-662. 2004.

PHILIPS, S. J.; DUDIK, M.; ELITH, J.; GRAHAN, C. H.; LEHMANN, A.; LEATHWICK, J., FERRIER, S. Sample selection bias and presence-only distribution models: implications for background and pseudo-absence data. Ecological Applications. v. 19 p. 181-197. 2009.

PIANKA, E. R. Latitudinal Gradients in Species Diversity: A Review of Concepts. The American Naturalist. v. 100 p. 33-46. 1966.

Pinto-Coelho, R. M. Fundamentos em Ecologia. Porto Alegre. Artmed. 2007. ISBN 978-85-363-1097-8

PRESSMAN, R. S.; Software Engineering: A Practitioner's Approach, 7 ed., McGraw Hill. 2010.

QUENOUILLE, M. H. Notes on bias in estimation. Biometrika, v. 43, n. 3-4, p. 353360, 1956.

R Development Core Team. R: A Language and Environment for Statistical Computing. R Foundation for Statistical Computing, Vienna. http://www.R-project.org. 2009.

RECKNAGEL, F. ; GINKEL, C. v.; CAO, H.; CETIN, L.; ZHANG, B. Generic limnological models on the touchstone: Testing the lake simulation library SALMO$\mathrm{OO}$ and the rule-based Microcystis agent for warm-monomictic hypertrophic lakes in South Africa. Ecological Modelling. v. 215 p. 144-158. 2008.

ROBERTSON, M. P.; CAITHNESS, N.; VILLET, M. H. A PCA-based modeling technique for predicting environmental suitability for organisms from presence records. Diversity and Distributions. v. 7 p. 15-27. 2001

RODDER, D.; LOTTERS, S.; Oz, M.; BOGAERTS, S.; ELEFTHERAKOS, K.; VEITH, $M$. A novel method to calculate climatic niche similarity among species with restricted ranges - the case of terrestrial Lycian salamanders. Organisms Diversity \& Evolution. v. 11 p. 409-423, 2011. 
RODRIGUES, E. S. C. Teoria da Informação e Adaptabilidade na Modelagem de Distribuição de Espécies. 2012. 137p. Tese (Doutorado) - Escola Politécnica, Universidade de São Paulo, São Paulo, 2012.

RODRIGUES, F. A. Um método de referência para análise de desempenho preditivo de algoritmos de modelagem de distribuição de espécies. 2011. 150p. Tese (Doutorado) - Escola Politécnica, Universidade de São Paulo, São Paulo, 2011.

ROYLE, J. A.; DORAZIO, R. M. Hierarchical Modeling and Inference in Ecology: The Analysis of Data from Populations, Metapopulations and Comunities. Elsevier. 1th Edition. 2008 p. 444.

RUSHTON, S. P.; ORMEROD, S. J.; KERBY, G. New paradigms for modeling species distributions? Journal of Applied Ecology. v.41, p193-200, 2004.

SALVANHA, P. Modelo para análise de desempenho do processo de replicação de dados em portais de biodiversidade. 2010. 79p. Dissertação (Mestrado) Escola Politécnica, Universidade de São Paulo, São Paulo, 2010.

SÁNCHEZ-CORDERO, V.; STOCWELL, D.; SARKAR, S.; LIU, H.; STEPHENS, C. R.; GIMENÉZ, J. Competitive interactions between felid species may limit the southern distribution of bobcats Lynx rufus. Ecography v. 31 p. 757-764. 2008.

SANTANA, F. S. Uma infraestrutura orientada a serviços para modelagem de nicho ecológico. 2009. 141p. Tese (Doutorado) - Escola Politécnica, Universidade de São Paulo, São Paulo, 2009.

SANTANA, F. S.; SIQUEIRA, M. F.; SARAIVA A. M., CORRÊA, P. L. P. A reference business process for ecological niche modelling. Ecological Informatics v. 3, p. 7586, 2008.

SEGURADO, P.; ARAUJO, M. B. An evaluation of methods for modelling species distributions. Journal of Biogeography. v. 31 p. 1555-1568. 2004.

SOBERON, J. Grinnellian and Eltonian niches and geographic distributions of species. Ecology Letters v. 10 p. 1115-1123. 2007.

SOBERON, J. Niche and area of distribution modeling: a population ecology perspective. Ecography v.33 p. 159_167. 2010..

SOBERÓN, J.; NAKAMURA, M. Niches and distributional areas: concepts, methods, and assumptions. PNAS Proceedings of the National Academy of Sciences of the United States of America. v. 106, sup. 2. p.19644-19650, 2009.

SOBERÓN, J.; PETERSON, A. T. Interpretation of models of fundamental ecological niches and species' distributional areas. Biodiversity Informatics. v. 2, p. 1-10, 2005. 
SOKAL, R. R.; ROHLF, F. J. Biometry: the principles and practice of statistics in biological research. New York Freeman. $3^{\circ}$ Edição. 1995. 887 p.

STOCKWELL, D.; PETERS, D. The GARP modeling system: problems and solutions to automated spatial prediction. International Journal of Geographical Information Science. v. 13 p 143-158. 1999.

THUILLER, W., BIOMOD - optimizing predictions of species distributions and projecting potential future shifts under global change. Global Change Biology, v. 9 p.1353-1362. doi: 10.1046/j.1365-2486.2003.00666.x, 2003.

THUILLER, W.; LAFOURCADE, B.; ARAUJO, M. ModOperating Manual for BIOMOD. Universite Josepf Fourier. 2009.

THUILLER, W. ; MÜNKEMÜLLER, T. Habitat suitability modeling. Moeller, A.P., Fielder, W. \& Berthold, P. eds., Effects of climate change on birds, Oxford University Press. 2010.

TUKEY, J. W. We Need Both Exploratory and Confirmatory. The American Statistician. v. 34, p. 23-25. 1980.

UCHÔA, J. Q.; PANONTIM, S. M.; NICOLETTI, M C.; Elementos da Teoria de Evidência de Dempster-Shafer. Relatório Dep. Cop. UFSCar. 2001.

UNDERWOOD, A.J. Experiments in Ecology: Their logical design and interpretation using analysis of variance. United Kingdom: Cambridge University Press. 1997504 p.

VELOZ, S. Spatially autocorrelated sampling falsely inflates measures of accuracy for presence-only niche models. Journal of Biogeography. v. 39 p. 2290-2299. 2009.

WIENS, John; Ackerly, David D.; Allen, Andrew P.; Anacker, Brian L.; Buckley, Lauren B.; Cornell, Howard V.; Damschen, Ellen I.; Davies, T. Jonathan; Grytnes, John A.; Harrison, Sandy P.; Hawkins, Bradford A.; Holt, Robert D.; McCain, Christy M.; Stephens, Patrick R. Niche conservatism as an emerging principle in ecology and conservation biology. Ecology Letters. v. 13. p. 1310-1324. 2010

WALLEY, P. Measures of uncertainty in expert systems. Artificial Intelligence. v. 83, p. 1-58. 1996.

WARREN, D. L.; SEIFERT, S. N., Ecological niche modeling in Maxent: the importance of model complexty and the performance of model selection criteria. Ecological Applications. p. 335-342, 2011.

WISZ, M. S.; GUISAN, A. Do pseudo-absence selection strategies influence species distribution models and their predictions? An information-theoretic approach based on simulated data. BMC Ecology. 2009. 
YEE, T.W.; MITCHELL N.D. Generalized additive models in plant ecology. Journal of Vegetation Science v.2 p. 587-602. 1991.

ZAR, J. H. Biostatistical Analysis, Pearson Prentice Hall. 5.ed. USA. 2010 994p. 